\title{
Studies on the inhibition of blood coagulation factor Xla
}

Citation for published version (APA):

Soons, J. W. P. H. (1987). Studies on the inhibition of blood coagulation factor XIa. [Doctoral Thesis, Maastricht University]. Rijksuniversiteit Limburg. https://doi.org/10.26481/dis.19871211js

Document status and date:

Published: 01/01/1987

DOI:

10.26481/dis.19871211js

Document Version:

Publisher's PDF, also known as Version of record

\section{Please check the document version of this publication:}

- A submitted manuscript is the version of the article upon submission and before peer-review. There can be important differences between the submitted version and the official published version of record.

People interested in the research are advised to contact the author for the final version of the publication, or visit the DOI to the publisher's website.

- The final author version and the galley proof are versions of the publication after peer review.

- The final published version features the final layout of the paper including the volume, issue and page numbers.

Link to publication

\footnotetext{
General rights rights.

- You may freely distribute the URL identifying the publication in the public portal. please follow below link for the End User Agreement:

www.umlib.nl/taverne-license

Take down policy

If you believe that this document breaches copyright please contact us at:

repository@maastrichtuniversity.nl

providing details and we will investigate your claim.
}

Copyright and moral rights for the publications made accessible in the public portal are retained by the authors and/or other copyright owners and it is a condition of accessing publications that users recognise and abide by the legal requirements associated with these

- Users may download and print one copy of any publication from the public portal for the purpose of private study or research.

- You may not further distribute the material or use it for any profit-making activity or commercial gain

If the publication is distributed under the terms of Article $25 \mathrm{fa}$ of the Dutch Copyright Act, indicated by the "Taverne" license above, 
STUDIES ON THE INHIBITION OF BLOOD COAGULATION FACTOR XIa 
Druk: Groenevelt Landgraaf 


\section{Studies on the inhibition of blood coagulation factor XIa}

Proefschrift

ter verkrijging van de graad van doctor in de geneeskunde aan de Rijksuniversiteit Limburg te Maastricht, op gezag van de Rector Magnificus, Prof. Dr. F.I.M. Bonke, volgens het besluit van het College van Dekanen, in het openbaar te verdedigen op vrijdag 11 december 1987 des namiddags om vier uur

door

Johannes Wilhelmus Pieter Hubertus Soons

geboren te Valkenburg 
Promotor : Prof. Dr. H. C. Hemker

Co-promotor: Dr. G. Tans

Referent : Dr. R. Bertina, Leiden

Referent : Prof. Dr. G. Blijham, Maastricht

The work presented in this thesis has been done in close cooperation with: Guido Tans, Gerbrand van Dieijen, Coen Hemker, and Truus Janssen-Claessen.

The Netherlands Heart Foundation contributed to the printing costs of this thesis. 
Ter herinnering aan mijn vader aan mijn moeder aan Jellie 

Introduction

CHAPTER II

Inhibition of Factor XIa by Antithrombin III.

[Biochemistry [1987] 26, 4624-4629]

CHAPTER III

The Heparin Catalyzed Inhibition of Human Factor XIa by Antithrombin III is Dependent on the Heparin Type.

CHAPTER IV

Activation of Factor IX by Factor XIa; Effect of Phospholipids.

CHAPTER V

The Effect of Platelets in the Activation of Human Blood Coagulation Factor IX by Factor XIa.

[Blood [1986] 68, 140-148]

CHAPTER VI

General Discussion

Summary

Samenvatting

Nawoord

Curriculum Vitae 


\section{ABBREVIATIONS}
ADP adenosine diphosphate
ATP adenosine triphosphate
DEAE diethyl aminoethyl
EDTA ethyl diamine tetraacetic acid
HEPES N-2-hydroxyethylpiperazine- $\mathrm{N}^{\prime}$-2-ethanesulfonic acid
HMWK high molecular weight kininogen
LDH lactic dehydrogenase
$\mathrm{M}_{\mathrm{r}} \quad$ relative molecular mass
pNA p-nitroanilide
p-NPGB p-nitrophenyl-p' ${ }^{\prime}$-guanidinobenzoate
$\mathrm{PC} \quad$ phosphatidylcholine
PK prekallikrein
PS phosphatidylserine
S2302 H-D-Pro-Phe-Arg-p-nitroanilide
S2337 N-benzoyl-Ile-Glu(Piperidyl)-Gly-Arg-p-nitroanilide
S2366 pyro-Glu-Pro-Arg-p-nitroanilide
SDS sodium dodecyl sulfate
Tris-HCl tris (hydroxymethyl) aminomethane hydrochloride 


\section{CHAPTER I}

\section{Introduction}

Normal blood, which is fluid within the blood vessels, quickly clots upon vascular injury or upon contact with "foreign' charged surfaces. Formation of the hemostatic plug is due to the close collaboration between blood platelets and the clotting factors. The major link between both systems is thrombin. That is the enzyme that catalyzes fibrin formation and it is also the most important stimulus of platelets. Already in 1835 Buchanan showed that the generation of a fibrin clot is caused by thrombin which is demonstrable in the clot (1). In 1910 Morawitz postulated that for the formation of thrombin four factors were needed i.e. fibrinogen, prothrombin, thromboplastin and calcium ions (2). It was thought that thromboplastin and calcium ions were needed to convert prothrombin into thrombin that subsequently formed fibrin from fibrinogen. Nowadays, we know that more than four factors participate in the reactions concerning blood coagulation. In 1964 the cascade-model was proposed independently by MacFarlane (3) and by Davie and Ratnoff (4). It describes the sequential conversion of proenzymes (zymogens) to enzymes. The enzymes formed activate progressively increasing amounts of substrate that are also coagulation zymogens, at each stage of the cascade. The general concept of a cascade still holds true, but unlike the orginal authors we now know that not all clotting factors are proenzymes.

A simplified version of the current state of knowledge of the coagulation cascade, is depicted in Figure 1 . Depending upon the trigger, coagulation proceeds in the so-called intrinsic or extrinsic pathway. Intrinsic coagulation is initiated when normal plasma comes in contact with negatively charged surfaces, such as glass, kaolin or sulfatides. The proteins involved in these contact activation reactions are factor XII, prekallikrein (PK) and high molecular weight kininogen (HMWK). During the initial stage of contact activation the 
zymogens, factor XII and prekallikrein, are involved in a so-called reciprocal activation mechanism in which kallikrein activates factor XII into factor XIIa, which in its turn converts prekallikrein into kallikrein. Optimal contact activation rates are obtained in the presence of a negatively charged surface. Factor XII binds to this surface and prekallikrein is linked to the surface by HMWK. For recent detailed reviews concerning contact activation see references $(5,6,7)$. Factor XIIa is the central enzym in contact activation, since it also activates factor XI $(8,9)$. This reaction is also favoured by the presence of a negatively charged surface and HMWK $(10,11,12)$. Thus, contact activation ultimately results in the formation of factor XIa. Factor XIa can efficiently activate factor IX $(13,14,15)$ in a reaction for which no surface requirement or cofactor has been established. Factor IX belongs to the so-called vitamin $\mathrm{K}$ dependent coagulation factors (i.e. factors VII, IX, X and II) and, like in all reactions concerning the activation of vitamin $\mathrm{K}$ dependent clotting factors calcium ions are essential in the activation of factor IX by factor XIa. Subsequently, factor IXa activates factor X. A phospholipid surface, such as factor 3 from activated platelets, calcium, and a modified form of factor VIII are established cofactors in the activation of factor X by factor IXa (16-19). Factor $\mathrm{Xa}$ in turn converts prothrombin (factor II) into thrombin (factor IIa). Factor Xa forms a complex with factor $\mathrm{V}$, calcium ions and phospholipids and this complex is the catalytic unit of the prothrombin activation $[20,21$, and for recent reviews see 22,23$]$. Finally, thrombin converts fibrinogen into fibrin.

Upon vascular unjury tissue-factor (thromboplastin) is exposed to the bloodstream and this starts the extrinsic pathway of blood coagulation. Tissue-factor consists of a protein-part (apoprotein III) and a lipid-part $(24,25)$. Factor VII binds to tissue factor in the presence of calcium ions upon which it probably changes conformation. The current model of initiation of the extrinsic pathway is that the factor VII-tissue factor complex possesses intrinsic enzymatic activity, that can generate minimal amounts of factor $\mathrm{Xa}$, which then rapidly back activates factor VII to factor VIla, which in turn dramatically increases the rate of activation of factor X (26). Since the factor VIIa-tissue factor complex can also activate factor IX, this can also lead to a strong increase in the activation of factor IX $(27,28)$. This was shown for the first time with isolated clotting factors by $\emptyset$ sterud and Rapaport (29) and later this has been confirmed by other investigators $(30,31)$. Thus, the intrinsic and extrinsic pathway meet each other in the factor $\mathrm{IX}$ and factor $\mathrm{X}$ activation. The severe bleeding problems, observed in patients with factor VIII deficiency (Hemophilia A) or factor IX deficiency (Hemophilia B) that are in marked contrast to the mild syndrome caused by deficiency of contact factors can be explained in this extra pathway for the activation of the intrinsic coagulation factor IX (32). 


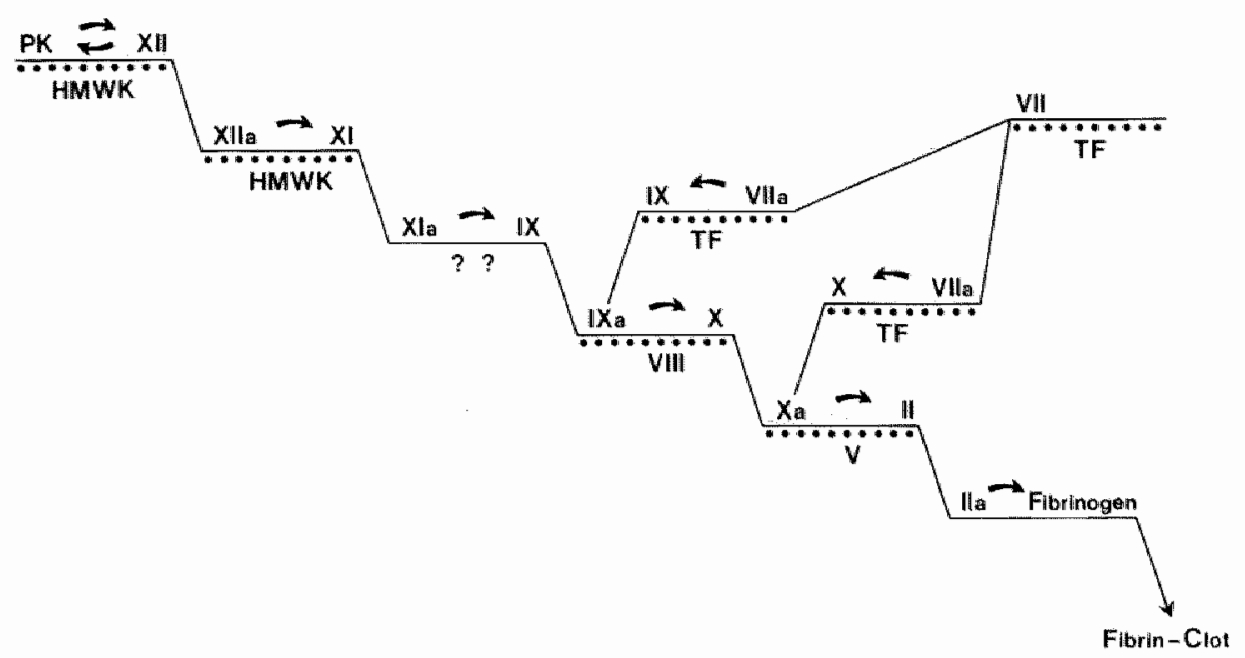

FIGURE 1. The coagulation cascade. The roman numbers refer to the respecrive clotting factors, PK is prekallikrein, HMWK is high molecular weight kininogen and TF is the protein part of tissue factor. The closed circles indicate that a negarively charged surface is required in the reaction.

Since factor IX can, therefore, be activated both by factor VIIa, in the presence of thromboplastin, and by factor XIa the question rises: What are the relative contributions of both enzymes to factor IX activation? The enzyme kinetics of factor IX activation are such that no indications are found on the relative importance of either intrinsic or extrinsic activation $(30,31,33)$. The reported kinetic data suggest that both factor XIa and factor VIra can play physiologically significant roles in the activation of factor IX. Clinical observations do not indicate a solution either. Factor XI and factor VII deficiency may both be associated with bleeding problems. However, part of the factor XI deficient individuals is asymptomatic and a deficiency in the contact system factors (factor XII, prekallikrein and HMWK) is not associated with a hemostatic disorder (for a recent review see 34 ). This indicates that besides the classical intrinsic factor IX activation, extrinsic factor IX activation also has a physiological role in blood coagulation. It also suggests that there have to be alternative mechanism(s) to activate factor XI.

With one notable exception all reactions participating in the coagulation cascade are dependent upon the presence of a negatively charged surface and dependent upon non-enzymatically active cofactors (factor V, factor VIII, tis- 
sue factor and high molecular weight kininogen). For example, factor $\mathrm{Xa}$, the enzyme that converts prothrombin into thrombin, forms a reversible complex with the non-enzymatically active cofactor, factor $\mathrm{Va}$, and phospholipids and this complex acts as the catalytic unit in the reaction $(20,21)$. The only reaction of the cascade for which such requirement for a surface and a cofactor is not described is the activation of factor $\mathrm{IX}$ by factor XIa. Thus, this reaction takes up a rather unique place among the coagulation reactions thus far known. The aim of the work presented here was to gain more insight in the regulation of factor XIa-dependent factor IX activation by naturally occuring inhibitors and by platelets. Although platelets and inhibitors exert important physiological functions in other coagulation reactions, this work will be restricted to those interactions pertinent for understanding their effect in the activation of factor IX by factor XIa. For reasons of clarity, the final part of this introduction is divided in three parts i.e. one a description of factor XI and factor XIa; two a description of factor IX and factor IXa and three a part in which the literature concerning the activation of factor IX by factor XIa is discussed.

\section{Factor XI/XIa.}

Factor XI is a glycoprotein with a carbohydrate content of approximately $5 \%$ and with an apparent molecular weight of 160,000 . It is unique in that it is the only coagulation zymogen that consists of two identical polypeptide chains held together by disulfide bonds $(35,36)$. In plasma factor XI is present in a complex with HMWK $(37,38)$. The molar ratio of binding of HMWK to factor XI is 2:1 (39). Recently, the amino acid sequence as predicted by the nucleotide sequence of a cDNA coding for human factor XI has been reported (40). Each of the two monomers of factor XI appears to be composed of 607 amino acids with a sequence that shows $58 \%$ identity with human plasma prekallikrein. Figure 2 shows the amino acid sequence and tentative secundary structure of the factor XI monomer as proposed by Fujikawa et al. (40). Factor $\mathrm{XI}$ is activated by cleavage of an internal Arg369-Ile370 bond in both precursor chains by the enzyme factor XIIa (see arrow fig. 2). Factor XIa is composed of two heavy chains $(50,000 \mathrm{D})$ and two light chains $(33,000 \mathrm{D})$ held together by disulfide bridges $(35,36)$. Each light chain contains one active site (36) and shows an amino acid sequence that is typical of the serine protease family (40). The heavy chain of factor XIa contains the binding site for HMWK and is also required for the calcium-dependent activation of factor IX by factor Xla $(41,42)$. As already mentioned, factor XI activation by factor XIIa occurs optimally in the presence of a negatively charged surface and HMWK. It is assumed that both the enzyme and the substrate bind to the sur- 


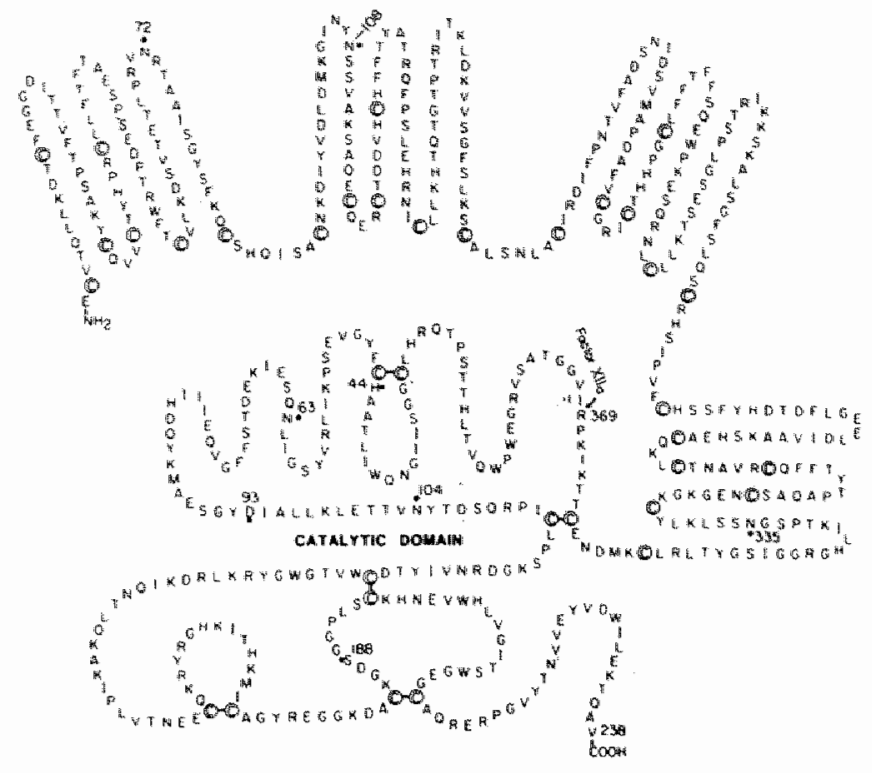

FIGURE 2. Amino acid sequence and tentative structure of human factor XI monomer. The cleavage site by factor XIIa is shown by the curved arrow. The amino acid residues are given by their single letter abbreviation. Taken from reference 40 .

face. Factor XIIa binds via its heavy chain (43) and HMWK links factor XI to the surface $(11,44)$. The generated factor XIa presumably dissociates from the surface leaving behind the surface bound HMWK $(45,46)$. With respect to this it has been suggested that proteolytic destruction of the HMWK-light chain by factor XIa causes the liberation of factor XIa from the surface and thereby, enables factor XIa to activate factor IX in the fluid phase or on a phospholipid micelle (46). This hypothesis remains, however, to be con* firmed.

Four plasma protease inhibitors, $\alpha_{1}$-antitrypsin, antithrombin III, $\mathrm{C}_{1}$ inhibitor, and $\alpha_{2}$-antiplasmin, have been reported to inactivate human factor Xla. In plasma, $\alpha_{\|}$-antitrypsin is thought to be the main factor XIa inhibitor followed by antithrombin III (47). The inactivation of factor XIa by antithrombin III is accelerated in the presence of heparin (48). In the literature there is no agreement on the rate enhancement of the inactivation of factor XIa caused by heparin (49). Scott et al, reported a 4-fold increase (50), while Beeler et al. reported a 40 -fold acceleration of the inactivation at saturating heparin concentrations (51). Also, the mechanism via which heparin catalyzes the inactivation of factor XIa remains to be established. Holmer et al. reported that the rate enhancement of factor XIa inhibition by antithrombin III is 
dependent upon the molecular weight of heparin (52). Beeler et al. on the other hand reported equal reaction rates for the inactivation of factor XIa by antithrombin III in the presence of saturating amounts of heparin preparations with a molecular weight of 7,000 and 15,000 daltons, respectively (51). Even in the absence of heparin the inactivation of factor XIa by antithrombin III remains an intriguing reaction. It is known that both light chains of factor XIa contain an active site, and that both can interact with antithrombin III (8). However, the kinetics of the inactivation of both active sites in the factor XIa molecule are not known.

\section{Factor IX/IXa.}

Factor IX (Christmas factor) plays an important role in blood coagulation and is essential for normal hemostasis. Patients with a deficiency of factor IX (Hemophilia B) have bleeding problems, the severity of which is directly related to the level of residual functional factor IX in their plasma. The disease is heterogeneous and patients can be subdivided into three classes: those with normal levels of immunologically detectable factor IX $\left(\mathrm{CRM}^{+}\right)$those with reduced levels of factor IX (CRM ${ }^{\text {red }}$ ) and those with no detectable factor IX ( $\mathrm{CRM}^{-}$). Recent developments in the molecular biology of factor IX have already enlightened several forms of Hemophilia B. For recent reviews see references 53 and 54.

Human factor IX is a glycoprotein with a carbohydrate content of approximately $17 \%$ and with an apparent molecular weight of $57,000(14,15)$. It is present in plasma as a zymogen at a concentration of 2.6 to $5.0 \mu \mathrm{g} / \mathrm{mL}$. Recently, the amino acid sequence predicted by the nucleotide sequence of a cDNA coding for human factor IX has been reported $(55,56)$. Factor IX consists of 415 amino acid residues. Figure 3 shows the amino acid sequence and tentative structure of factor IX as proposed by Thompson (54). It is a vitamin $\mathrm{K}$-dependent protein and contains $12 \gamma$-carboxy-glutamylic acid (GLA) residues in the amino-terminal region. These GLA-residues confer metal-binding properties essential for biological activity. Factor IX binds to negatively charged phospholipid vesicles $(57,58)$, whereas GLA-domainless factor IX shows a decreased phospholipid affinity that coincidles with a decreased rate of factor $X$ activation (58). It has been suggested that vitamin $\mathrm{K}$ dependent coagulation proteins directly bind to phospholipid surfaces via calcium bridging between the GLA-residues and the negatively charged phospholipids (59). As far as factor IX is concerned, however, recent studies using monoclonal antibodies have shown that factor IX upon metal binding undergoes two sequential conformational transitions. The first transition is metal- 


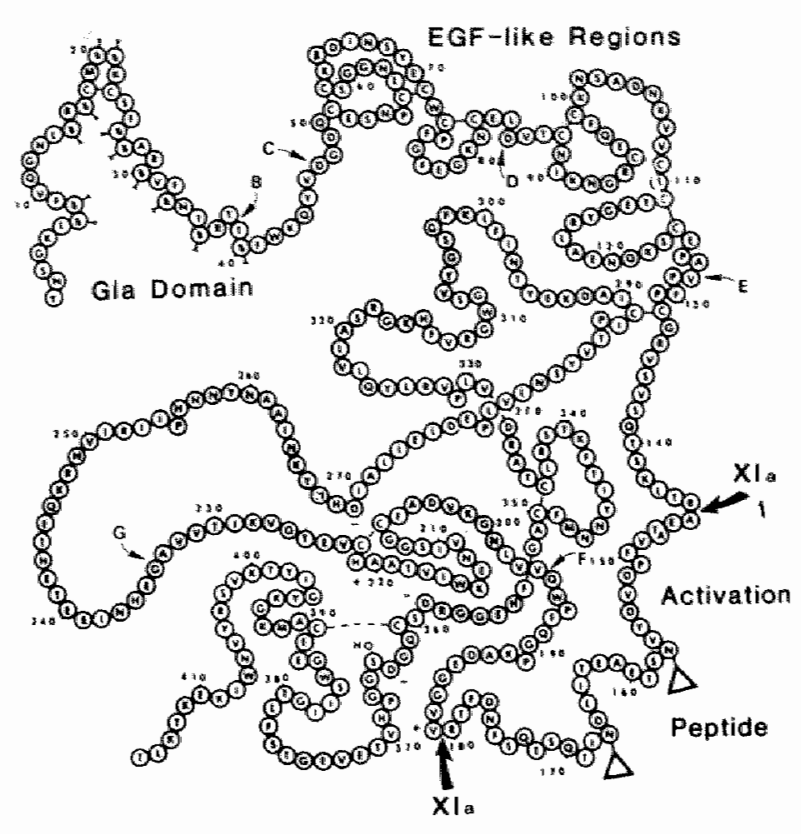

FIGURE 3. Amino acid sequence and tentative structure of human factor $I X$. The cleavage sites by factor XIa are shown by the curved arrows. The amino acid residues are given by their single letter abbreviation. Taken from reference 54.

selective but cation-nonselective; the second transition is selective for calcium and strontium. Accordling these studies, the second transition results in the expression of conformational determinants necessary for membrane binding. These determinants also appear needed in the calcium-dependent activation of factor IX by factor XIa (60). This calcium induced conformation change, upon which expression of a phospholipid binding site occurs is a possible alternative for the hypothesis that coagulation factors bind to phospholipids via calcium bridges between GLA-residues and negatively charged phospholipids.

As already mentioned activation of factor IX can be accomplished by factor $\mathrm{XIa}$ as well as by the factor VIIa-tissue factor complex. Both enzymes cleave the same bonds in factor IX. It appears that the activation of factor IX is a two step mechanism. In the first step the Arg 145-Alal 46 bond is cleaved giving rise to a two-chain inactive intermediate, which is further cleaved at the Arg 180-Vall 181 bond resulting in the release of an activation peptide $\left(M_{r}\right.$ 11,000 ) and the formation of active factor IXaß (see figure 3). The heavy chain of factor $\mathrm{IXa} \beta$ contains the active site and the light chain contains the 12 GLA-residues. Another form of active factor IX, factor IXa $\alpha$, is obtained when factor IX is cleaved by a protease from Russell's viper venom. This en- 
zyme prefers to cleave the Arg180-Val181 bond, upon which factor IX becomes active (61). Other proteases such as chymotrypsin and elastase can give a similar cleavage pattern, even though they do not specifically cleave arginyl bonds and do not activate factor IX $(61,62)$.

\section{Factor IX activation.}

The molecular data of the proteins involved in the activation of factor IX by factor Xla have been clescribed above. As already mentioned the reaction itself is the only reaction of the cascade for which no surface requirement or cofactor is known. This has intrigued many investigators and many suggestions concerning possible surface or cofactor requirements have been made in the past. For example, the surface of activated platelets and HMWK have been suggested for such roles (63). The data dealing with a platelet or endothelial cell involvement in the activation of factor IX will be summarized in this part of the introduction. Although in this thesis no data will be presented concerning involvement of endothelial cells in the activation of factor IX by factor XIa, for the sake of completeness the possible role of endothelium will be briefly discussed. But first the assays used to measure the rate of factor IX activation that are known from the literature will be summarized.

Assays.

Several assays have been described in literature for the determination of factor IX activation: a coagulation assay in factor IX deficient plasma $(61,64,65)$, a tritiated activation peptide release assay $(64,66,67)$, an immunoradiometric assay (61) and an assay in which factor IXa is measured indirectly by determining the initial rate of factor $X$ activation (68). The most widespread used is the tritiated activation peptide release assay, which was originally described for the activation of factor X by Silverberg et al. (69). In highly purified systems the appearance of factor IXa procoagulant activity follows the peptide release with a small lag period. However, the release method measures factor IXa activity indirectly and in less purified systems other enzymes may be present that give rise to similar peptide fragments but destroy the procoagulant activity of factor IX (62).

\section{Platelet involvement.}

It is assumed that platelets are involved in the activation of factor IX by 
factor XIa $(70,71)$. This relative old hypothesis is supported by a variety of recent studies. Binding sites for factor XI and factor XIa are found on stimulated platelets $(72,73)$. This binding to activated platelets is increased by the presence of HMWK, calcium ions and low concentrations of zinc ions. HMWK is present in the $\alpha$-granules of platelets and can be secreted upon stimulation by thrombin or collagen (74). However, other investigators could not confirm this and reported that HMWK is localized in the cytosole of the platelets and is still present in the platelets after stimulation by thrombin (75). Recently, Schmaier et al. reported that 28 percent of the total amount of platelet HMWK becomes secreted and expressed on the membrane of activated platelets (76). External HMWK binds to stimulated (77) and unstimulated platelets (78). It has even been reported that platelets itself contain factor XI activity and factor $\mathrm{XI}$ antigen $(79,80)$. All these reports together suggest that factor XI activation can take place on the platelet surface and that the formed factor XIa can stay on this surface to activate factor IX. Walsh et al. have recently reported that factor XIa bound to stimulated platelets activates factor IX with the same rate as free factor XIa does (81). That factor IX also has a binding site on the stimulated platelets is reported by Ahmad et al (82). However, the presence of both, enzyme and substrate on the platelet surface, does not necessarily imply an enhanced activation of the substrate. There are also reports that point to an inhibitory role of platelets. Platelets contain inhibitors of factor XIa. $\alpha_{i}$-Antitrypsin (83) and $\mathrm{C}_{1}$ inhibitor (84) are localized in the platelets and upon stimulation they are secreted. Reports, in which platelet factor 3 (procoagulant surface) is imitated by using negatively charged phospholipids, are contradictory as to the effect caused by the surface on the factor IX activation by factor XIa. It has been reported that negatively charged phospholipids, accelerate (85), have no influence (41) or even inhibit (33) factor IX activation by factor XIa. Summarizing, it is clear that the role of platelets in the activation of factor IX by factor XIa is not yet established and only direct measurement of the rate of activation of factor IX by factor Xla in the presence of stimulated platelets can give the beginning of an answer to the question whether platelets indeed play a role in the activation of factor IX by factor XIa.

\section{Endothelial cell involvement.}

Another cell surface continuously interacting with coagulation factors is endothelium. Recently, participation of endothelial cells in procoagulant reactions has received increased attention. Stern et al. describe an endothelial celldependent pathway of coagulation (86). They also reported that factor IX bound to endothelial cells can be activated by both the intrinsic and extrinsic 
pathway of coagulation and that cell bound factor IXa in the presence of factor VIII can activate factor X (87). This factor LX/LXa-endothelial cell interaction is allegedly mediated by a specific receptor, not by phospholipids. Recently, Rimon et al. identified a cell surface protein with a molecular weight

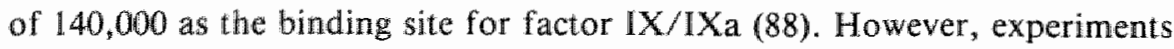
determining the kinetic parameters of endothelial cell mediated factor IX activation both via the intrinsic and extrinsic pathway, will have to show if endothelial cell mediated factor $\mathbb{I X}$ activation is physiologically relevant.

\section{The present investigation.}

This thesis describes a number of studies on the inhibition of blood coagulation factor XIa. Four plasma protease inhibitors, $\alpha_{1}$-antitrypsin, antithrombin III, $C_{1}$ inhibitor, and $\alpha_{2}$-antiplasmin, have been reported to inactivate human factor XIa. The rate of inactivation by antithrombin III can be accelerated in the presence of heparin. Due to this rate enhancement it is suggested that antithrombin III can play a significant role in the inhibition of factor XIa by plasma containing heparin. One of the aims of this study is to investigate the kinetics of inactivation of factor XIa by antithrombin III in the absence and presence of heparin. Studies to explore the kinetics of the inactivation of both active sites of factor XIa in the presence and absence of heparin are described in Chapter II. Further studies, using different heparin preparations, were performed to gain more insight in the nature of the stimulation by heparin of the kinetics of inactivation of factor Xla by antithrombin III. The results of these studies are reported in Chapter III.

In the intrinsic pathway of blood coagulation factor IX is the natural substrate of factor XIa. The activation of factor IX by factor XIa is the first calcium dependent reaction in this pathway and in contrast to the other activations no surface or cofactor requirement has been described. However, it is assumed that stimulated platelets are involved in the activation of factor IX. Another aim of this study was to explore the role of stimulated platelets in the activation of factor IX by factor XIa. To attain this aim the rate of activation of factor IX by factor XIa was determined in the presence of negatively charged phospholipids and in the presence of (non)stimulated platelets. Measurement of the rate of activation was performed by using an assay that determines functional factor IXa activity. In Chapter IV the results concerning the effect of negatively charged phospholipids in the activation of factor IX by factor XIa are presented and finally in Chapter $\mathrm{V}$ evidence is presented that platelets, upon stimulation, secrete an inhibitor that interferes with factor IX activation by factor XIa. 


\section{REFERENCES}

1. Buchanan, A. (1835) Med. Gaz. 18.50

2. Morawitz, P. (1905) Ergebnisse der Physiologie Biologischen Chemie und Experimental Pharmakologie 4,307

3. MacFarlane, R.G. (1964) Nature (London) 202, 498-499

4. Davie, E.W. and Ratnoff, O.D. (1964) Seience 145, 1310-1312

5. Tans, G. and Rosing, J. (1987) Seminars in Thrombosis and Hemostasis 13, 1-14

6. Bouma, B.N. and Griffin, J.H. (1986) In Blood Coagulation (Zwaal, R.F.A. and Hemker H.C., editors), 103-128, Elsevier, Amsterdam

7. Kaplan, A.P. and Silverberg, M. (1987) Blood 70, 1-15

8. Kurachi, K. and Davie, E.W. (1977) Biochemistry 16, $5831-5839$

9. Bouma, B.N. and Griffin, J.H. (1977) J. Biol. Chem 252, 6432-6437

10. Kurachi, K., Fujikawa, K. and Davie, E.W. (1980) Biochemistry 19, 1330-1338

11. Wiggins, R.C., Bouma, B.N., Cochrane, C.G. and Griffin, J.H. (1977) Proc. Natl Acad. Sci. USA $74,4636-4640$

12. Akiyama, H., Sinha, D., Seaman, F.S., Kirby, E.P. and Walsh, P.N. (1986) J. Clin. Inwest. $78,1631-1637$

13. Ratnoff, O.D., Davie, E.W., and Mallet, D.L. (1961) J. Clin. Invest. 40, 803-819

14. Di Scipio, R.G., Kurachi K. and Dawie E.W. (1978) J. Clin. Invest. 61, 1528-1538

15. Osterud, B., Bouma, B.N. and Griffin, J. H. (1978) J. Biol. Chem. 253, 5946-5951

16. Van Dieyen, G., Tans G., Rosing, J. and Hemker, H.C. (1981) J. Biol. Chern. 256, 3433-3442

17. Mertens, K. and Bertina, R.M. (1984) Biochem. J. 223, 607-615

18. Rosing, J., van Rijn, J.L.M.L., Bevers, E.M., van Dieyen. G., Comfurius, $P_{.,}$and Zwat R.F.A. (1985) Blood, 319-332

19. Hemker, H. C. and Kahn M. J. P. (1967) Nature (London) 215, 1201-1202

20. Papahadjopoulos, D.P. and Hanahan, D.J. (1964) Biochim. Biophys. Acta 90, 436-439

21. Hemker, H.C., Esnouf, M.P., Hemker. P.W., Swart, A.C.W. and MacFarlane, R.G. (1967) Nature (London) 215, 248-251

22. Mann, K.G. (1987) Trends in Biochenx. Science 12, 229-233

23. Tans, G. and Rosing, J. (1986) In Blood Coagulation (Zwaal, R.F.A. and Hemker, H.C., editors), 59-85, Elsevier, Ansterdam

24. Broze, G. J., Jr., Leykam, J. E., Schwartz, B. D. and Miletich, J. P. (1985) J. Biol. Chem. $260,10917-10920$

25. Guha, A., Bach, R., Konigsberg, W. and Nemerson, Y. (1986) Proc. Natl. Acad. Sci. USA 83, 299-302

26. Rao, L.V.M., Rapaport, S.I. and Bajaj, S.P. (1986) Blood 68, 685-691

27. Biggs, R. and Nossel, H.L. (1961) Thromb. Diathes. Haemorrh. 6, 1-14

28. Josso, F. and Prou-Wartelle, O. (1965) Tromb. Diathes Haenorrh, 17, 35-44

29. Osterud, B. and Rapaport, S.1. (1977) Proc. Nall. Acad. Sci. USA 74, 5260-5264

30. Zur, M. and Nemerson, Y. (1980) J. Biol. Chem. 255, 5703 5707

31. Jesty, J. and Silverberg, S.A. (1979) J. Bioll. Chem. 254, 12337-12345

32. Hemker, H. C. (1984) Scand, J. Haematol. 33, 11:19

33. Warn-Craner, B. J. and Bajaj, S.P. (1986) Biochem, J. 239, 757-762.

34. Saito, H. (1987) Seminars in Thrombosis and Hemostasis 13,36-49

35. Bouma, B.N. and Griffin, J.H. (1977) J. Biol. Chem. 252, 6432-6437

36. Kurachi, K. and Davie, E.W. (1977) Biochemistry $\llbracket 6,5831.5839$

37. Thompson, R.E., Mandle jr. R. and Kaplan, A.P. (1979) Proe. Natl. Acad. Sci. USA 76, $4862-4866$

38. Bouma, B.N., Vlooswijk, R.A.A. and Griffin, J.H. (1983) Blood 62, 1123-1131

39. Warn-Cramer B.J, and Bajaj, S.P. (1985) Biochem. Biophys. Res. Commun. 133, 417.422

40. Fujikawa, K., Chung, D.W., Hendrickson, L.E. and Davie, E.W.(1986) Biochemistry 25 , $2417-2424$ 
41. Van der Grat, F., Greengard, J.S.,Bouma, B.N., Kerbiriou, D.M. and Griffin, J.H. (1983) J. Biol. Chent. 258,9669-9675

42. Sinha, D., Koshy, A., Seaman, F.S. and Walsh, P.N. (1985) J. Biol. Chem. 260, $10714-10719$

43. Revak, S.D. and Cochrane, C.G. (1976) J. Clin. Invest. $57,852-860$

44. Mandle, R.J., Colman, R.W. and Kaplan, A.P. (1976) Proc. Natl. Acad. Sci. USA 73, $4179-4183$

45. Mannhalter, C.H. (1987) Seminars in Thrombosis and Hemostasis $13,25-35$

46. Colman, R.W. (1984) J. Clin. Invest. 73, 1249-1253

47. Scott, C.F., Schapira, M., James, H.L., Cohen, A.B. and Colman, R.W. (1982) J. Clin. Invest $699,844-852$

48. Damus, D.S., Hicks, M. and Rosenberg, R.D. (1973) Nature (London) 246, 355-357

49. A. Colman, R.W. and Scott, C.F. (1987) Blood 69, 703-704 (letter)

b. Beeler, D.L., Marcum, I.A., Schiffman, S. and Rosenberg, R.D. (1987) Blood 69, 704 (letier)

50. Scott, C.F., Schapira, M. and Colman, R.W. (1982) Blood 60,940-947

51. Beeler, D.L., Marcum, J.A., Schiffman, S. and Rosenberg, R.D. (1986) Blood 67, $1488-1492$

52. Holmer, E., Kurachi, K. and Söderströrn, G. (1981) Biochem, J, 193, 395-400

53. MeGraw, R.A., Davis, L.M., Lundblad, R.L. Stafford, D. W. and Roberts, H.R. (1985) Clin. Haematol. 14, 359-383

54. Thompson, A.R. (1986) Blood 67, 565 572

55. Ansion, D.S., Choo, K.H., Rees, D.J.G., Giannelli, F., Gould, K., Huddleston, J.A.and Brownlee, G.G. (1984) EMBO J. 3, 1053-1060

56. Yoshitake, S., Schach, B.G., Foster, D.C., Davie, E.W. and Kurachi, K. (1985) Biochemistry $25,3736-3750$

57. Nelsestuen, G.L., Kisie L, W. and Di Scipio, R.G. (1978) Biochemistry 17, 2134-2138

58. Jones, M.E., Griffith, M.J., Monroe, D.M., Roberts, H.R. and Lentz B.R. (1985) Biochemistry $24,8064-8069$

59. Lim T. K., Blcomfield, V. A. and Nelsestuen, G. L. (1977) Biochemistry 16, 4177-4181

60. Liebman, H.A., Furie, B.C. and Furie, B. (1987) J. Biol. Chem. 262, 7605-7612

61. Enfield, D.L. and Thompson, A.R. (1984) Blood 64, 821-831

62. Takaki, A., Enfield, D.L. and Thompson, A.R. (1983) J. Clin. Invest, 72, 1706-1715

63. Walsh, P.N. (1987) Seminars in Thrombosis and Hemostasis 13, 86-94.

64. Walsh, P.N., Bradford, H., Sinha, D., Piperno, J.R. and Tuszynski, G.P. (1984) J. Clin. Invest. 73, 1392-1399

65. Griffith, M.J., Breitkreuz, L., Trapp, H., Briet, E., Noyes, C.M., Lundblad, R.L. and Roberts, H.R. (1985) 1. Clun. Lnvest. $75,4-10$

66. Bajaj, S.P. (1982) J. Biol. Chem. 257, 4127-4132

67. Zur, M. and Nemerson, Y. (1980) J. Biol. Chem. 255, 5703-5707

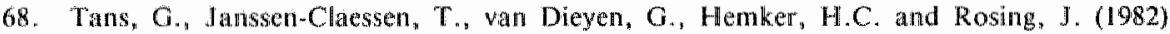
Thromb. Haemost. 48, $127-132$

69. Silverberg, S.A., Nemerson, Y. and Zur, M. (1979) J. Biol. Chem. 252, 8481-8488

70. Walsh, P.N. and Griffin, I. H. (1981) Blood 57, 106-118

71. Walsh, P.N. (1972) Br. J. Haematol. 22, 393-405

72. Greengard, J. S., Heeb, M.J., Ersdal, E., Walsh, P.N and Griffin, J.H. (1986) Biochemistry $25,3884-3890$

73. Sinha, D., Seaman, F.S., Koshy, A., Kaight, L.C. and Walsh. P.N. (1984) J. Clin. Invest. $73,1550-1556$

74. Schmaier, A.H., Zuckerberg, A., Silverman, C., Kuchibhotla, J., Tuszynski, G.P. and Colman, R.W. (1983) J. Clin. Invest. 71, 1477-1489

75. van lwaarden, F. and Bouma, B.N. (1985) Thromb. Haemostas. 54,1493 (abstract)

76. Schmaier, A.H., Smith, P.M., Purdon, A.D., White. J.G. and Colman R.W. (1986) Blood $67,119-130$

77. Greengard, J. S. and Griffin, J.H. (1984) Biochemistry 23, 6863-6869 
78. Gustafson, E.J., Schutsky, D., Knight, L.C. and Sehmaier, A.H. (1986) I. Chin. Invest. 78, $310-318$

79. Lipscomb, M.S. and Walsh, P.N. (1979) J. Clin. Invesi. 63, 1006-1014

80. Tuszynski, G.P. Bevacqua, S.J., Schmaier, A.H., Colman, R.W. and Walsh. P. N. (1982) Blood $59,1148-1156$

81. Walsh, P.N., Sinha, D., Koshy., A., Seaman., F.S. and Bradford, H. (1986) Blood 68, $225 \div 230$

82. Ahmad, S.S., Rawala, R. and Walsh, P.N. (1987) Thromb. Haemostas. 58, 351 (abstraci)

83. Bagdasarian, A. and Colman, R.W. (1978) Blood 51, 139-156

84. Schmaier, A. H., Smith, P.M. and Colman, R.W. (1985) J. Clin. Invest. 75, 242-250

85. Mannhalter, C., Schifiman, S. and Deutsch, E. (1984) Br. J. Haematol. 56, 261-271

86. Stern, D., Nawroth, P., Handley, D. and Kisiel, W. (1985) Proc. Natl. Acad. Sci. USA 82, $2523-2527$

87. Stern, D., Drillings, M., Kisiel, W., Nawroth, P., Nossel, H. and La Gamma, K. (1984) Proc. Nat1. Acad. Sci. USA 81, 913-917

88. Rimon, S., Melamed, R., Savion, N., Scott, T., Nawroth, P. and Stern, D.M. (1987) J. Biol. Chem. 262, 6023-6031 



\section{Inhibition of Factor XIa by Antithrombin III}

\section{Abstract}

The inactivation of human factor Xla by human antithrombin III was studied under pseudo first order reaction conditions (excess antithrombin III) both in the absence and presence of heparin. The time course of inhibition was followed using polyacrylamide gel electrophoresis in the presence of sodium dodecyl sulfate. After electrophoresis, proteins were blotted onto nitrocellulose and stained either for glycoprotein or for antithrombin III using antibodies against antithrombin III. Concomitant with factor XIa inactivation, two new slower migrating bands, one of which represented the intermediate complex consisting of one antithrombin III complexed with factor XIa, appeared as a transient band. Complete inactivation resulted in a single band representing the complex of factor XIa with two antithrombin III molecules. Quantitative analysis of the time course of inactivation was accomplished by measurement of the disappearance of factor XIa amidolytic activity towards the chromogenic substrate S2366. Pseudo first order reaction kinetics were observed throughout. The rate constant of inactivation was found to be $10^{3}$ $\mathrm{M}^{-1} \mathrm{~s}^{-1}$ in the absence of heparin and $26.7 \times 10^{3} \mathrm{M}^{-1} \mathrm{~S}^{-1}$ in the presence of saturating amounts of heparin. From the kinetic data, a binding constant $\left(\mathrm{K}_{\mathrm{d}}\right)$ of $0.14 \mu \mathrm{M}$ was inferred for the binding of antithrombin III to heparin. The time course of inactivation and the distribution of the reaction products observed upon gel electrophoresis are best explained assuming a mechanism of inactivation in which the two active sites present in factor XIa are inhibited in random order (i.e., independent of each other) with the same rate constant of inhibition. 
Factor $\mathrm{XI}$ is a coagulation protein present in plasma in a precursor form (Bouma et al., 1977). It is the (projenzyme that links the contact phase to the intrinsic factor IX activation. Four proteins appear to be involved in contact activation reactions: factor XII, factor XI, prekallikrein and high molecular weight kininogen (Cochrane and Griffin, 1982). Active factor XII with high molecular weight kininogen as a cofactor can convert factor XI to an active form (Griffin and Cochrane, 1979), which subsequently is able to activate factor IX by hydrolyzing two internal peptide bonds (Di Scipio et al., 1978).

Factor XI is a dimeric molecule which contains two identical protein chains ( 80,000 molecular weight) held together by (a) disulfide bond(s). Factor XI is converted to factor XIa by the cleavage of an internal peptide bond in both precursor chains. Factor XIa is composed of two heavy chains $\left(M_{r} 50,000\right)$ and two light chains $\left(M_{1}, 33,000\right)$ and contains one active site at each light chain (Bouma et al., 1977; Fujikawa et al, 1986). It is the only known enzyme participating in blood coagulation that contains two active sites.

Four plasma protease inhibitors, $\alpha_{1}$-antitrypsin, antithrombin III, $C_{1}$ inhibitor and $\alpha_{2}$-antiplasmin, have been reported to inactivate human factor XIa. In plasma, $\alpha_{1}$-antitrypsin is thought to be the main factor Xla inhibitor followed by antithrombin III (Scott et al., 1982a). However, the inactivation by antithrombin III can be accelerated in the presence of heparin (Damus et al., 1973). Scott et al. reported a 4-fold enhancement while Beeler et al. reported a 40 -fold acceleration of the inactivation at saturating heparin concentrations (Scott et al., 1982b; Beeler et al., 1986).

The stoichiometry of the complex formed between factor XIa and antithrombin III has been shown to be $1 \mathrm{~mol}$ factor XIa to $2 \mathrm{~mol}$ of inhibitor (Kurachi and Davie, 1977), indicating that both the active sites interact with antithrombin III. Thus, the presence of an intermediate, factor XIa complexed with one antithrombin III, formed during the inactivation of factor XIa is likely to be expected but has not been demonstrated yet. The kinetics of the inactivation of both active sites of factor XIa as well as the mutual interactions of factor XIa, antithrombin III, and heparin remain also to be established.

This study was undertaken to explore the kinetics of the inactivation of factor Xla by antithrombin III in the presence and absence of heparin. A model is suggested in which the two active sites of factor XIa are inhibited independent of each other by antithrombin III and in which the enhancement of the inactivation due to the presence of heparin is correlated to the binding of antithrombin III to heparin. 
Materials. Chromogenic substrates pyro-Glu-Pro-Arg-pNA (S2366) and HD-Pro-Phe-Arg-pNA (S2302) were purc ased from AB Kabi Diagnostica, Sweden. Rabbit anti-human antithrombin III, concanavalin $\mathrm{A}$, and horseradish peroxidase were obtained from Sigma Chemical Co., St. Louis, MO, USA. Nitrocellulose membrane was from Biorad Laboratories, Richmond, California, USA. 3.3' -Diaminobenzidine tetrahydrochloride was purchased from Fluka AG, Switzerland. Swine anti-rabbit lgG horseradish peroxidase conjugated antibodies were obtained from Nordic, Tilburg, Holland. All reagents used were of the highest grade commercially available.

Proteins. Human factor XI was purified according to Bouma et al. (1983). Human factor XII was isolated as described by Griffin and Cochrane (1976). Human antithrombin III was purified as described by Thaler and Schmer (1975). $\beta$-Factor XIIa was prepared from purified factor XII as described by Fujikawa and McMullen (1983). Human serum albumin (Sigma) was further purified on a concanavalin A-Sepharose column to remove glycoprotein impurities. Factor XI, factor XII, and antithrombin III preparations were homogeneous and pure as determined by gel electrophoresis in the presence of sodium dodecyl sulfate on $10 \%$ gels according to Laemmli (1970). The specific activities determined in a clotting assay for factors XI and XII were 211 and 74 units $/ \mathrm{mg}$, respectively, assuming 1 unit to be present per milliliter of normal human plasma. All proteins were stored at $-70{ }^{\circ} \mathrm{C}$ after dialysis against $50 \mathrm{mM}$ Tris- $\mathrm{HCl}, 175 \mathrm{mM} \mathrm{NaCl}, \mathrm{pH} 7.9$ for human antithrombin III and $4 \mathrm{mM}$ sodium acetate, $2 \mathrm{mM}$ acetic acid, $0.15 \mathrm{M} \mathrm{NaCl}$ and $0.5 \mathrm{mM}$ EDTA, pH 5.0 for human factors XI and XII.

Heparin was crude porcine intestinal mucosal heparin (Organon). It had a mean molecular weight of 15,000 and an anti-Xa and anti-thrombin activity of 175 units $/ \mathrm{mg}$.

Preparation of human factor XIa from human factor XI using human $\beta$ factor XIIa was performed as described earlier (Soons et al. 1986). Factor XIa was separated from $\beta$-factor XIla on a DEAE-Sephadex column $(1.5 \times 11.5$ $\mathrm{cm})$ at $4{ }^{\circ} \mathrm{C}$ in $50 \mathrm{mM}$ Tris- $\mathrm{HCl}$ and $150 \mathrm{mM} \mathrm{NaCl}$ at $\mathrm{pH} 8.0$.

Amidolytic activity of human factor XIa was measured by using the chromogenic substrate $\mathrm{S} 2366$ in a buffer containing $50 \mathrm{mM}$ Tris- $\mathrm{HCl}, 175 \mathrm{mM}$ $\mathrm{NaCl}, 20 \mathrm{mM}$ EDTA, and $0.5 \mathrm{mg} / \mathrm{mL}$ human serum albumin, $\mathrm{pH}$.7.9. The kinetic parameters of the hydrolysis of the chromogenic substrate S2366 by human factor XIa were $\mathrm{K}_{\mathrm{tm}}=0.42 \mathrm{mM}$ and $\mathrm{k}_{\mathrm{cat}}=758 \mathrm{sec}^{-1}$ " 
Protein concentrations were routinely determined according to Bradford (1976). Factor Xla concentrations were expressed as 80,000 molecular weight subunits (van der Graaf et al., 1983). Antithrombin III concentration was measured employing an $E_{280 m}(1 \%)$ of 5.7 (Kurachi and Davie, 1977) and by a titration against a known concentration human thrombin.

Gel Electrophoretic Analysis. Proteins were subjected to gel electrophoresis in the presence of sodium dodecyl sulfate on $5 \%$ slab gels as described by Laemmli (1970) and subsequently transferred onto nitrocellulose sheets as described by Towbin et al. (1979). The b]ots were soaked in $0.1 \%$ bovine serum albumin and $0.05 \%$ Tween-20 in phosphate-buffered saline. Immunological detection of antithrombin III and antithrombin III-protease complexes was performed essentially as described by Towbin et al. (1979) with rabbit anti-human antithrombin III and using swine anti-rabbit IgG conjugated with horseradish peroxidase as second antibodies. Glycoprotein staining was performed as described by Clegg (1982) by incubating the blots with concanavalin $\mathrm{A}(50 \mu \mathrm{g} / \mathrm{mL})$ in phosphatebuffered saline containing $1 \mathrm{mM} \mathrm{CaCl}, 0.1 \mathrm{mM} \mathrm{MgCl}_{2}, 0.1 \mathrm{mM} \mathrm{MnCl}, 0.1 \%$ bovine serum albumin and $0.05 \%$ Tween-20. Horseradish peroxidase $(10 \mu \mathrm{g} /$ $\mathrm{mL}$ ) in the same buffer was used as indicator. Staining of the blots was achieved by soaking in a freshly prepared and filtered solution of diaminobenzidine tetrahydrochloride $(0.5 \mathrm{mg} / \mathrm{mL})$ and $0.01 \% \mathrm{H}_{2} \mathrm{O}_{2}$ in $0.05 \mathrm{M}$ Tris- $\mathrm{HCl}, \mathrm{pH} 7.5$.

Fluorescence studies were performed using an SLM/Aminco SPF-500 C spectrophotometer at $25^{\circ} \mathrm{C}$. The excitation and emission wavelengths were 285 and $345 \mathrm{~nm}$ (band-passes 2 and $5 \mathrm{~nm}$, respectively). The interaction of heparin with antithrombin III was measured by changes in intrinsic fluorescence of antithrombin III. Small aliquots of heparin were added in succession to a solution of antithrombin III ( 1 and $2 \mu \mathrm{M}$ ) in $50 \mathrm{mM}$ Tris- $\mathrm{HCl}, 100 \mathrm{mM}$ $\mathrm{NaCl}, \mathrm{pH}$ 7.5. After each addition, the intrinsic fluorescence intensity of antithrombin III was determined. The data were plotted, and the titer was measured from the point of intersection of lines drawn through the ascending limbs and the plateaus of the plots.

Kinetic Data Analysis. The disappearance of factor XIa amidolytic activity appeared to follow pseudo first order reaction kinetics both in the absence and presence of heparin over the whole time course of inactivation. Since inactivation was only complete upon covalent binding of two antithrombin III molecules to each factor XIa dimer, it appears that the reaction of a catalytic site on factor XIa occurs in a random fashion and is not influenced by the fact of whether or not the other active site in the dimer has already been occupied by another antithrombin III molecule (AT III) (see also under Results). Therefore, the inactivation can be described as 
in which XIa is the concentration of factor XIa expressed per $80,000 \mathrm{M}_{\text {r }}$ subunit. The rate constant $k_{1}$ can then be obtained as described in the legend to Figure 1.

The stimulation of the inhibition of factor Xla by antithrombin III due to the presence of heparin was assumed to be due to the binding of antithrombin III to heparin. In that case, the reaction is given as

$$
\begin{aligned}
& \mathrm{XIa}+\mathrm{AT}-\mathrm{III} \mathrm{f}_{\mathrm{f}} \stackrel{\mathrm{k}_{1}}{\longrightarrow} \text { XIa.AT-III } \\
& \mathrm{XIa}+\mathrm{AT}-\mathrm{III}_{\mathrm{b}} \stackrel{\mathrm{k}_{2}}{\longrightarrow} \text { XIa.AT-III }
\end{aligned}
$$

in which XIa is again the concentration of factor XIa expressed per $M_{r}$ 80,000 subunit and in which AT- $\mathrm{III}_{r}$ and AT- $\mathrm{III}_{\mathrm{b}}$ are the concentrations of free antithrombin III and of antithrombin III bound to heparin, respectively. $k_{1}$ and $k_{2}$ are the rate constants of inactivation by free antithrombin III and by the antithrombin III-heparin complex. Assuming rapid binding equilibrium, the rate equation can be written as

$$
\mathrm{d}[\mathrm{XIa}] / \mathrm{dt}=-\left(\mathrm{k}_{1} \cdot\left[\mathrm{AT}-\mathrm{III}_{\mathrm{f}}\right]+\mathrm{k}_{2} \cdot\left[\mathrm{AT}-\mathrm{III}_{\mathrm{b}}\right]\right) \cdot[\mathrm{XIa}]
$$

and the slope of a pseudo first order plot will equal $-\left(k_{1} \cdot\left[\right.\right.$ AT $\left.-I I I_{1}\right]+k_{2} \cdot[A T-$ $\left.\mathrm{III}_{b}\right]$ ). $\mathrm{k}_{3}$ and $\mathrm{k}_{2}$ can be independently determined. Measurement of the reaction in the absence of heparin (all antithrombin III is free) yields $k_{1}$ and in the presence of saturating amounts of heparin (all antithrombin III is bound) yields $k_{2}$. Thus, from the observed rates of factor XIa inactivation, the binding of antithrombin III to heparin can be determined. It should be stressed that in the above it is tacitly assumed that the binding equilibrium of antithrombin III binding to heparin is not influenced by factor XIa or by the produced factor XIa-antithrombin III complexes. Since the reaction kinetics appear to remain first order in factor XIa over a wide range of factor XIa concentrations (0.1-200 $\mathrm{nM})$ this assumption appears to hold.

Binding of Antithrombin III to Heparin. The binding parameters $\left(\mathrm{K}_{\mathrm{d}}\right.$ and amount of binding sites) of antithrombin III binding to heparin were determined from the kinetic data of factor XIa inactivation at varying antithrombin III and heparin concentrations. At a given heparin concentration, the rate of factor XIa inhibition was determined at varying antithrombin III concentrations. At each concentration of antithrombin III, the amounts of antithrombin III bound and free were calculated from the slope of the pseudo 

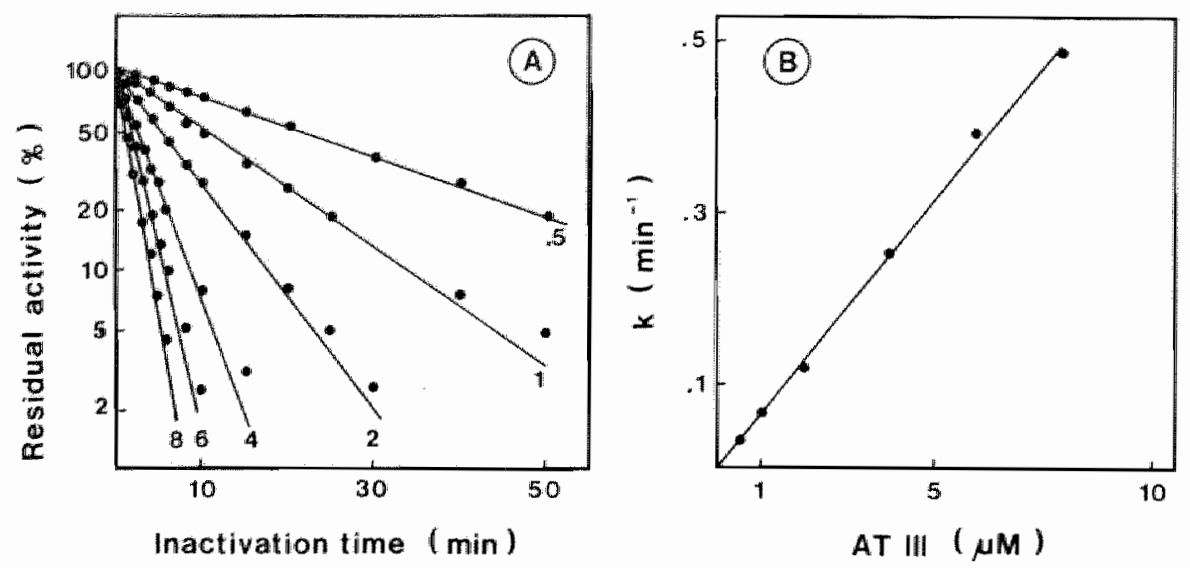

FIGURE I: Inactivation of human factor XIa by human antithrombin III in the absence of heparin. Factor XIa was incubated at $37^{\circ} \mathrm{C}$ in $50 \mathrm{mM}$ Tris $\left(p H 7.5\right.$ at $\left.37^{\circ} \mathrm{C}\right)$, $175 \mathrm{mM} \mathrm{NaCl}, 20 \mathrm{mM}$ EDTA, and $0.5 \mathrm{mg} / \mathrm{mL}$ human serum albumin. Afier $5 \mathrm{~min}$, reaction was statted by adding varying amounts of antithrombin III. Final concentravions were: $8 \mathrm{nM}$ factor XIa and antithrombin III in micromolar as indicated in figure. (Panel A) At the time points indicated, aliquots were removed from the reaction mixtwre and diluted 20 -fold in the above mentioned buffer containing $0.29 \mathrm{mM} \mathrm{S2366}$. The amidolytic activity remaining was determined by measurement of the rate of change in absorbance at 405-500 $\mathrm{nm}$ on an Aminco DW2a spectrophotometer set in the dual wavelength mode. The residual amidolytic activity was expressed as percentage of the original amidolytic activity present in the absence of antithrombin III taken as 100\%. Panel B' shows the pseudo first order rate constant obtained from the slope of the plots shown in panel A as a function of the concentration of antithrombin III present.

first order plot of inactivation using the experimentally determined $k_{1}$ and $k_{2}$ as described above. The binding constant $\mathrm{K}_{\mathrm{d}}$ is given as

$$
\mathrm{K}_{\mathrm{d}}=\left[\mathrm{AT}-\mathrm{III}_{\mathrm{f}}\right]\left[\mathrm{S}_{\mathrm{f}}\right] /\left[\mathrm{AT}-\mathrm{III}_{b}\right]
$$

and this can be rearranged to

$$
\left.1 /[\mathrm{AT}-1 \mathrm{I}]_{b}\right]=\left(\mathrm{K}_{\mathrm{d}} / \mathrm{S}_{\mathrm{tod}}\right)\left(\mathbb{1} /\left[\mathrm{AT}-\mathrm{HI}_{\mathrm{i}}\right]\right)+1 / \mathrm{S}_{\mathrm{tot}}
$$

Thus, the binding constant $\mathrm{K}_{\mathrm{d}}$ and the total amount of binding sites present $\left(S_{\text {tot }}\right)$ at the given heparin concentration can be determined from a plot of $1 /\left[\mathrm{AT}^{\mathrm{H}}-11 \mathrm{I}_{\mathrm{b}}\right]$ versus $1 /\left[\mathrm{AT}-\mathrm{III}_{\mathrm{f}}\right]$. 
The inhibition of human factor XIa by human antithrombin III was studied in the presence and absence of heparin by measurement of the disappearance of factor XIa amidolytic activity towards the chromogenic substrate S2366. The reaction was pseudo first order in factor Xla since a semi logarithmic plot of the residual amidolytic activity versus time yielded a straight line (Figure 1A). The apparent first order rate constant obtained from the slope of these lines was directly proportional to the amount of antithrombin III present (Figure 1B). Therefore, in aggreement with the literature (Scott et al., 1982a), the inactivation was found to be second order and the rate constant obtained was $10^{3} \mathrm{M}^{-1} \mathrm{~s}^{-1}$. Figure $2 \mathrm{~A}$ shows that in the presence of heparin $(0.1$ $\mathrm{mg} / \mathrm{mL}$ ) the reaction was also pseudo first order but the rate of inactivation was increased some 30 -fold. At saturating amounts of heparin (see also below), the second order rate constant of inactivation was $26.7 \times 10^{3} \mathrm{M}^{-1} \mathrm{~s}^{-1}$.

It has been shown that factor XIa consists of two identical subunits of 80,000 each which both contain an active site. The stoichiometry of the interaction of factor XIa with antithrombin III has been shown to be $1: 2$ (Kurachi and Davie, 1977), indicating that both active sites become occupied. However, to our knowledge, the intermediate in which one active site is occupied has never been shown and no attempts have been made yet to correlate the occurrence of the various reaction products with the disappearance of factor Xla amidolytic activity. Therefore, during the time course of factor XIa inactivation, samples were withdrawn from the reaction mixture and subjected to sodium dodecyl sulfate (SDS)-5\% polyacrylamide gell electrophoresis under nonreducing conditions. The protein bands were blotted onto nitrocellulose sheets and subsequently stained for glycoprotein using concanavalin A (Figure 2B). Since factor XIa and antithrombin III are glycoproteins, both were stained using this method. Factor XIa was present as a single band and antithrombin III migrated at the dye front of the gel (lane C, Figure 2B). Free antithrombin III was not visible on the blots because it migrates at the dye front together with an excess of carrier protein (human serum albumin) that interferes with the staining of the free antithrombin III.

The glycoprotein pattern on the blot showed three protein bands, which changed in intensity during the inactivation of factor XIa. The protein band, representing factor XIa, decreased in intensity during the inactivation, and after $10 \mathrm{~min}$, no factor XIa was visible. Concomitantly, two slower migrating bands appeared. Both these bands stained positive for antithrombin III antigen using rabbit anti-human antithrombin III antibodies (Figure 2C). Free factor XIa was not visible on this blot. These results demonstrate the appear- 

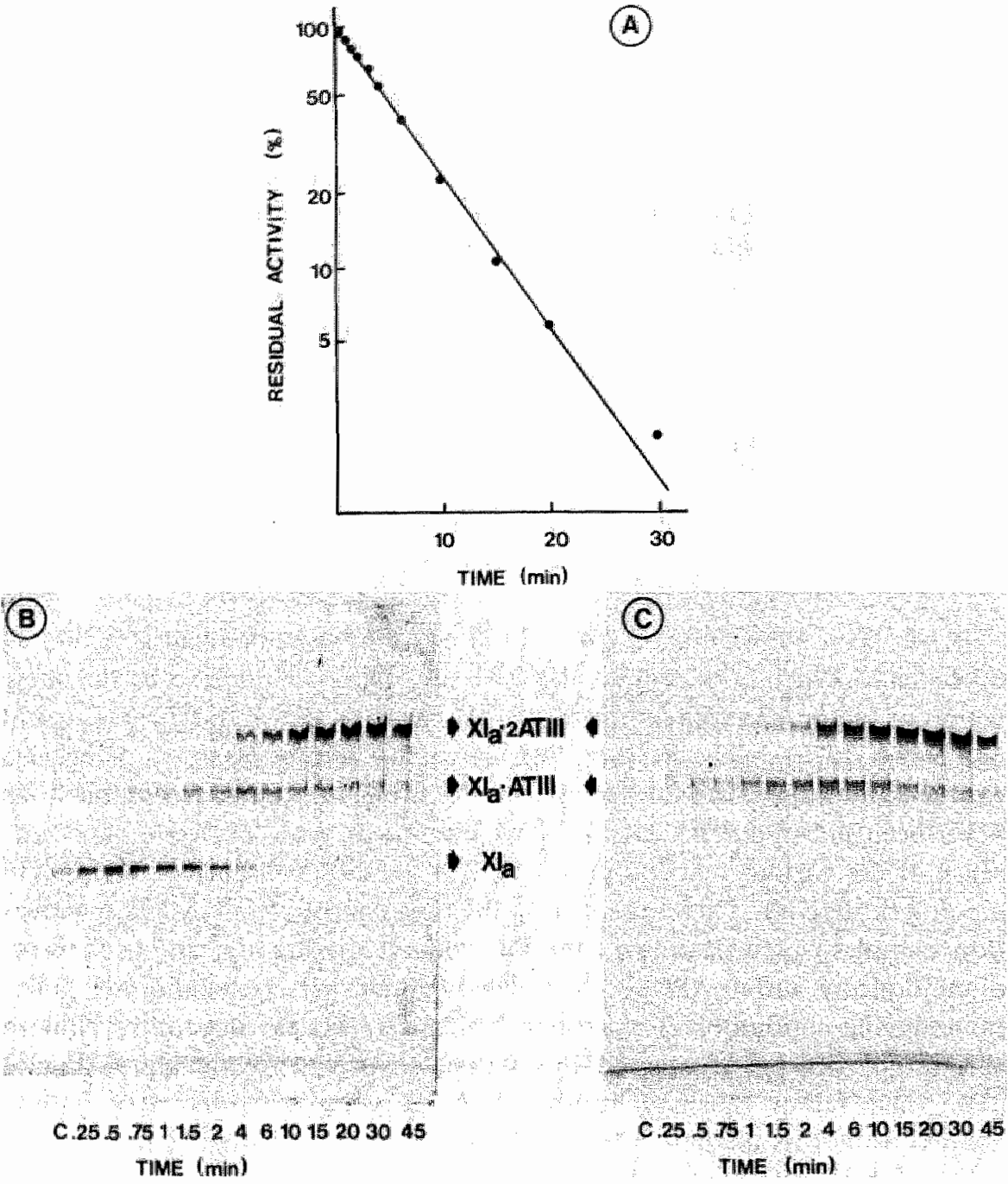

FIGURE 2: Inactivation of human factor Xla by human antithrombin III in the presence of heparin. Factor XIa $(8 \mathrm{mM})$ and heparin $(0.1 \mathrm{mg} / \mathrm{mL})$ were preincubated at $37^{\circ} \mathrm{C}$ in $50 \mathrm{mM}$ Tris (pH 7.5 at $37^{\circ} \mathrm{C}$ ), $175 \mathrm{mM} \mathrm{NaCl}, 20 \mathrm{mM}$ EDTA, and 0.5 $\mathrm{mg} / \mathrm{mL}$ human serum albumin. After $5 \mathrm{~min}$, reaction was started with the addition of antithrombin III to result in a final concentration of $64 \mathrm{nM}$. At the time points indicat ed in the figure, aliquots were withdrawn from the reaction mixture for the determination of the anidolytic activity remaining (panel A) and for gel electrophoresis under nonreducing conditions on 5\% slabgels (panels $B$ and $C$ ). (Panel A) From the residual amidotytic activity present in the sample, the pseudo first order plot was constructed as described in legend to Figure 1 . The obtained pseudo first order reaction rate consfam was $0.13 \mathrm{~min}^{-1}$. (Panel B) After gel electrophoresis, protein was blotted onto nitrocellulose sheets and stained for glycoprotein using concanavalin A. (Panel C) A second blot was stained for antithrombin III antigen using antibodies against human antithrombin III. For further experimental details see under Materials and Methods. 


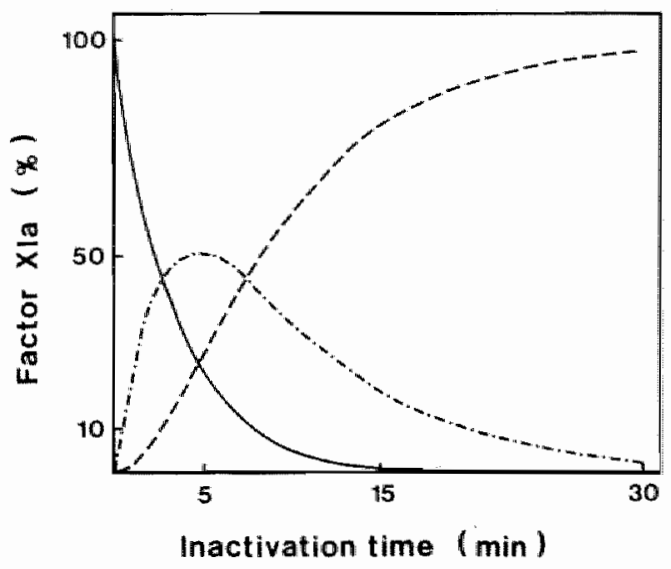

FIGURE 3: Calculated time course of appearance and disappearance of reaction products during the inactivation of factor XIa by antithrombin III in the presence of heparin. The time course of the changes in the concentration of factor XIa $(-)$, factor XIa complexed with one antithrombin $I I(-\ldots)$, and the final reaction product, factor XIa complexed with two antithrombin III molecules (- _ -), was calculated for the experiment presented in Figure 2. For the calculation, it was assumed that (1) both active sites had the same amidolytic activity, (2) both active sites were independent of each other inhibited by antithrombin III with the same measured pseudo first order reaction rate constant $(k)$, and (3) the factor XTa dimer disappeared with a rate constant of $2 \mathrm{k}$. With these assumptions the amount of factor XIa decreased in time according C. $e^{-2 k r}$ while factor XIa complexed with one or two antithrombin III's increased in time according $2 C_{\cdot}\left(e^{-k t}-e^{-2 k i}\right)$ and $C .\left(1-2 e^{-m t}+e^{-2 k t}\right)$, respectively (Moare, 1972). The constant $C$ was the amount of factor XIa present at the beginning and was taken $100 \%$ and $k$ was $0.13 \mathrm{~min}^{-1}$ as obtained from the data of Figure 2 .

ance and disappearance of the intermediate (in which only one active site is occupied in factor XIa) during the time course of the reaction. This intermediate which, represents the faster migrating band, rapidly appeared and reached an optimum between 2 and $15 \mathrm{~min}$ after which it slowly decreased. The slowest migrating band representing the final reaction product (one factor XIa and two antithrombin III molecules), gradually increased during the time course of factor Xla inactivation. From the data represented in Figure $2 \mathrm{~A}-\mathrm{C}$, it is cllear that only the final reaction product had no amidolytic activity. However, although factor XIa rapidly disappeared within $10 \mathrm{~min}$ and substantial amounts of intermediate were visible on the gels, the reaction remained first order throughout the whole time course of inactivation (Figure 2A). This strongly suggests that both active sites in factor XIa are inactivated with the same rate constant independent of each other (i.e., irrespective of whether or not the other site is already occupied). In such a model, the distribution of the various reaction products (i.e., XIa, XIa.AT-III, and XIa.2AT- 

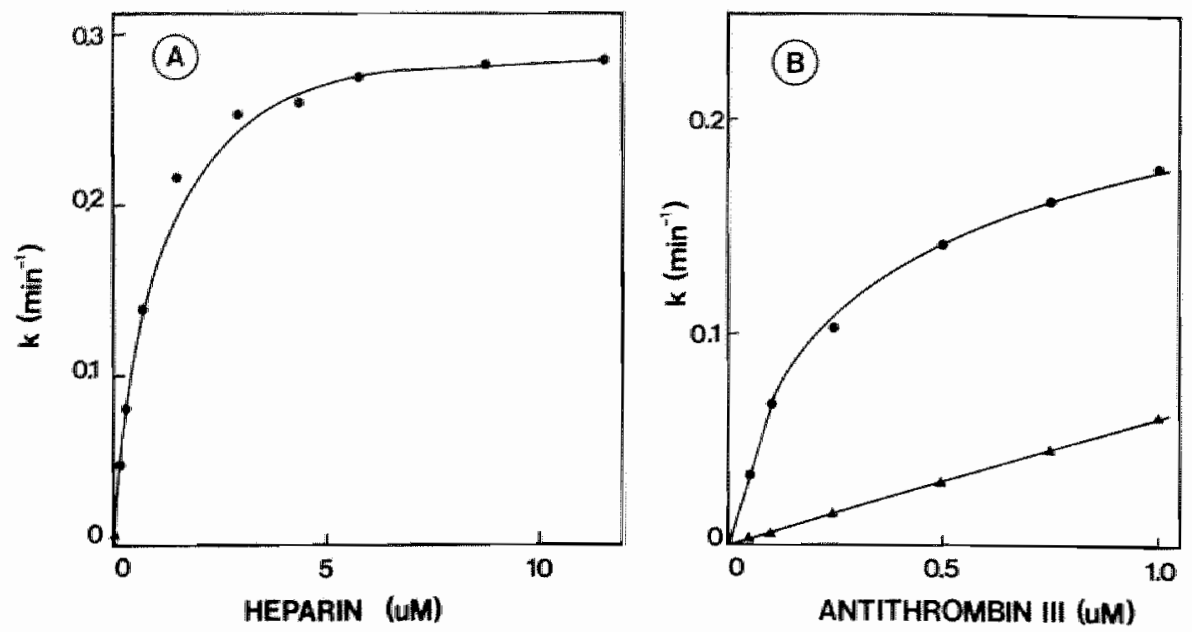

FIGURE 4: Titration experiments.

Panel $A$ shows the changes in the pseudo first order reaction rate constant, $k$, when factor XTa $(8 \mathrm{nM})$ and antithrombin III (100 nM) were titrated with heparin (range. $0.067-10 \mu \mathrm{M}$ ). The pseudo first order reaction rate constants were obtained as described in the legend to Figure l, and at least seven time points were used. Pamel $B$ shows the changes in the pseudo first order reaction rate constant, $k$, when factor XIa $(8 \mathrm{nM})$ and heparin $(0.3 \mu \mathrm{M})$ were titrated with antithrombin III (range: $0.05-1.0 \mu \mathrm{M}$ ) (closed circles). This experiment was also performed in the absence of heparin (closed (riangles).

III) at each given time interval can be calculated by using the rate constant determined from the pseudo first order plot (see also legend to Figure 3). Figure 3 shows the result of such a calculation for the experiment described in Figure 2. As can be seen, the appearance and disappearance of the various reaction products as calculated correlate quite well with the distribution of these products as seen on the blots in Figure 2.

The inactivation of factor XIa by antithrombin III in the presence of heparin is a three-component reaction. To investigate the mutual interactions, the concentration of each of the three components was varied while the two others were kept constant. Figure 4A shows that the pseudo first order reaction rate constant increased, when factor XIa $(8 \mathrm{nM})$ and antithrombin III $(0.1 \mu \mathrm{M})$ were titrated with heparin $(0.067-10 \mu \mathrm{M})$ and reached a plateau at a heparin concentration of approximately $5 \mu \mathrm{M}$. The second order reaction rate constant at saturating heparin concentrations was calculated to be $26.7 \times 10^{3}$ $\mathrm{M}^{-1} \mathrm{~s}^{-1}$. Figure $4 \mathrm{~B}$ shows that the pseudo first order reaction rate constant also increased, when at a constant concentration of factor XIa $(8 \mathrm{nM})$ and heparin $(0.3 \mu \mathrm{M})$ the concentration of antithrombin III was increased $(0.05$ 


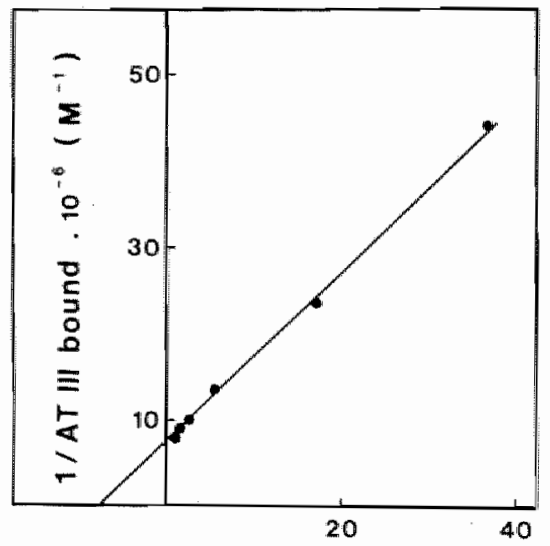

$1 /$ AT III free $.10^{-6}\left(\mathrm{M}^{-4}\right)$
FIGURE 5: Replot of the data of Jigwe $4 B$ according the presented model described in equation II. For eack lotal antithrombin III concentration, the concentration bound and free anththrombin III were calculated as described in Materials and Methods, and the reciprocals of thew were plotied against eact orher. The binding parameters of the anththrombin IIIheparin interaction found were a $\boldsymbol{K}_{d l}$ of $142 \mathrm{nM}$ and 0.42 antithrombin III binding sites per mole of heparin according equation $\mathrm{V}$.

$-1.0 \mu \mathrm{M})$. The rate constant did not reach a plateau (closed circles). This is due to the fact that the rate constant of factor XIa inhibition in the absence of heparin (closed triangles) was not negligible. The pseudo first order reaction rate constant did not change $\left(\mathrm{k}=0.15 \mathrm{~min}^{-1}\right)$, when heparin $(0.17 \mu \mathrm{M})$ and antithrombin III $(1.0 \mu \mathrm{M})$ were titrated with factor XIa $(0.1-200 \mathrm{nM})$. These data suggest that the rate of inactivation of factor XIa by antithrombin III in the presence of heparin is a direct measure for the binding of antithrombin III to heparin and that this binding is not influenced by factor XIa. That this is indeed the case is illustrated in Figure 5 in which the data of the experiment presented in Figure 4 were used to obtain the binding data of antithrombin III to heparin. For this, the data were analyzed as described under Materials and Methods using rate constants of $10^{3} \mathrm{M}^{-1} \mathrm{~s}^{-1}$ for the inhibition of factor XIa by free antithrombin III and of $26.7 \times 10^{3} \mathrm{M}^{-1} \mathrm{~S}^{-1}$ for heparin- bound antithrombin III. Figure 5 shows a plot calculated from the data shown in Figure $4 \mathrm{~B}$. As can be seen, a straight line was obtained from which a $\mathrm{K}_{\mathrm{d}}$ of $142 \mathrm{nM}$ was determined. The amount of sites present on heparin was calculated to be $0.42 \mathrm{~mol}$ antithrombin III per mol of heparin assuming a molecular weight of 15,000 for the heparin.

\section{Discussion}

The results presented in this paper give insight in the way via which the two active sites in factor XIa are inhibited by antithrombin III. In aggreement with earlier studies (Kurachi and Davie, 1977; Scott et al., 1982a), it was found that the final reaction product has no amidolytic activity and consists of a complex of factor XIa to which two antithrombin III molecules become attached. 
However, the experiments presented in Figure 2 also clearly demonstrate the occurrence of the intermediate consisting of one factor XIa with one antithrombin III molecule as a transient product during the time course of the reaction. To our knowledge, this is the first time that this intermediate has been unequivocally demonstrated using gelelectrophoretic techniques. The intermediate appears amidolytically active since even when the band representing free factor Xla has disappeared there is still considerable amidolytic activity present in the reaction mixture. However, in aggreement with literature (Scott et al., 1982b), it was found that both in the absence and in the presence of heparin the disappearance of factor XIa amidolytic activity cannot be distinguished from pseudo first order kinetics over the whole time course of the reaction. This is most likely explained by a mechanism in which both active sites of factor XIa interact with antithrombin III in random order (i.e., independent of each other) with the same rate constant. The changes in the distribution of the reaction products visible on the gels during the time course of the reaction correlate well with changes calculated according, such a model (cf. Figures 2 and 3). Simulation experiments showed that, as soon as the two rate constants would differ by a factor 2 or more, a deviation of pseudo first order kinetics would have been readily observable (data not shown).

The kinetic data obtained in the presence of heparin can be used to determine the binding parameters of antithrombin III binding to heparin (cf. Figures 4 and 5). The $K_{d}$ of $142 \mathrm{nM}$ determined is in good aggreement with that reported in literature (Griffith, 1982). The stoichiometry of the interaction of antithrombin III with heparin was found to be $0.42 \mathrm{~mol}$ antithrombin III per mol of heparin assuming an average molecular weight of 15,000 for the heparin used. This is somewhat lower than reported in literature (Nesheim et al., 1986). The stoichiometry of the interaction was confirmed for the used reactants by independent measurement using the fluorescence technique described by Nesheim et al. (1986) (data not shown). Therefore, it seems justified to conclude that the stimulation of the reaction by heparin is due to the binding of antithrombin III to heparin and since the inactivation remains first order for all the concentrations of factor XIa tested $(0.1-200 \mathrm{nM})$ the binding of antithrombin III to heparin is apparently not influenced by factor XIa and/or by the reaction products formed. It has been shown that factor XIa binds to heparin-Sepharose (Osterud and Rapaport, 1977). Therefore, it can be expected that factor XIa may interact with heparin under our experimental conditions. At the moment, we do not know whether binding of factor XIa to heparin influences the rate of factor XIa inactivation by antithrombin III. If such is the case, however, the fact that the reaction is saturable with heparin and the fact that the kinetics are first order in factor XIa, indicate that then either all factor XIa has to be bound or that no factor Xla is bound at all to heparin under our conditions. 
The rate constants determined were $10^{3} \mathrm{M}^{-1} \mathrm{~S}^{-1}$ in the absence of heparin and $26.7 \times 10^{3} \mathrm{M}^{-1} \mathrm{~s}^{-1}$ in the presence of saturating amounts of heparin. This rate enhancement induced by heparin is in good aggreement with the value reported by Beeler et al (1986). However, the actual values of rate constants reported here are considerably higher than earlier reported values (Beeler et al., 1986; Scott et al., 1982b). Apart from differences in experimental conditions, a possible explanation for these discrepancies is that in the present study factor XI activated by $\beta$-factor XIIa was used whereas in the previous studies trypsin-activated factor XI has been used. Similar differences have been reported for the enzymatic activity of factor XIa in the activation of factor IX (Walsh et al., 1984; Soons et al., 1986). Beeler et al. have argued that under certain conditions antithrombin III may become a physiologically significant inhibitor of factor XIa (Beeler et al., 1986). The finding that the rates of inactivation of $\beta$-factor XlIa activated factor XI are even higher than the values reported by these authors can be regarded to support this concept. It should be stressed, however, that the conditions in whole plasma are so much more complicated than those in purified systems that much more will need to be done to gain insight in the biological importance of the regulation of factor XIa inactivation by antithrombin III.

Finally, we would like to emphasize that our data periain to the mechanism of the interaction of the two active sites in factor XIa with its macromolecular substrate antithrombin III. The intriguing question remains whether the remaining active site in a factor XIa molecule, complexed with one antithrombin III, can also interact with factor IX the same way as free factor XIa or whether in this case changes occur in the mechanism of activation of factor IX by factor Xla.

\section{Acknowledgements.}

We thank G.M. Willems, T. Lindhout and J. Rosing for valuable discussions. Antithrombin III was kindly donated by J. Franssen. We would also like to thank T. Camphuisen-Engel for typing this manuscript.

This paper has been published in Biochemistry.

Soons, H., Janssen-Claessen, T., Tans, G., and Hemker, H. C.

Inhibition of Factor XIa by Antithrombin III.

Biochemistry $1987,26,4624-4629$. 


\section{References}

Beeler, D.L., Marcum, J.A., Schiffman, S., and Rosenberg, R.D. (1986) Blood 67, 1488.

Bouna, B.N., and Griffin, J.H. (1977) J, Biol.Chem. 252, 6432 .

Bouma, B.N., Vlooswijk, R.A.A., and Griffin, J.H. (1983) Blood 62, 1123.

Bradford, M.M. (1976) Anal. Bochem. 72, 248.

Clegs, J.C.S. (1982) Anal Biochem. 127, 389.

Cochrane, C.G., and Griffin, J.H. (1982) Adv. Immunol. 33,241.

Damus, P.S., Hicks, M., and Rosenberg, R.D. (1973) Nature 246, 355.

Di Scipio, R.G., Kurachi, K., and Davie, E.W. (1978) J. Clin. Invest. 61, 1528.

Fujikawa, K., and McMullen, B.A. (1983) J. Biol. Chem. 258, 10924.

Fujikawa, K., Chung, D.W. Hendrickson, L.E., and Dawie, E.W. (1986) Biochemistry 25, 2417. van der Graaf, F., Greengard, J.S., Bouma "B.N., Kerbiriou, D.M., and Griffin, J.H. (1983) J. Biol. Chem, 258, 9669.

Griffin, J.H., and Cochrane, C.G. (1976) Meth. Enzymol. 45, 56.

Griffin, J.H, and Cochrane, C.G. (1979) Semin. Thromb. Hemostasis 5, 254.

Griffith, M.J. (1982) J. Biol. Chem. 257, 13899.

Kurachi, K., and Davie, E.W. (1977) Biochemistry 16, 5831.

Laemmli, U.K. (1970) Nature 227, 680,

Moore, W.J. (1972) Physical Chemistry (Prentice-Hall, London) page 345.

Nesheim, M. Blackburn, M.K., Lawler, C.M., and Mann, K.G. (1986) J. Biol. Chen. 261 , 3214.

Osterud, B., and Rapaport, S.I. (1977) Proc. Natl. Acad. Sci. USA. 74, 5260

Scott, C.F., Schapira, M., James, H.L., Cohen, A. B., and Colman, R.W. (1982a) J. Clin. Invest. 69,844 ,

Scott, C.F., Schapira, M., and Colman, R.W. (1982b) Blood 60, 940.

Soons. H., Janssen-Claessen, T., Hemker, H.C., and Tans ${ }_{*}$ G. (1986) Blood 68, 140.

Thaler, E., and Schmer, O. (1975) Br. J. Heamatol. 31, 233.24.

Towbin., H., Staehelin, T., and Gordon, J. (1979) Proc. Natl. Acad. Sci. USA 76, 4350.

Walsh, P.N., Bradfrod, H., Sinha, D., Piperno, J.R., and Tuszynski, G.P. (1984) J. Clin. Invest. $73,1392$. 


\section{The Heparin Catalyzed Inhibition of Human Factor XIa by Antithrombin III is Dependent on the Heparin Type}

\section{Abstract}

The effect of various well characterized heparin preparations on the inactivation of human factor Xla by human antithrombin IIl was studied. The heparin preparations used were unfractionated heparin and four heparin fractions obtained after anion exchange chromatography. Inactivation of factor XIa was monitored using S2366 as chromogenic substrate and followed pseudo first order reaction kinetics under all reaction conditions tested. Enhancement of the rate of inhibition of factor XIa in the presence of unfractionated heparin correlated to the binding of antithrombin III to heparin. From the kinetic data a binding constant of $0.1 \mu \mathrm{M}$ was inferred. The maximum rate enhancement, achieved at saturating heparin concentrations was 30 -fold.

The rate enhancement achieved in the presence of each of the heparin fractions could also be correlated to the binding of antithrombin III to the heparin. The binding constant inferred from the kinetic data varied from 0.10 to $0.28 \mu \mathrm{M}$ while the number of binding sites for antithrombin lll varied from 0.06 to 0.74 sites per heparin molecule. The maximum rate enhancements, achieved at saturating heparin concentrations, were strongly dependent on the type of heparin used and varied from 7 -fold for fraction $A$ to 41 -fold for fractilon $\mathrm{D}$.

Therefore, although the stimulation of factor XIa inactivation by antithrombin III could be quantitatively correlated to the binding of antithrombin III to heparin, the heparin catalyzed inhibition of factor Xla is not only dependent upon the degree of binding of antithrombin III to heparin but also upon the type of heparin to which antithrombin III is bound. 
Human factor XIa is the protease, that links the contact phase of blood coagulation to intrinsic factor $\mathrm{X}$ activation. It is a dimeric molecule, which is composed of two heavy chains $\left(M_{r} 50,000\right)$ and two light chains $\left(M_{r} 33,000\right)$ held together by disulfide bonds (Bouma and Griffin, 1977). It is the only known dimeric enzyme participating in blood coagulation and the light chain of each monomer contains an active site (Fujikawa et al., 1986).

Antithrombin III is one of the four plasma protease inhibitors, that have been reported to inactivate factor XIa (Scott et al., 1982). Both active sites in factor XIa interact with antithrombin. III (Kurachi and Davie, 1977) and we recently showed that the two sites are inhibited independent of each other both in the absence and presence of heparin (Soons et al., 1987). Heparin is a mixture of muco-polysaccharides which is heterogeneous with respect to molecular weight, charge density and affinity to antithrombin III. In a previous study we have shown that the rate of inactivation of factor XIa by antithrombin III is a direct measure for the binding of antithrombin III to heparin (Soons et al., 1987). The mechanism via which the heparin-induced rate enhancement for bound antithrombin III is brought about remains, however, to be established. Holmer et al. reported that the rate enhancement of factor XIa inhibition by antithrombin III is dependent upon the molecular weight of heparin (Holmer et al., 1981). However, more recently Beeler et al. reported equal reaction rates for the inactivation of factor XIa by antithrombin III in the presence of saturating amounts of heparin preparations with a molecular weight of 7,000 and 15,000 , respectively (Beeler et al., 1986).

The present study concerns a detailed kinetic analysis of the inactivation of factor XIa by antithrombin III in the presence of different well characterized heparin preparations. The data show that the rate enhancement by heparin is not solely caused by binding of antithrombin III to heparin persé, but that the final magnitude of the reaction rate at saturating heparin concentrations also depends upon the type of heparin used.

\section{Materials and Methods}

Materials. Chromogenic substrates pyro-Glu-Pro-Arg-pNA (S2366) and H-DPro-Phe-Arg-pNA (S2302) were purchased from AB Kabi Diagnostica, Sweden. Porcine mucosal sodium heparin was fractionated by ion exchange chromatography on DEAE-Sephacel with increasing salt molarities. The four fractions obtained, corresponding to the fractions $\mathrm{A}, \mathrm{B}, \mathrm{C}$, and D described by Sache et al. (1982) as well as the unfractionated heparin were a kind gift 
Table 1 . Characteristics of heparin fractions obtained by ion exchange chromatography on DEAE-Sephaced ${ }^{\text {foy }}$

\begin{tabular}{lllll}
\hline Compound & $\begin{array}{l}\text { Elution } \\
\text { position } \\
\text { (M NaCl) }\end{array}$ & $\begin{array}{l}\text { Molecular } \\
\text { weight } \\
\text { (daltons) }\end{array}$ & $\begin{array}{l}\text { Charge } \\
\text { density } \\
\left(Z^{2}\right)\end{array}$ & $\begin{array}{l}\text { High affinity } \\
\text { AT III } \\
(\% \%)\end{array}$ \\
\hline UFH $^{(c)}$ & - & 17,300 & 10.96 & 52 \\
Fractions & & 7,300 & 6.81 & 23 \\
A & 0.55 & 13,200 & 9.67 & 43 \\
B & 0.65 & 17,300 & 10.56 & 86 \\
C & 0.75 & 20,300 & 11.02 & 100 \\
D & 0.85 & & & \\
\hline
\end{tabular}

a) Data taken from Sache et al., 1982

b) Calculated using the data of Sache et al. 1982 according to Hurst et al., 1979

$(Z=1+$ sulfate content/uronic acid content $)$

c) UFH, unfractionated heparin

from the Choay Institute, Paris. The physico-chemical properties of the different heparin preparations are listed in table 1.

Proteins. Human factor XI was purified according to Bouma et al. (1983). Human factor XII was isolated as described by Griffin and Cochrane (1976). Human antithrombin III was purified as described by Thaler and Schmer (1975).

$\beta$-Factor XIIa was prepared from purified factor XII as described by Fujikawa and McMullen (1983). Factor XI, factor XII, and antithrombin III preparations were homogeneous and pure as determined by gel electrophoresis in the presence of sodium dodecyl sulfate on $10 \%$ gels according to Laemmli (1970). The specific activities determined in a cloting assay for factors $\mathrm{XI}$ and $\mathrm{XII}$ were 211 and 74 units/mg, respectively, assuming 1 unit to be present per milliliter of normal human plasma. All proteins were stored at $-70^{\circ} \mathrm{C}$ after dialysis against $50 \mathrm{mM}$ Tris $-\mathrm{HCl}, 175 \mathrm{mM} \mathrm{NaCl}, \mathrm{pH} 7.9$, for human antithrombin III and $4 \mathrm{mM}$ sodium citrate, $2 \mathrm{mM}$ acetic acid, $0.15 \mathrm{M}$ $\mathrm{NaCl}$, and $0.5 \mathrm{mM}$ EDTA, pH 5.0 , for human factors XI and XII.

Preparation of human factor XIa from human factor XI using human $\beta$ factor XIIa was performed as described earlier (Soons et al., 1986). Factor Xla was separated from $\beta$-factor XIla on a DEAE-Sephadex column (1.5X $11.5 \mathrm{~cm}$ ) at $4^{\circ} \mathrm{C}$ in $50 \mathrm{mM}$ Tris- $\mathrm{HCl}$ and $150 \mathrm{mM} \mathrm{NaCl}$ at pH 8.0. Amidolytic activity of human factor XIa was measured by using the chromogenic substrate $\mathrm{S} 2366$ in a buffer containing $50 \mathrm{mM}$ Tris $-\mathrm{HCl}, 175 \mathrm{mM} \mathrm{NaCl}, 20 \mathrm{mM}$ EDTA, and $0.5 \mathrm{mg} / \mathrm{mL}$ human serum albumin, $\mathrm{pH} 7.9$. The kinetic parameters of the hydrolysis of the chromogenic substrate $\$ 2366$ by human 
factor Xla were $K_{\mathrm{m}}=0.42 \mathrm{mM}$ and $k_{\text {cai }}=758 \mathrm{sec}^{-1}$.

Protein concentrations were routinely determined according to Bradford (1976). Factor Xla concentrations were expressed as 80,000 molecular weight subunits (van der Graaf et al., 1983). Antithrombin III concentration was measured employing an $E_{280 m m}(1 \%)$ of 5.7 (Kurachi and Davie, 1977) and by a titration against a known concentration human thrombin.

Kinetic Data Analysis. In a previous study, we have shown that the inactivation of factor Xla by antithrombin III, both in the absence and presence of heparin, can be fully described according to a mechanism in which both active sites in factor XIa are inhibited independent of each other with the same rate constant of inhibition. Furthermore, it was shown that the stimulation of the reaction rate in the presence of heparin can be satisfactorily explained by the binding of antithrombin IIII to heparin (Soons et al., 1987). Therefore, in a first approximation, the data obtained in the present study with different heparin preparations were also analyzed by assuming that the stimulation of the reaction rate in the presence of heparin was due to antithrombin III binding. In that case, the reaction can be written as

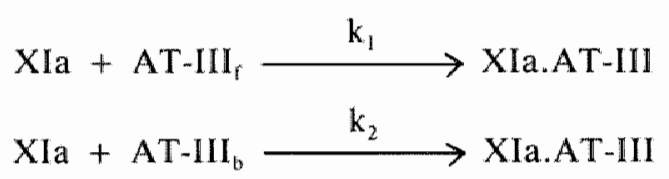

in which XIa is the concentration of the $M_{r} 80,000$ subunit of factor Xla and in which $\mathrm{AT}$ - $-\mathrm{III}_{\mathrm{r}}$ and $\mathrm{AT}-\mathrm{III}_{\mathrm{b}}$ are the concentrations of free antithrombin III and of antithrombin III bound to heparin, respectively. $k_{1}$ and $k_{2}$ are the rate constants of inactivation by free antithrombin 111 and by the antithrombin III-heparin complex. The rate equation can be written as

$$
d[X I a] / d t=-\left(k_{1} \cdot\left[A T-1 I I_{i}\right]+k_{2} \cdot\left[A T-I I I_{b}\right]\right) \cdot[X I a]
$$

and the slope of a pseudo first order plot will equal $-\left(k_{1}=\left[\right.\right.$ AT $\left.-11 I_{f}\right]+k_{2} \cdot \llbracket$ AT $\left.\left[1 I_{1,}\right]\right) \cdot k_{1}$ and $k_{2}$ can be independently determined in the absence of heparin (all antithrombin III is free) and in the presence of saturating amounts of heparin (all antithrombin III is bound). Since also the total amount of antithrombin III is known, the amounts of antithrombin III bound and of free antithrombin IIII can be calculated.

It should be stressed, that in the above, it is tacitly assumed that the equilibrium of binding of antithrombin III to heparin is not influenced by factor Xla or by products formed during the reaction. Since the inactivation of 
factor XIa remained pseudo first order throughout the whole time course of inactivation and since the binding data obtained were independent of the amounts of factor XIa present over the whole range of factor XIa concentrations tested $(0.1$ to $200 \mathrm{nM})$, this assumption appears to hold.

Binding of Antithrombin III to Heparin. The parameters ( $\mathrm{K}_{\mathrm{d}}$ and amounts of binding sites) of antithrombin III binding to heparin were obtained by determination of the rate of inactivation of factor Xla by antithrombin III in the presence of heparin at varying concentrations of heparin and antithrombin III. From the slopes of the pseudo first order plots, the amounts of free antithrombin III and of antithrombin III bound to heparin were calculated as described above using the independently determined $k_{1}$ and $k_{2}$. The binding constant $\mathbb{K}_{d}$ is given as

$$
\mathrm{K}_{\mathrm{d}}=\left[\mathrm{AT}-\mathrm{III}_{\mathrm{f}}\right]\left[\mathrm{S}_{\mathrm{f}}\right] /\left[\mathrm{AT}-\mathrm{III}_{\mathrm{b}}\right]
$$

in which $S_{f}$ is the concentration of free binding sites available and in which $\mathrm{AT}-\mathrm{III}_{\mathrm{f}}$ and AT-III $\mathrm{b}$ equal the concentrations of free and bound antithrombin III, respectively. Equation IIIA can be rearranged to a linear form with either bound and free antithrombin III as the variables

$$
1 /\left[\mathrm{AT}-\mathrm{III} \mathrm{I}_{\mathrm{b}}\right]=\left(\mathrm{K}_{\mathrm{d}} / \mathrm{S}_{\mathrm{bof}}\right)\left(1 / \mathrm{AT}-\mathrm{III}_{i}\right)+1 / \mathrm{S}_{\mathrm{tot}}
$$

or with free and occupied binding sites present on heparin as the variables:

$$
1 / \mathrm{S}_{\mathrm{b}}=\left(\mathrm{K}_{\mathrm{d}} / \mathrm{AT}-\mathrm{III}_{\mathrm{tot}}\right)\left(1 / \mathrm{S}_{\mathrm{f}}\right)+1 / \mathrm{AT}-\mathrm{III}_{\mathrm{tot}}
$$

Thus, the binding constant $\mathrm{K}_{\mathrm{d}}$ and the total amount of binding sites ( $\mathrm{S}_{10 \mathrm{t}}$ ) present at a given heparin concentration can be determined from a plot of $1 /$ AT-III $I_{b}$ versus $1 / A T-I I I_{i}$. Subsequently, from a plot of $1 / S_{b}$ versus $1 / S_{i}$ at a given constant antithrombin $1 \mathrm{II}$ concentration, the binding constant $\mathrm{K}_{\mathrm{d}}$ and the total amount of antithrombin III, used in the experiment, are obtained (eg. IIIc). This enables an internal check, for the kinetic data analysis, because both experiments should give the same $\mathrm{K}_{\mathrm{d}}$ for a given heparin preparation and the calculated total antithrombin III concentration should of course be equal to the amount of antithrombin III added to the reaction mixture.

\section{Results and Discussion}

The inhibition of human factor XIa by human antithrombin III was studied in the presence of different heparins by measurement of the disappearance of 

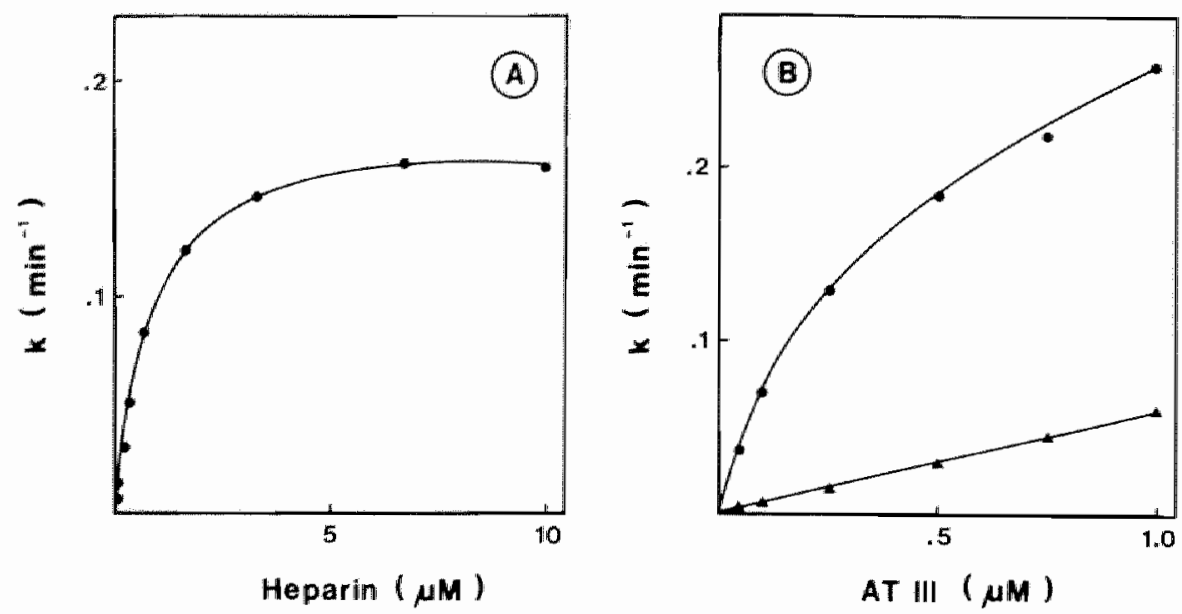

FIGURE I: The heparin catalyzed inactivation of factor XIa by antithrombin III measured at varying concentrations of antithrombin $I I$ and unfractionated heparin. The pseudo first order reaction rate constants, $k$, were obtained from semilogarithmic plots of residual factor Xla amidolytic activity versus the inactivation time. For each deter. mination at least 6 ime points were used.

Panel $A$ shows the changes in the pseudo first arder reaction rate constant, $k$, when factor XIa $(8 \mathrm{nM})$ and antithrombin $\mathrm{II}(0.16 \mu \mathrm{M})$ were titrated with unfractionated heparin (range: $0.06-11.6 \mu \mathrm{M}$ ) (closed circles). The rate constant in the absence of heparin is given by a closed triangle.

Panel $B$ shows the changes in the pseudo first order rate reaction constant, $k$, when factor XIa $(8 \mathrm{mM})$ and unfractionated heparin $(0.28 \mu \mathrm{M})$ were titrated with antithrombin III (range: $0.05-1.0 \mu \mathrm{M}$ ) (closed circles). The same experiment was also performed in the absence of heparin (closed iriangles).

factor XIa amidolytic activity towards the chromogenic substrate S2366. Under all conditions tested, the inactivation of factor XIa was pseudo first order in factor XIa since semilogarithmic plots of the residual activity versus time yielded straight lines. From such plots, the apparent first order reaction rate constants (k) were obtained. Figure $1 \mathrm{~A}$ shows a saturation curve obtained, when the apparent first order rate constant of inhibition of factor XIa $(8 \mathrm{nM})$ by antithrombin III $(0.16 \mu \mathrm{M})$ was determined as a function of the heparin concentration $(0.06-11.6 \mu \mathrm{M})$. Figure 1B shows the pseudo first order reaction rate constants obtained, when at a constant concentration of factor Xla $(8 \mathrm{nM})$ and heparin $(0.28 \mu \mathrm{M})$ the concentration of antithrombin III was varied $(0.05-1.0 \mu \mathrm{M})$. In the latter case, the rate constant did not reach a plateau (closed circles), because the rate of factor XIa inhibition in the absence of heparin was not negligible (closed triangles). 


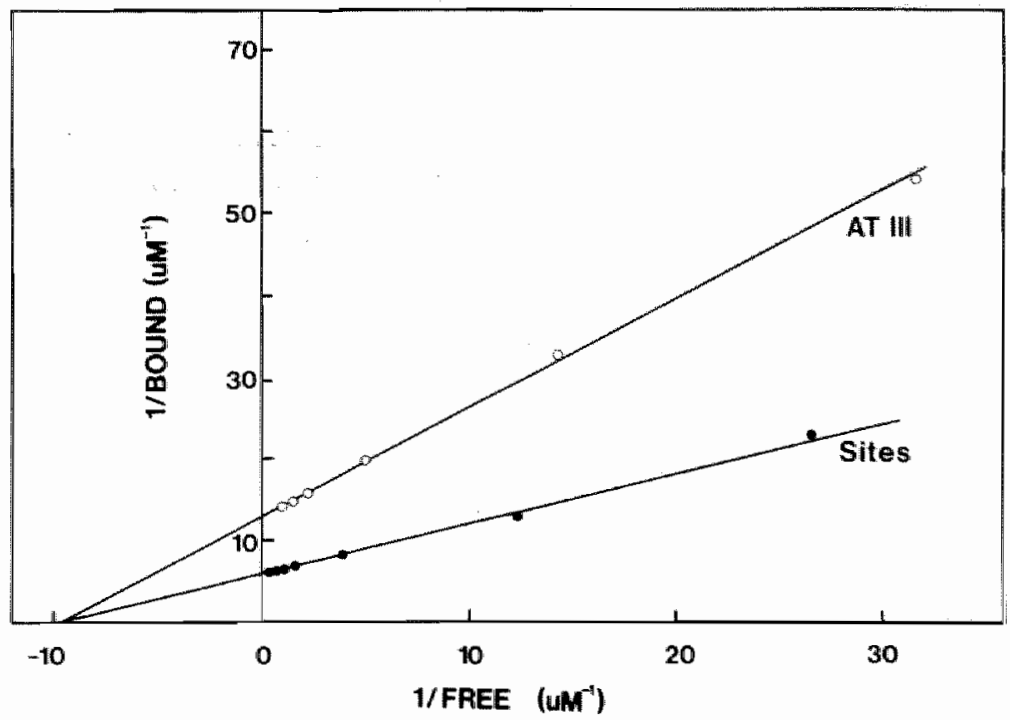

FIGURE 2:" Replot of the date of Figure 1 according the presented model described in equation I. For each total antithrombin III concentration (Figure 1 A), the concentrations bound and free antithrombin III were calculated as described in Materials and Methods and the reciprocals of them were plotted against each other (open circles). From the intercept at the abscissa, a $K_{d}$ of $101 \mathrm{nM}$ was obtained and from the intercept at the ordinate, the amount of binding sites present on heparin was calculated to be 0.276 mol sites/mol heparin (see under Material and Methods, eq. IIIB). Each tolal heparin concentration, shown in Figure $1 B$, was expressed in antithrombin III binding sites using the value of 0.276 sites/mol of heparin. The concentrations occupied and free antithrombin III binding sites were calculated as described in Materials en Methods and the reciprocals of them were plotted against each other (closed circles).

The data from Figure 1 can be analyzed according to a mechanism in which the stimulation by heparin is assumed to be due to binding of antithrombin III to heparin (see Materials and Methods). For this it is necessary that the rate constants of inactivation of factor XIa by free antithrombin III $\left(k_{1}\right)$ and by antithrombin III bound to heparin $\left(k_{2}\right)$ are known. $k_{1}$ can be determined from the rate of factor Xla inhibition in the absence of heparin (triangles, Figure $1 \mathrm{~B}$ ) and $\mathrm{k}_{2}$ is obtained from the rate of factor XIa inactivation at saturating heparin concentrations (plateau, Figure $₫ \mathrm{~A}$ ). From the data shown in Figure $1, k_{1}$ was determined to be $1.0 \times 10^{3} \mathrm{M}^{-1} \mathrm{~s}^{-1}$ and $\mathrm{k}_{2}$ was $29.6 \times 10^{3}$ $\mathrm{M}^{-1} \mathrm{~S}^{-1}$.

Using these two rate constants, the binding of antithrombin III was calculated at each heparin and antithrombin III concentration and plotted as described under Materials and Methods to obtain the parameters of an- 
tithrombin lil binding to heparin. Figure 2 shows the result obtained. A plot of $1 / \mathrm{AT}-\mathrm{L} \mathrm{I}_{\mathrm{b}}$ versus $\mathbb{1} / \mathrm{AT}-\mathrm{III} \mathrm{I}_{\mathrm{f}}$ at a given heparin concentration (data from Figure 1B) yielded a straight line from which a $K_{d}$ of $101 \mathrm{nM}$ was determined (Figure 2, open circles). This is in good aggreement with the values reported in the literature (Griffith, 1982; Jordan et al., 1979). The amount of antithrombin III binding sites was calculated to be $0.276 \mathrm{~mol}$ antithrombin III per mol heparin assuming a molecular weight of 17,300 . From the rate constants obtained at varying heparin concentrations (Figure 1A), again a straight line was obtained (Figure 2, closed circles). As can be seen, the same $\mathrm{K}_{\mathrm{d}}$ was obtained and from the intercept at the ordinate, the total antithrombin III concentration present in the reaction mixture was calculated to be $167 \mathrm{nM}$ (160 $\mathrm{nM}$ was added to the reaction mixture). Thus, analysis of the data presented in Figure 1A and $1 \mathrm{~B}$ yields a set of internally consistent data which support the assumption that stimulation of the inactivation of factor XIa by antithrombin III in the presence of heparin is due to the binding of antithrombin III to heparin.

Standard heparin is a heterogeneous mixture of polysaccharide chains with different molecular weight, charge density, and affinity for antithrombin III. To gain insight in the mode of action by which binding of antithrombin III to heparin stimulated the inactivation of factor Xla, the reaction was also analyzed using four different, well characterized heparin fractions. These fractions were obtained by ion exchange chromatography and the physicochemical properties of them are listed in table 1. They differ in molecular weight, charge density, and their affinity for antithrombin IIL. Figure $3 \mathrm{~A}$ shows the saturation curves obtained when factor XIa $(8 \mathrm{nM})$ and antithrombin III $(0.16 \mu \mathrm{M})$ were titrated with the four heparin fractions. Figure 3B shows that when the antithrombin III concentration was varied $(0.05-1.0 \mu \mathrm{M})$, the pseudo first order reaction rate constant increased more in the presence of the heparin fractions (closed symbols) than in the absence of heparin (open circles). The amounts of heparin chosen for the different fractions in the experiment presented in Figure 3B was chosen such that the amounts of antithrombin III binding sites were approximately equal. Thus, although the amounts of heparin present in each antithrombin III titration experiment was different, on molar basis the amounts of antithrombin III binding sites present were the same in each titration experiment presented in Figure 3B. In all cases the stimulatory effect of heparin increased in the order of fraction $\mathrm{A}<\mathrm{B}<\mathrm{C}<\mathrm{D}$.

From the data shown in Figure 3A, the rate constants of inhibition at saturating heparin concentration $\left(\mathrm{k}_{2}\right)$ were obtained and these are summarized in table 2 . The binding of antithrombin III to fraction A caused a seven- 

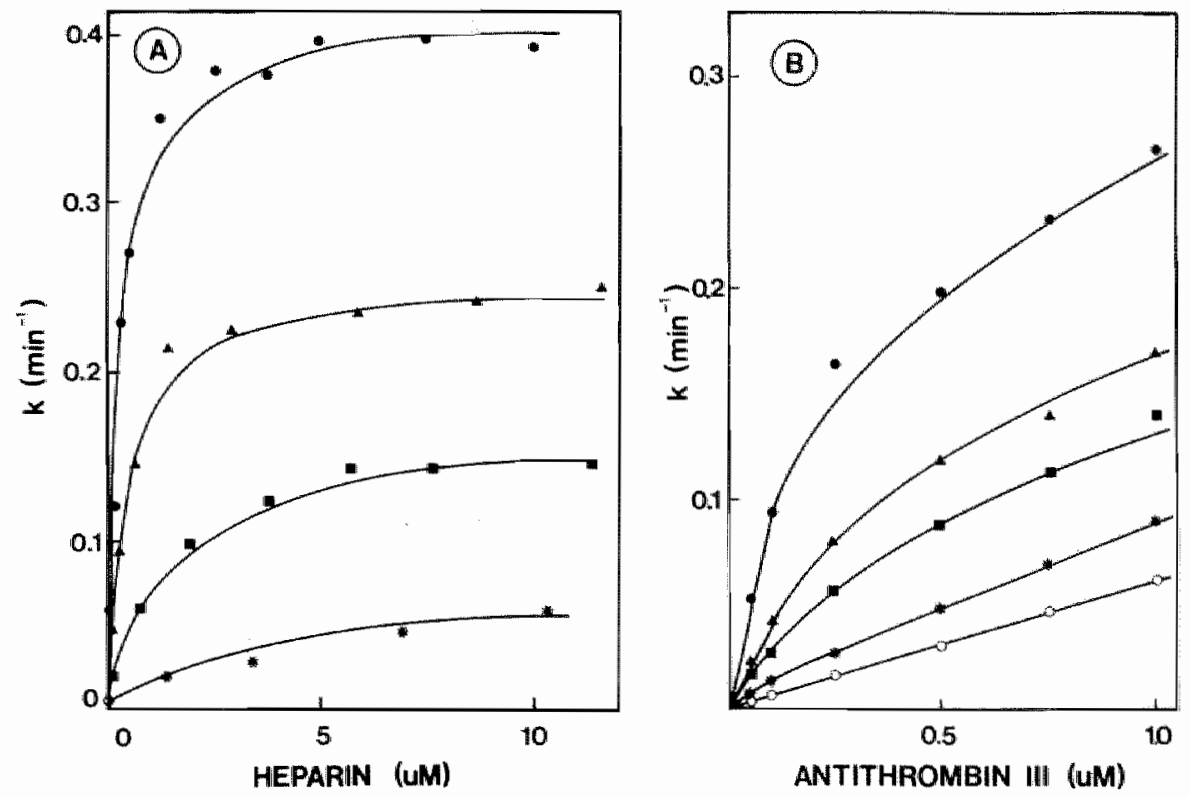

FIGURE 3: Heparin catalyzed factor XIa inactivation by antithrombin III in the presence of four different heparin fractions. The pseudo first order reacion rate constants, $k$, were determined at varying heparin concentrations (pamel A) and at varying antithrombin III concentrations (panel B) as described under Materials and Methods for each of the heparin fractions. The symbols $* \mathbf{\square}, \mathbf{\Delta}$, and $\bullet$ in the figure represent data obtained for the heparin fractions $A, B, C$, and $D$, respectively. Open circles show the inhibition of factor Xla in the absence of heparin. Panel $A$ shows the changes in the pseudo first order reaction rate constant, $k$, when factor XIa $(8 \mathrm{nM})$ and antithrombin $\mathrm{HI}(0.16 \mu \mathrm{M})$ were titrated with each heparin fraction. The concentration ranges used were: $A: 1.4-13.7 \mu M, B: 0.2-11.4 \mu M, C: 0.15-11.6 \mu M$, and D: 0.06 - $9.9 \mu M$. Panel $B$ shows the changes in the pseudo first order reaction rate constant, $k$, when factor $X I a(8 \mathrm{nM})$ and one of the heparin fractions were titrated with antithrombin III (range: $0.05-1.0 \mu M$ ). The concentration of the fractions $A, B, C$, and $D$ was $1.49,0,44,0.17$ and $0.12 \mu M$, respectively. Expressed as concentrations an tithrombin III binding sites present in the experiment, this corresponded 10 86, 105 , 85 , and $89 n M$ sites for fractions $A, B, C$, and $D$, respectively.

fold increase in the rate constant compared with the rate constant obtained in the absence of heparin. Binding of antithrombin III to fraction D caused an acceleration of 41.2 times.

From the data in which the antithrombin III concentrations were varied at a given heparin concentration (Figure $3 \mathrm{~B}$ ), the parameters of binding of antithrombin III to heparin were determined as described under Methods. The results are also summarized in table 2 . The calculated $\mathrm{K}_{\mathrm{d}}$ 's showed a threefold variation $(280 \mathrm{nM}-96 \mathrm{nM})$ whereas the number of antithrombin III bind- 


\begin{tabular}{|c|c|c|c|}
\hline Compound & $k_{2}\left(\mathrm{M}^{-b_{5}}-1\right)$ & $\begin{array}{l}\mathrm{K}_{\mathrm{d}} \\
(\mathrm{nM})\end{array}$ & $\begin{array}{l}\text { AT III sites/heparin } \\
\text { (mole/mole) }\end{array}$ \\
\hline $\begin{array}{l}\text { UFH } \\
\text { Fractions }\end{array}$ & $29.6 \quad 10^{3}$ & 101 & 0.276 \\
\hline A & $7.210^{3}$ & 280 & 0.058 \\
\hline $\mathrm{B}$ & $15.310^{3}$ & 243 & 0.239 \\
\hline $\mathrm{C}$ & $26.710^{3}$ & 205 & 0.502 \\
\hline $\mathrm{D}$ & $41.210^{3}$ & 96 & 0.740 \\
\hline
\end{tabular}

The kinetic data given in this table were calculated from the data presented in Figure J. and 3 according to the analysis described under Materials and Methods. The second order reaction rate constant, $k_{2}$, was calculated using the data given in Figure $1 \mathrm{~A}$ for the unfractionated heparin and the data given in Figure $3 \mathrm{~A}$ for the heparin fractions. The antithrombin III-heparin binding constants, $K_{d}{ }^{*} s$ and the number of antithrombin III binding sites per heparin, were derived from the data given in Figure IB for the unfractionated heparis and from the dara given in Figure $3 \mathrm{~B}$ for the heparin fractions.

ing sites varied from 0.058 to 0.74 sites per mol of heparin. These data are in aggreement with the data of Sache et al. who also described an increase in antithrombin III binding material from fraction A to D (Sache et al., 1982). Using the total amounts of sites as determined above the data in Figure 3A were also replotted as described under Methods to obtain the binding parameters. From such plot, the same $\mathbb{K}_{d}$ 's were obtained (data not shown). Therefore, as described for the unfractionated heparin, both titration experiments yielded a set of internally consistent data. We, therefore, conclude that the inactivation of factor XIa by antithrombin III in the presence of heparin can be satisfactorily explained in terms of the binding of antithrombin III to heparin.

However, the final magnitude of the rate constant obtained at saturating heparin concentrations was dependent upon the type of heparin used (cf. Figure $3 \mathrm{~A}$, table 2 ). With regard to this, it may be useful to compare the effects of unfractionated heparin with its fractions. Unfractionated heparin and fraction $B$ have approximately the same percentage of antithrombin III binding material ( $\mathrm{cf}$. table 1), yet the rates of factor XIa inhibition at saturating heparin concentrations for fraction $B$ are only half of those observed with unfractionated heparin. This underscores the fact that besides binding of antithrombin 111 persé also the type of heparin is important.

At this moment, at least two possibilities remain to explain these observations. First, it is possible that the inactivation of factor XIa is solely dependent 
upon the binding of antithrombin III and no interactions between heparin and factor XIa contribute to the observed reaction rate. This so-called allosteric model of activation of antithrombin III by heparin has been proposed (Jordan et al., 1979). However, for the interactiın of antithrombin IIII with factor $\mathrm{XIa}$, this is somewhat unlikely since our data can only be accommodated then if one assumes that the change in antithrombin III upon binding to heparin differs for each different type of heparin. A second and we think more likely explanation is that factor XIa-heparin interactions influence the rate of inactivation of factor XIa by antithrombin III bound to heparin. This is supported by the observation that factor XIa has affinity for heparin-Sepharose (Osterud and Rapaport, 1977). However, direct binding experiments of factor XIa binding to the different types of heparin will be needed to gain more insight in this question.

\section{References}

Beeler, D.L., Marcum, J.A., Schiffman, S., and Rosenberg, R.D. (1986) Blood 67, 1488-1492 Bouma, B.N., and Griffin, J.H. (1977) J. Biol. Chem. 252, 6432-6437

Bouma, B.N., Vlooswijk, R.A.A., and Griffin, J.H. (1983) Blood 62, 1123-1131

Bradford, M.M. (1976) Anal. Biochem. 72, 248-254

Fujikawa, K., and McMullen, B.A. (1983) J. Biol. Chem 258, 10924-10833

Fujikawa, K., Chung, D.W., Hendrickson, L.E., and Dawie E.W. (1986) Biochemistry, 25 , $2417-2424$

van der Graaf, F., Greengard, J.S., Bouma, B.N., Kerbiriou, D.M., and Griffin, J.H. (1983) J. Biol. Chem. 258, 9669-9675

Griffin, J.H., and Cochrane, C.G. (1976) Methods Enzymol. 45, 56-65

Griffith, M.J. (1982) J. Biol. Chem. 257, 7360-7365

Holmer, E., Kurachi, K., and Söderström, G. (1981) Biochem. J. 193, 395-400

Hurst, R.E., Menter, J.M., West, S.S., Settine, J.M., and Coyne, E.H. (1979) Biochemistry, 18. 4283-4287

Jordan, R., Beeler, D., and Rosenberg, R.D. (1979) J. Biol. Chem. 254, 2902-2913

Kurachi, K., and Davie, E.W. (1977) Biochemistry 16, $5831-5839$

Laemmli, U.K. (1970) Nature 227, 680-685

Osterad, B., and Rapaport, S.1. (1977). Proc. Natl. Acad. Sci. USA, 74, 5260.5264

Sache, E., Maillard, M., Bertrand, H., Maman, M., Kunz, M., Choay, J., Fareed, J. and Messmore, H. (1982) Thromb. Res. 25, 443-458

Scott, C.F., Shapira, M., James, H.L. Cohem, A.B., and Colman, R. W. (1982) J. Chim. Invest. $69,844-852$

Soons, H., Janssen-Claessen, T., Hemker, H.C. and Tans, G. (1986) Blood 68, 140-148

Soons, H., Janssen-Claessen, T., Tans, $\mathrm{G}_{\text {n }}$ and Hemker, H.C. (1987) Biochemistry 26, 4624-4629

Thaler, E., and Schmer, G. (1975) Br. J. Haematol. 31, 233-243 



\section{Activation of Factor IX by Factor XIa; Effect of Phospholipids}

\section{Abstract}

We report here the effect of phospholipids on the activation of human factor IX by human factor XIa. Factor IXa formed during activation was determined via its ability to activate bovine factor $\mathrm{X}$ in the presence of $\mathrm{CaCl}_{2}$, phospholipids and bovine factor VIIla. The kinetic parameters of factor IX activation were determined in the presence of $10 \mathrm{mmol} / \mathrm{L} \mathrm{CaCl} . \mathrm{K}_{\mathrm{m}}$ was $0.37 \mu \mathrm{mol} / \mathrm{L}$ and $\mathrm{k}_{\text {eat }}$ was $2.8 \mathrm{~s}^{-1}$. Negatively charged phospholipid vesicles $(\mathrm{PS} / \mathrm{PC}=25 / 75)$ inhibited the activation of factor IX by factor XIa, whereas neutral phospholipid vesicles (100 percent $\mathrm{PC}$ ) did not cause significant inhibitron.

The observed inhibition of activation of factor IX in the presence of negatively charged phospholipids can be explained if we assume that the rate of activation of phospholipid bound factor IX is negligible as compared to the activation of factor IX in free solution. Using this assumption a dissociation constant, $\mathrm{K}_{\mathrm{d}}$, of $0.26 \mu \mathrm{M}$ was determined for binding of factor IX to phospholipid $(\mathrm{PS} / \mathrm{PC}=25 / 75)$ and the amount of factor $\mathbb{I X}$ binding sites was found to be 0.022 mole sites per mole phospholipid. These values agree well with the binding parameters reported for factor IX binding to negatively charged phospholipid vesicles $\left(K_{\mathrm{d}}=1.0 \mu \mathrm{M}\right.$, sites $=0.023 \mathrm{~mole} / \mathrm{mole}$ phospholipid; Jones M.E., et al. (1985) Biochemistry 24, 8064), which supports our assumption that phospholipid bound factor IX is not or much less activated by factor XIa. 


\section{Introduction}

Human blood coagulation factor $\mathrm{XI}$ is the (pro)enzyme that links the contact phase to intrinsic factor IX activation. Factor XI is a dimeric molecule, which contains two identical protein chains held together by (a) disulfide bond $(s)(1,2)$. When activated by factor XIla, an internal peptide bond in each of its two precursor chains is cleaved. Factor XIa is composed of two heavy chains $\left(M_{r} 50,000\right)$ and two light chains $\left(M_{r} 33,000\right)$ and each light chain contains an active site (3).

The activation of factor IX by factor XIa is a calcium-dependent two step mechanism (4). In the first step, the $\mathrm{Arg}_{145}-\mathrm{Ala}_{146}$ bond is cleaved giving rise to a two chain intermediate, which is further cleaved at the $\mathrm{Arg}_{180^{-}}-\mathrm{Val}_{181}$ bond resulting in the release of an activation peptide $\left(M_{r} 11,000\right)$ and the formation of active factor IXa. The heavy chain of factor IXa contains the active site and the light chain contains the $12 \gamma$-carboxyglutamic acid (Gla) residues $(5,6)$.

The activation of factor IX by factor XIa appears to be the only blood coagulation reaction for which a surface requirement has not been established. The reports concerning a possible effect of negatively charged phospholipids on this reaction appear to contradict each other. Thus, it has been reported that phospholipids are capable of accelerating (7), have no effect (8) or even inhibit (9) the activation of factor IX by factor XIa.

Recently, Liebman et al. reported that the domain of factor IX which is involved in calcium-dependent binding of factor IX to phospholipids is also essential in the calcium-dependent interaction of factor IX with factor Xlla (10). In this calcium-dependent activation of factor IX by factor Xla the heavy chain of the enzyme is involved in the binding of the substrate which is essential for obtaining optimal reaction rates $(8,11)$.

These reports prompted us to determine in more detail the effect of phospholipids on the initial steady-state kinetics of activation of factor IX by factor XIa. For this we used an assay with which functional factor IXa is determined via its ability to activate bovine factor $X$ in the presence of phospholipids and $\mathrm{CaCl}_{2}$ (12). To increase sensitivity down to pmolar levels of factor IXa bovine factor VIIla was also present.

\section{Materials and methods}

Materials. Chromogenic substrate N-benzoyl-Ile-Glu(Piperidyl)-Gly-Arg-pnitroanilide hydrochloride (S2337) was purchased from A.B. Kabi Diagnostica, Stockholm. Plasmas deficient in coagulation factors IX, XI or XII were from patients congenitally deficient in these factors and were obtained from 
George King Biomedical, Overland Park, Kan. Fatty acid free human serum albumin was from Sigma Chemical $\mathrm{Co}, \mathrm{St}$. Louis. All reagents used were of the highest grade commercially available.

Proteins. Human factor IX was purified based on a modification of the isolation procedure described by di Scipio et al. and the sulfated dextran column as described by Miletich et al. was added as described earlier $(13,14)$. Human factor IXa was prepared from purified human factor IX as described earlier for bovine factor IXa (15). Human factor XI was purified according to Bouma et al (16). Human factor XII was isolated as described by Griffin and Cochrane (17). Human factor XIa was prepared from purified human factor XI using human $\beta$-factor XIla as described by van der Graaf (8). $\beta$-Factor XIla was prepared from purified human factor XII as described by Fujikawa and McMullen (18). Bovine factor $X$ was purified according to Fujikawa et al. (19). Bovine factor VIIIc was purified according (20) and factor VIIla was prepared by activation of factor VIIIc $(1.75 \mathrm{nmol} / \mathrm{L})$ with thrombin (4 $\mathrm{nmol} / \mathrm{L}$ ) for one minute at $37^{\circ} \mathrm{C}$ as described earlier $(15,20)$. Bovine thrombin was purified as a prothrombin activation product as described by Rosing et al. (2i).

The human factor IX, XI and XII and the bovine factor X preparations were homogeneous and pure as determined by gel electrophoresis in the presence of sodium dodecyl sulfate on $10 \%$ gels according to Laemmli (22). The specific activities of the protein preparations as determined with a clotting assay were $193,211,74$ and $100 \mathrm{U} / \mathrm{mg}$ for human factors IX, XI, XII and bovine factor $\mathrm{X}$, respectively, one unit being the amount of coagulation factor present per milliliter of normal plasma. All proteins were stored at $.70^{\circ} \mathrm{C}$ after dialyzing against the following buffers: $50 \mathrm{mmol} / \mathrm{L}$ Tris- $\mathrm{HCl}, 175 \mathrm{mmol} / \mathrm{L}$ $\mathrm{NaCl}$ at $\mathrm{pH} 7.9$ for human factor $\mathrm{IX}$ and bovine factor $\mathrm{X} ; 4 \mathrm{mmol} / \mathrm{L}$ sodium citrate, $2 \mathrm{mmol} / \mathrm{L}$ acetic acid, $0.15 \mathrm{~mol} / \mathrm{L} \mathrm{NaCl}$, and $0.5 \mathrm{mmol} / \mathrm{L} \mathrm{EDTA}$ at $\mathrm{pH} 5.0$ for human factor X1 and XII; and $10 \mathrm{mmol} / \mathrm{L}$ morpholino ethane sulfonic acid, $175 \mathrm{mmol} / \mathrm{L} \mathrm{NaCl}, 10 \mathrm{mmol} / \mathrm{L} \mathrm{CaCl}_{2}$, and $10 \%$ glycerol at $\mathrm{pH}$ 6.5 for bovine factor VIllc.

Protein concentration. Determinations of protein concentrations were routinely done according to Bradford (23). Factors IXa, Xa and thrombin were determined by active-site titration with p-nitrophenyl-p'-guanidinobenzoate (p-NPGB) according to Tans et al. (12), Smith (24) and Chase and Shaw (25). Factor XIa concentrations were determined from the amount of protein present assuming a molecular weight of 160,000 daltons and by active site titration with antithrombin III in the presence of heparin assuming two active sites per factor XIa molecule. Concentrations of factor $\mathbb{I X}$ and factor $\mathrm{X}$ were determined by complete activation and subsequent determination of the active 
enzyme. Factor VIIla concentrations were determined according to the method of van Dieyen et al. (20).

Phospholipid vesicles. Phosphollipid vesicles were made from a mixture of 1.2-dioleoyl-sn-glycero-3-phosphoserine (PS) and 1.2.-dioleoyl-sn-glycero3-phosphocholine (PC) in a buffer containing $50 \mathrm{mmol} / \mathrm{L}$ Tris- $\mathrm{HCl}$ and 175 mmol/L NaCl at pH 7.9 as described by Rosing et al (21). In the assay for factor IXa vesicles containing 40 mole percentage PS and 60 mole percentage PC were used, whereas in experiments concerning the activation of factor IX by factor XIa vesicles containing a molar ratio of $25 / 75$ of PS over PC were employed.

Factor IXa determinations. To follow the activation of factor IX by factor $\mathrm{XIa}$ an assay system was developed in which factor $\mathbb{I X a}$ was determined via its abillity to activate bovine factor $\mathrm{X}$ in the presence of $\mathrm{CaCl}_{2}$, phospholipids and factor VIIIa. Factor IXa containing samples were diluted in ice-cold buffer containing $50 \mathrm{mmol} / \mathrm{L}$ Tris $(\mathrm{pH} 7.9), 175 \mathrm{mmol} / \mathrm{L} \mathrm{NaCl}, 0.5 \mathrm{mg} / \mathrm{mL}$ human serum albumin, and $20 \mathrm{mmol} / \mathrm{L}$ EDTA to block further activation of factor IX. The amounts of factor IXa present in the samples were then determined as follows. $305 \mu \mathrm{L}$ buffer containing $50 \mathrm{mmol} / \mathrm{L}$ Tris $(\mathrm{pH} \mathrm{7.9),} 175$ mmol $/ \mathrm{L} \mathrm{NaCl}, 9.8 \mathrm{mmol} / \mathrm{L} \mathrm{CaCl}, 0.5 \mathrm{mg} / \mathrm{mL}$ human serum albumin, and $16.4 \mu \mathrm{mol} / \mathrm{L}$ phospholipid vesicles was prewarmed at $37^{\circ} \mathrm{C}$ for 4.5 minutes, after which $45 \mu \mathrm{L}$ bovine factor $\mathrm{X}(16.67 \mu \mathrm{mol} / \mathrm{L})$ and a $50-\mu \mathrm{L}$ sample were added. Factor $\mathrm{X}$ activation was started by adding $100 \mu \mathrm{L}$ factor VIIIa $(1.75$ $\mathrm{nmol} / \mathrm{L})$. The final reaction mixture $(500 \mu \mathrm{L})$ contained $50 \mathrm{mmol} / \mathrm{L}$ Tris $(\mathrm{pH}$ 7.9), $175 \mathrm{mmol} / \mathrm{L} \mathrm{NaCl}, 6 \mathrm{mmol} / \mathrm{L} \mathrm{CaCl}, 2 \mathrm{mmol} / \mathrm{L}$ EDTA, $10 \mu \mathrm{mol} / \mathrm{L}$ phospholipid, $1.5 \mu \mathrm{mol} / \mathrm{L}$ factor $\mathrm{X}, 0.35 \mathrm{nmol} / \mathrm{L}$ factor VIIIa, $0.5 \mathrm{mg} / \mathrm{mL}$ human serum albumin, and the factor IXa present in the sample. The rate of factor $X$ activation was determined by measurement of the amounts of factor $X a$ formed after one and two minutes in these reaction mixtures using the factor Xa-specific chromogenic substrate $\$ 2337$ as described earlier $(12,15)$. From the observed rate of factor $X$ activation, the amomt of factor $\mathrm{X}$ a present in the sample was calculated using a calibration curve made with known amounts of active-site tirated factor IXa (see also Figure 1).

Kinetic parameters. $\mathrm{K}_{\mathrm{m}}$ for factor $\mathrm{IX}$ and $\mathrm{k}_{\mathrm{ca}}$ of factor $\mathrm{XX}$ activation were determined by measurement of the rate of factor $\mathrm{IXa}$ formation in a reaction mixture containing $10 \mathrm{mmol} / \mathrm{L} \mathrm{CaCl}, 0.5 \mathrm{mg} / \mathrm{mL}$ human serum albumin, $0.1 \mathrm{mmol} / \mathrm{L}$ factor $\mathrm{XIa}$, and varying anounts of factor $\mathrm{LX}$, using the assay described above. $K_{m}$ and $V_{\text {max }}$ (expressed as factor $\mathrm{X}$ a formed per minute) were then determined by statistical analysis of the data as described by Eisenthal and Cornish-Bowden (26). $k_{\text {eat }}$ was calculated by dividing $V_{\max }$ 
with the enzym concentration assuming a molecular weight of 160,000 for factor XIa.

Binding parameters. When it is assumed that only free factor IX is activated by factor XIa, then the amount of free factor IX can be determined at each phospholipid and factor IX concentration by measurement of the rate of activation of factor IX by factor XIa according to equation 1 .

$$
I X_{f}=v \cdot K_{m} /\left(V_{\max }-v\right)
$$

in which $\mathrm{IX}_{\mathrm{f}}$ is the free factor $\mathrm{IX}$ concentration, $\mathrm{v}$ is the rate of factor IX activation and $\mathrm{K}_{\mathrm{r} u}$ and $\mathrm{V}_{\text {max }}$ are the kinetic parameters of factor IX activation by factor XIa. The concentration of factor IX bound to phospholipids (IX $\mathrm{X}_{\mathrm{b}}$ ) is obtained by subtracting the free factor IX concentration from the known total factor IX concentration $\left(\mathrm{IX}_{\mathrm{r}}\right)$. The binding constant $\mathrm{K}_{\mathrm{d}}$ is given as

$$
\mathbb{K}_{\mathrm{d}}=\mathrm{IX} \cdot \mathrm{S}_{\mathrm{f}} / \mathrm{IX}_{\mathrm{b}}
$$

in which $K_{d}$ is the binding constant and $S_{f}$ is the concentration free factor IX binding sites. Defining $q$ as the maximal amount of factor $\mathrm{IX}$, that can bind to phospholipid (mole/mole) then:

$$
\mathrm{S}_{\mathrm{T}}=\mathrm{q} \cdot \mathrm{PL}=\mathrm{S}_{\mathrm{i}}+\mathbb{I X}_{\mathrm{b}}
$$

$\mathrm{S}_{\mathrm{T}}$ is the total amount of factor IX binding sites and PL is the concentration phospholipid. Substitution of eq 3 into eq 2 , and rearrangement yields

$$
\mathrm{PL} / \mathrm{IX}_{\mathrm{b}}=1 / \mathrm{q}+\mathrm{K}_{\mathrm{d}} / \mathrm{q} \cdot 1 / \mathbf{I X}
$$

Thus, when at a given concentration of factor IX present the amount of phospholipid is varied a plot of $\mathrm{PL} / \mathrm{IX}_{\mathrm{b}}$ versus $1 / \mathrm{IX}_{\mathrm{f}}$ should give a straight line from which $K_{d}$ and $q$ can be determined (see also figure 5).

Simulation. The binding parameters $\mathrm{K}_{\mathrm{d}}$ and $\mathrm{q}$ obtained as indicated were used to simulate the rate of activation of factor IX by factor XIa as a function of phospholipid concentration. It follows from eq. 2 that at a given total concentration of factor IX at each phospholipid concentration the amount of factor $\mathrm{IX}_{\mathrm{b}}$ is given by

$$
I X_{b}^{2}-\left(K_{d}+I X_{T}+q \cdot P L\right) \cdot I X_{b}+q \cdot P L \cdot I X_{T}=0
$$




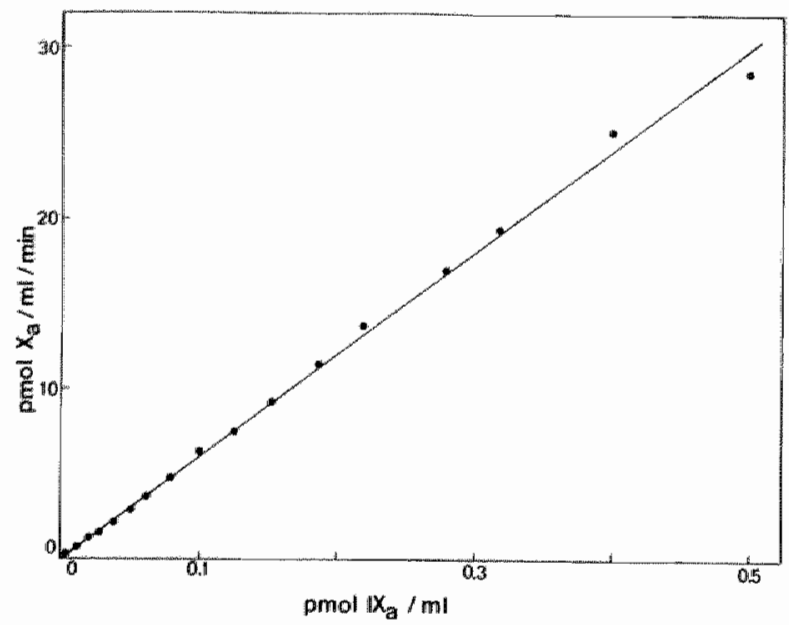

FIGURE 1 . Factor IXa calibration curve. The rate of activation of bovine factor $X$ $(1.5 \mu \mathrm{mol} / L)$ at warying amounts of factor $I X a$ was determined in the presence of $\mathrm{CaCl}_{2}$, phospholipids and bovine factor VIIla at $37^{\circ} \mathrm{C}$. The slope of this plot reflects the rate of factor Xa formation per factor IXa present $(59.5 \mathrm{mmol} X \mathrm{Xa} / \mathrm{min} / \mathrm{mmol}$ IXa). For experimental details, see Materials and Methods under factor IXa derermination.

of which the physical acceptable solution $\left(\mathrm{IX}_{\mathrm{b}}<\mathrm{IX}_{\mathrm{T}}\right)$ is

$I X_{b}=\left(K_{d}+I X_{T}+q P L-\sqrt{\left(K_{d}+I X_{T}+q P L\right)^{2}-4 q P L I X}\right) / 2$

Since the total amount of factor IX present is known the amount of free factor IX can be calculated. The rate of activation was then calculated as a function of phospholipid concentration making use of the kinetic parameters, $K_{m}$

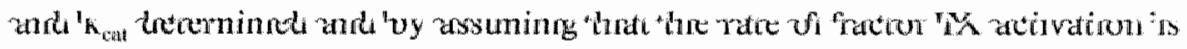
determined by the concentration of free factor IX.

\section{Results}

In this study an assay for the activation of factor IX was used in which functional factor IXa activity was determined via the activation of bovine factor $X$ as described earlier (12). To increase sensitivity the activation of bovine factor $\mathrm{X}$ by human factor IXa was performed in the presence of $\mathrm{CaCl}_{2}$, phospholipids and bovine factor VIlla. In the assay the amounts of $\mathrm{CaCl}_{2}$, phospholipid, bovine factor $\mathrm{X}$ and bovine factor VIIIa were standardized. The concentration of factor Xa formed was linear in time for at least two minutes. Figure 1 shows that the initial rate of factor $\mathrm{Xa}$ formation was 


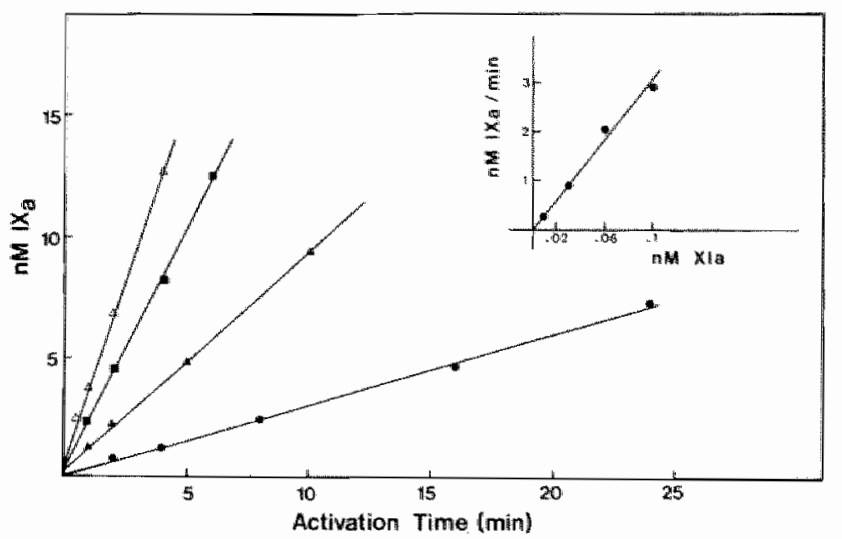

FIGURE 2. Human factor $I X$ activation at varying factor $X I a$ concentrations. The activation of factor $I X(100 \mathrm{nmol} / \mathrm{L})$ was determined in the presence of $10 \mathrm{mmol} / \mathrm{L}$ $\mathrm{CaCl}_{2}$ at $37{ }^{\circ} \mathrm{C}$. The final reaction mixtures contained 50 mmollL Tris $\mathrm{HCl}$ pH 7.9, $175 \mathrm{mmol} / \mathrm{L} \mathrm{NaCl}, 0.5 \mathrm{mg} / \mathrm{mL}$ human serum albumin, $10 \mathrm{mmol} / \mathrm{L} \mathrm{CaCl}, 100$ nmol/L factor $I X$ and varying factor XIa concentrations. At the time intervals indicated, samples were withdrawn and assayed for factor IXa as described under Materials and Methods. The concentrations factor $X \mathrm{~F}$ a used were $0.01 \mathrm{nmol} / \mathrm{L}(\bullet), 0.03 \mathrm{nmol} / \mathrm{L}$ (4), $0.06 \mathrm{nmol} / \mathrm{L}(\mathbf{D})$ and $0.1 \mathrm{mmol} / L(\Delta)$. The rates of factor $I X$ activation were also plotted versus their factor XIa concentrations (inset). The slope of the plot (inser) reflects the rate of factor LXa formation per factor XIa present $129.9 \mathrm{mmol}$ IXa/min/nmol XIa).

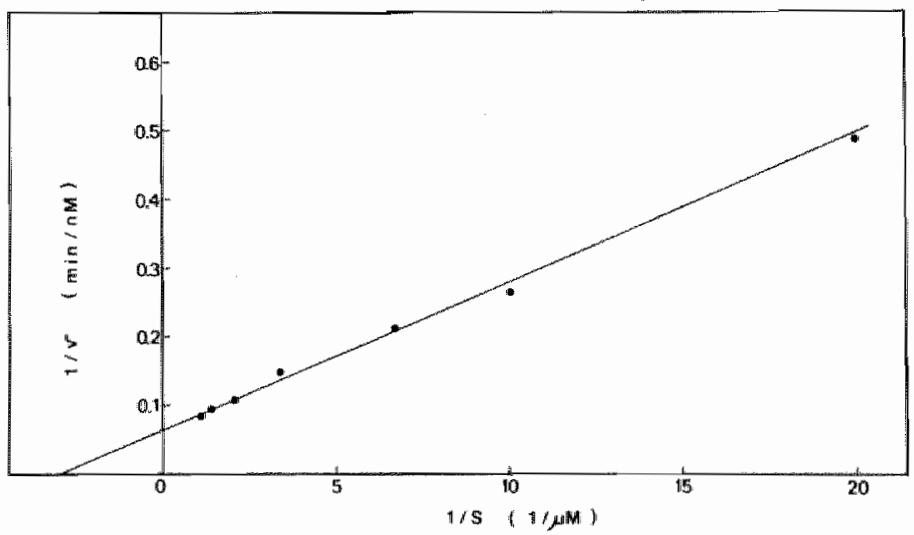

FIGURE 3. Lineweaver Burk plot of the activation of factor $1 X$ by factor XIa. This experiment gives a typical example for the determination of the kinetic parameters. Varying concentrations of factor $I X$ (range: $0.05-1.0 \mu \mathrm{mol} / \mathrm{L}$ ) were activated by faclor Xla (0.I nmol/L) in the presence of $10 \mathrm{mmol} / \mathrm{L} \mathrm{CaCl}$ at $37{ }^{\circ} \mathrm{C}$. Rates of factor IX activation were obtained as described under Materials and Methods and from these the Lineweaver-Burk plot was constructed. The kinetic parameters obtained from this experiment were a $K_{m}$ of $0.3 \mu m o l / L$ and a $V_{\max }$ of $14.4 \mathrm{mmol} L \mathrm{~L} / \mathrm{Ka} / \mathrm{min}$. 


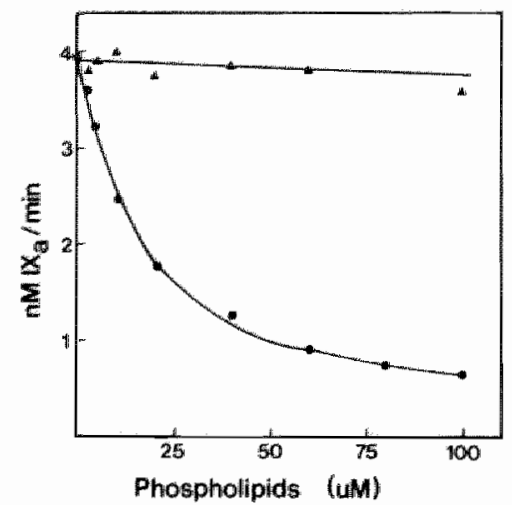

FIGURE 4. Facior IX activation by factor XIa in the presence of varying phospholipid concentrations. Factor $I X, \mathrm{CaCl}_{2}$ and phospholipid vesicles were preincubated for 5 min. at $37{ }^{\circ} \mathrm{C}$ before the acrivation was started by added factor XIa. The final reaction mixtures contained $50 \mathrm{mmol} / \mathrm{L}$ Tris $\mathrm{HCl} \mathrm{pH} 7.9,175 \mathrm{mmol} / \mathrm{L} \mathrm{NaCl}, 0.5 \mathrm{mg} / \mathrm{mL}$ human serum abumin, $100 \mathrm{mmol} / \mathrm{L}$ factor $X X, 10 \mathrm{mmol} / \mathrm{L} C a C l, 0.1 \mathrm{mmol} / \mathrm{L}$ factor $X I a$ and varying concentrations phospholipid as indicated. The rates of factor $I X a$ formation were determined as described under Materials and Methods. The experiment was performed using phospholipid vesicles, containing only phosphatidyl choline ( $\mathbf{\Delta}$ and phospholipid vesicles containing a molar ratio of $25 / 75$ of phosphatidyl serine over phosphatidyl choline (*).

proportional to the amounts of factor IXa added in the range of 0 to $0.5 \mathrm{pmol}$ $\mathrm{IXa} / \mathrm{mL}$. Using this calibration curve the activation of factor IX by factor XIa was determined. Figure 2 shows that the amount of factor IXa formed by factor XIa was linear in time and proportional to the amounts of factor XIa addled (inset).

The kinetic parameters of factor IX activation by factor Xla in the presence of $10 \mathrm{mM} \mathrm{CaCl} 2$ were determined. Figure 3 shows a Lineweaver-Burke plot of factor IX activation by factor XIa in the presence of $10 \mathrm{mM} \mathrm{CaCl}$. The kinetic parameters (mean of three experiments) were $\mathrm{K}_{\mathrm{m}}=0.37 \mu \mathrm{M}$ and $\mathrm{k}_{\text {eat }}$ $=2.8 \mathrm{~s}^{-1}$ assuming a molecular weight of 160,000 daltons for factor Xla.

The effect of phospholipids in the activation of factor IX by factor XIa was studied. Figure 4 shows that phospholipid vesicles, containing only phosphatidylcholine, did not influence the factor IXa formation rate significantly (closed triangles). Phospholipid vesicles containing 25 percent (mole/mole) phosphatidylserine, caused a decrease in the factor IXa formation rate (closed circles). This inhibition was dose-dependent in that increasing phospholipid concentrations caused a continuous decrease in the activation rate of factor IX. Half of the maximal rate was obtained in the presence of $20 \mu \mathrm{M}$ phospholipids. 


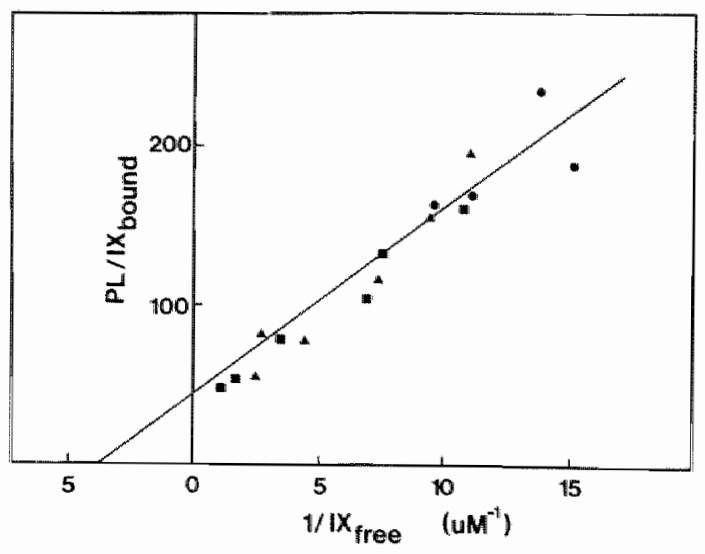

FIGURE 5. Determination of binding parameters of factor $I X$ binding to phospholipid. The rates of acrivation of factor $I X$ by factor Xla in the presence of $\mathrm{CaCl}$, were determined at varying phospholipid concentrations. Factor $I X$, phospholipid $(P S / P C=25 / 75)$ and $10 \mathrm{mmol} / \mathrm{L} \mathrm{CaCl}$ were preincubated for 5 min at $37{ }^{\circ} \mathrm{C}$, before the activation was started by adding 0.1 nmoll $L$ factor XIa. The concentrations factor IX used were: $120 \mathrm{mmol} / \mathrm{L}(\mathrm{H}), 490 \mathrm{mmol} / \mathrm{L}$ (4) and $1250 \mathrm{nmol} / \mathrm{L}$ (D). Using the rates of factor $I X a$ formation the concentration of factor $I X$ bound to phospholipid and the free factor $I X$ concentration were determined at each total factor $I X$ and phospholipid concentration. The binding parameters, $K_{d \prime}$ and $q$, were determined by statistical analysis as described by Eisenthal and Cornish-Bowden (26) of a plot of $P L / I X_{b}$ versus $I / I X_{j}$. For a detailed description see under Materials and Methods.

The activation of factor IX by factor XIa in the absence and in the presence of negatively charged phospholipids $(200 \mu \mathrm{M})$ was also followed on an immuno-blot using antibodies against human factor IX. In the absence of phospholipid vesicles both the intermediate and the end product, factor IXaß, were formed. In contrast in the presence of negatively charged phospholipids neither the intermediate nor factor $(\mathrm{Xa} \beta$ was visible (data not shown), indicating that the presence of negatively charged phospholipids inhibits both cleavages of factor IX by factor XIa.

From the literature it is known that factor IX binds to negatively charged phospholipids $(27,28)$. A possible explanation of the inhibitory effect caused by negatively charged phospholipids can be found in the binding of factor IX to phospholipids if it is assumed that factor IX bound to phospholipids is not activated by factor XIa. To further explore this possibility, the rate of factor IXa formation by factor XIa in the presence of varying phospholipid concentrations was measured at three factor IX concentrations. 
Making use of the kinetic parameters $\mathrm{K}_{\mathrm{m}}$ and $\mathrm{V}_{\max }$ of activation of factor IX by factor XIa at each phospholipid concentration, the rate of factor IX activation was used to calcullate the amounts of factor IX free in solution available for activation by factor Xla. Since the amount of total factor IX added is known, the amounts of phospholipid bound factor IX could be calculated and a plot of $\mathrm{PL} / \mathrm{IX}_{\mathrm{b}}$ versus $1 / \mathrm{IX}$ was constructed (see also eq. (4) under Methods).

Figure 5 shows the plot obtained and from the intercept at the ordinate the amount of binding sites present per mole of phospholipid, q, was determined to be 0.022 moles binding sites per mole of phospholipid. From the intercept at the abscissa a $K_{\triangleleft}$ of $263 \mathrm{nM}$ was determined.

Figure 6 shows the fit of the experimental data obtained when these binding parameters were used to calculate the rate of factor IX activation as a function of the phospholipid concentration. As can be seen, the experimental data were well fitted indicating that the inhibition of the rate of activation of factor IX by factor XIa can be satisfactorily explained under the assumption that the rate of activation of phospholipid bound factor IX is negligible as compared to the rate of free factor IX activation.

\section{Discussion}

In this paper we describe an assay that measures functional human factor IXa via its ability to activate bovine factor $\mathrm{X}$. The presence in our assay of standardized concentrations of phospholipid, $\mathrm{CaCl}_{2}$ and bovine factor VIlla in the factor $\mathrm{X}$ activation by factor IXa allows an accurate determination of factor IXa down to levels of $2.5 \mathrm{pmol} / \mathrm{L}$ and the rate of factor Xa formation is linear with the concentration of factor IXa up to $0.5 \mathrm{nmol} / \mathrm{L}$ factor IXa (Figure 1). This assay enables us to study the activation of human factor IX by human factor XIa and the effect of negatively charged phospholipid vesicles on this reaction. The formation of factor IXa is linear with time and the formation rate of factor IXa is linear with the concentration of factor XIa used (Figure 2). The kinetic parameters, $K_{m 1}$ and $V_{\max }$, of the factor IX activation by factor XIa in the presence of $10 \mathrm{mM} \mathrm{CaCl}_{2}$ were determined from Lineweaver-Burk plot (Figure 3). The kinetic parameters found are a $K_{m}$ of $0.37 \mu \mathrm{M}$ for factor $\mathrm{IX}$ and a $\mathrm{V}_{\max }$ of $16.8 \mathrm{nM} \mathrm{IXa/min}$ at $0.1 \mathrm{nM}$ factor XIa, which corresponds to a catalytic rate constant, $k_{\text {cat }}$, of $2.8 \mathrm{sec}^{-1}$ assuming a molecular weight of 160,000 daltons for factor XIa.

Using this assay, we determine the effect of phospholipid vesicles on the rate of factor IXa formation by factor XIa. The data reported here clearly 


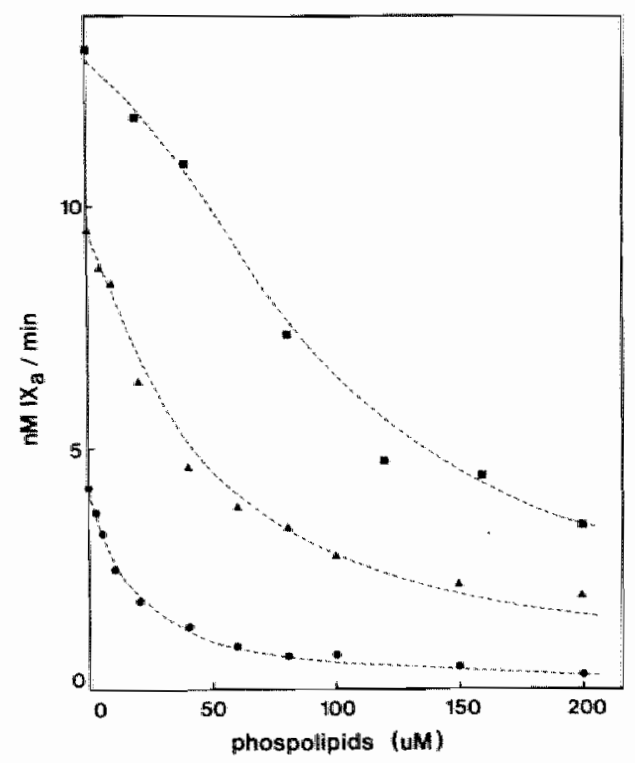

FIGURE 6 . Simulation of the rates of factor IXa formation using kinetic and binding parameters. The rates of activation of factor $I X$ by factor XIa in the presence of $\mathrm{CaCl}_{2}$ were determined at varying phospholipid concentrations. Factor $I X$, phospholipid $(P S / P C=25 / 75)$ and $10 \mathrm{mmol} / \mathrm{L} \mathrm{CaCl} \mathrm{Cl}_{6}$ were preincubared for $5 \mathrm{~min}$ at 37 ${ }^{\circ} \mathrm{C}$ before activation was started by adding $0.1 \mathrm{mmol} / \mathrm{L}$ factor XIa. The concentrations factor IX used were: $120 \mathrm{nmol} / \mathrm{L}(\bullet), 490 \mathrm{nmol} / \mathrm{L}(\Delta)$, and $1250 \mathrm{mmol} / \mathrm{L}(\mathbf{C})$. The rates of factor $I X a$ formation were determined as described under Materials and Methods. The rates of factor IXa formation were also simulated (dotted lines) asing the kineric parameters of facior $I X$ activation $\left(K_{k n}=370 \mathrm{nmol} / \mathrm{L}\right.$ and $V_{\max }=16.8$ $n M /$ mint $)$ and the binding parameters of factor $I X$ binding to phospholipid $\left(K_{d}=263\right.$ $n m o l / L$ and $q=0.022)$. For the simulation was assumed that only free factor $I X$ was activated by factor XIa. For a detailed description see under Materials and Methods.

demonstrate that the negativily charged phospholipid vesicles, containing 25 percent (mole/mole) phosphatidyl serine, cause a decrease in the rate of factor IXa formation by factor XIa, whereas neutral phospholipid vesicles, containing only phosphatidyl choline, have no significant effect (Figure 4). In the literature there is some disagreement concerning the effect of phospholipids in the activation of factor IX by factor XIa. Mannhalter et al. reported a two to three fold acceleration of factor $\mathrm{IX}$ activation by surface bound factor XIa using cephalin as a source of phospholipids (7). Van der Graaf et al. could not confirm this acceleration caused by cephalin (8). Recently, Warn-Cramer and Bajaj reported that phospholipids showed some inhibition in the activation of factor IX by factor XIa (9). This disagreement in the literature is probably due to differences in concentrations and sources of phospholipids used. It is clear however, that our data support the observation reported by WarnCramer and Bajaj (9). 



\section{References.}

1. Bouma, B.N., and Griffin, J.H. (1977), J. Biol. Chem. 252, 6432 .

2. Fujikawa, K., Chung, D. W., Hendrickson, L.E., and Davie, E.W. (1986), Biochemistry 25, 2417.

3. Kurachi, K., and Davie, E.W. (1977) Biochemistry 16, 5831.

4. Fujikawa, K., Legaz, M.E., Kato, H., and Davie, E.W. (1974) Biochemistry 13, 4508.

5. Di Scipio, R.G., Kurachi, K., and Davie, E.W. (1978) J. Clin. Invest. 61, 1528.

6. Osterud, B., Bouma, B.N., and Griffin, J.H. (1978) J. Biol. Chem. 253, 5946.

7. Mannhalter, C., Schiffman, S., and Deutsch, E. (1984) Br. J. Haematol. 56. 261.

8. Van der Graaf, F., Greengard., J.S., Bouma, B.N., Kerbiriou, D.M., and Griffin, J.H. (1983) J, Biol. Chem. 258, 9669.

9. Warn-Cramer, B.J., and Bajaj, S.P. (1986) Biochem. J. 239. 757.

10. Liebman, H.A., Furie, B.C. and Furie, B. (1987) J. Biol. Chem. 262, 7605.

11. Sinha, D., Seaman, F.S., and Walsh, P.N. (1987) Biochemistty $26,3768$.

12. Tans, G., Janssen-Claessen, T., van Dieijen, G., Hemker, H.C., and Rosing, J. (1982) Tromb. Haemost. $48,127$.

13. Di Scipio, R.G., Hermodsen, M.A., Yates, S.G., and Davie, E.W. (1977) Biochemistry 16, 698.

14. Miletich, J.P., Brose, G.J., and Majerus., P.W. (1980) Anal. Biochem. 105, 304.

15. Van Dieijen, G., Tans, G., Rosing, J, and Henker, H.C. (1981) J. Biol. Chen. 256, 3453 .

16. Bouma, B.N., Vlooswijk, R.A.A., and Griffin, J.H. (1983) Blood 62. 1123.

1.7. Griffin, J.H., and Cochrane, C.G. (1976) Methods Enzymol. 45, 56.

18. Fujikawa,K., and McMullen, B.A. (1983) J.Biol.Chem. 258, 10924.

19. Fujikawa, K., Legaz, M.E, and Davie, E.W. (1972) Biochemistry II, 4882.

20. Van Dieijen, G., van Rijn, J.L.M.L., Govers-Riernslag, J.W.P., Hemker, H.C., and Rosing, J. (1.985) Thromb. Haemost. 53, 376.

21. Rosing, J. Tans, G., Govers-Riemslag, J.W.P., Zwaal, R.F.A., and Hemker, H.C. (1980) J. Biol. Chem. 255, 274.

22. Laemmli, U.K. (1970) Nature 227, 680.

23. Bradford, M.M. (1976) Anall. Biochem. 72, 248.

24. Snith, R.L. (1973) J. Biol. Chem. 248, 24.18.

25. Chase, T., and Shaw, E. (1969) Biochemistry 8, 2212.

26. Eisenthal, R., and Cornish-Bowden, A., (1974) Biochern. J. 139, 175.

27. Neisestuen, G.L., Kisiel, W., and Di Scipio, G.D. (1978) Biochemistry 17, 2134.

28. Jones, M.E., Griffith, M.J., Monroe, D.M., Roberts, H.R., and Lentz, B.R. (1985) Biochemistry 24,8064 



\section{The Effect of Platelets in the Activation of Human Blood Coagulation Factor IX by Factor XIa.}

\section{Abstract}

We report here the effect of activated human platelets on the activation of human factor IX by human factor XIa. Factor IXa formed during activation was determined via its ability to activate bovine factor $X$. To increase sensitivity, phospholipids and bovine factor VIIIa were present in the assay. The kinetic parameters of the factor IX activation were determined in the presence of $10 \mathrm{mM} \mathrm{CaCl}_{2}$. The $\mathrm{K}_{\mathrm{in}}$ for factor IX was $0.30 \mu \mathrm{M}$ and $\mathrm{k}_{\text {cat }}$ was $2.4 \mathrm{sec}^{-1}$.

Activated human platelets inhibited factor IX activation by factor XIa in a dose-dependent manner, whereas unstimulated platelets had no effect. Factor IX activation was inhibited for more than $90 \%$ at a platelet concentration of $4.10^{8} / \mathrm{ml}$, whereas concentrations less than $10^{6} / \mathrm{ml}$ had no influence. The inhibitory effect could be induced by thrombin, collagen, calcium ionophore A 23187, and adrenalin. The appearance of inhibitory activity could be blocked by addition of the prostacyclin analog ZK. 36374 at any time during platelet activation. Stirring during platelet activation was not necessary. These results suggest that the inhibition is caused by a release reaction. This was confirmed by centrifugation experiments that showed that the inhibitory activity could be recovered from the supernatant of the activated platelets. The inhibitory activity was destroyed upon boiling and was susceptible to trypsin digestion. Passage of platelet supernatant over ACA 22 showed that the inhibitory activity eluted with an apparent molecular weight of less than 1,200,000 but greater than 669,000 . The inhibition of factor Xla was reversible.

These data suggest that platelets release an antiprotease of factor Xla that reversibly inhibits factor XIa. Lineweaver-Burk analysis showed that the inhibitor cause both an increase of the $\mathrm{K}_{\mathrm{m}}$ for factor IX and a decrease in $\mathrm{k}_{\mathrm{eat}}$ of factor IXa formation by factor XIa. 
Human factor $\mathrm{IX}$ is a vitamin $\mathrm{K}$-dependent plasma protein that participates in the intrinsic pathway of blood coagulation (1). It is present in plasma as a zymogen with molecular weight $\left(\mathrm{M}_{\mathrm{r}}\right)$ of 57,000 at a concentration of 2.6 to $5.0 \mu \mathrm{g} / \mathrm{ml}$. Human factor IX is converted to a serine protease, factor IXa, through proteolysis of two internal peptide bonds. This results in the release of an activation peptide $\left(M_{r}, 11,000\right)$ from the internal region of the precursor molecule. The resulting factor IXat $\left(\mathrm{M}_{s} 46,000\right)$ consists of a light chain $\left(M_{r} 18,000\right)$ and heavy chain $\left(M_{r} 28,000\right)$ held together by disulfide bond(s) $(2,3)$. Activation of factor IX in plasma can be accomplished by factor XIa $(2,3)$ or by the factor VIla-tissue thromboplastin complex $(4,5)$.

Platelets play an important role in blood coagulation. The platelet surface strongly promotes prothrombin and intrinsic factor $\mathrm{X}$ activation (6). The activation of factor IX by factor XIa is one the few reactions of coagulation for which no surface requirement is known. It has been suggested that collagen stimulated platelets exhibit factor XIa-like activity which can be determined in a clotting test $(7,8)$. However, others have failed to confirm this (9), and it is not known whether factor XIa is involved. Up till now nothing is known about whether platelets have any effect in the activation of factor IX by factor XIa.

Several assays have been described in literature for the determination of factor IX activation: a coagulation assay in factor IX deficient plasma $(10-12)$, a tritiated activation peptide release assay $(5,10,13)$, an immunoradiometric assay (11), and an assay in which factor IXa is measured indirectly by determining the initial rate of factor $\mathrm{X}$ activation (14). The most widespread used is the tritiated activation peptide release assay $(5,10,13)$, which was originally described for the activation of factor $X$ by Silverberg et al. (15). In highly purified systems, the appearance of factor IXa procoagulant activity follows the peptide release by a small lag period (10). However, in less-purified systems other enzymes may be present that give rise to similar peptide fragments but destroy the procoagulant activity of factor IX (16). Therefore, to circumvent these potential difficulties, we have chosen to use an assay for factor IX activation by factor Xla, which detects the functionall factor IXa activity via its ability to activate bovine factor $X$, in the presence of phospholipids and $\mathrm{CaCl}_{2}$ (14). To increase its sensitivity, bovine factor VIIla was present. In that case, however, care has to be taken to add factor VIlla under rigorously standardized conditions, since the assay is critically dependent on the amount of factor VIIIa present.

This study was undertaken to explore the role of platelets in factor IX activation by factor XIa. We present evidence that platelets, upon stimulation, secrete an inhibitor which interferes with factor IX activation by factor XIa. 
Materials. Chromogenic substrates L-pyroglutamyl-L-prolyl--L-arginine-pnitroanilide hydrochloride (S2366) and N-benzoyl-L-isoleucyl-L-glutamyl (piperidyl)-glycyl-L-arginine-p-nitroanilide-hydrochloride (S2337) were purchased from AB Kabi Diagnostica, Stockholm, Sweden. The prostacylin ana$\log$ ZK. 36374 was a kind gift from Schering AG. Berlin, Germany. Plasma deficient in coagulation factors IX, XI, or XII were from patients congenitally deficient in these factors and were obtained from George King Biomedical, Overland Park, Kan. Hormon tendon collagen was obtained from Hormonchemie, Munich, Germany. Fatty-acid free human serum albumin and trypsin were from Sigma Chemical Co., St. Louis. Two-milliliter plastic fllat-bottom reaction tubes were obtained from Sterilin Ltd. Teddington, England; Tefloncoated magnetic stirring bars $(7 \times 2 \mathrm{~mm})$ were purchased from Bel-Art Products, Peguannock, NJ. All reagents used were of the highest grade commercially available.

Proteins. Human factor IX was purified based on a modification of the isolation procedure described by di Scipio et al. (17) and the sulfated dextran column as described by Miletich et all. (18) was added. Citrated fresh frozen human plasma was thawed, and benzamidine $(10 \mathrm{mM})$, heparin $(6 \mathrm{mg} / \mathrm{L})$, and soybean trypsin inhibitor $(10 \mathrm{mg} / \mathrm{L})$ were added. The barium citrate absorption was followed by ammonium sulfate precipitations ( $40 \%$ and $70 \%$ saturation) before the vitamin $\mathrm{K}$-dependent protein preparation was applied to a DEAE-Sephadex column followed by a heparin Sephadex column (17). Finally, a sulfated dextran column was used to purify factor $\mathbb{I X}(18)$. Human factor IXa was prepared from purified human factor IX as described earlier for bovine factor IXa (19). Human factor XI was purified according to Bouma et al. (20). Human factor XII was isolated as described by Griffin and Cochrane (21). $\beta$-Factor XIIa was prepared from the purified human factor XII as described by Fujikawa and McMullen (22). Bovine factor $\mathrm{X}$ was purified according to Fujikawa et al. (23). Bovine factor VIIlc was prepared as described earlier (24). Factor VIIIa was prepared by activation of factor VIIIc (1.75 nM) with thrombin ( $4 \mathrm{nM}$ ) for $1 \mathrm{~min}$ at $37^{\circ} \mathrm{C}(19,24)$. Bovine thrombin was purified as a prothrombin activation product as described by Rosing et al. (25). The specific activity of the thrombin preparation was \& National Institutes of Health $(\mathrm{NIH}) \mathrm{U} / \mathrm{mL}=11 \mathrm{nmol} / \mathrm{L}$ when a molecular weight of 35,600 was used for thrombin. The human factor IX, XI and XII and the bovine factor $\mathrm{X}_{1}$ and $\mathrm{X}_{2}$ preparations were homogeneous and pure as determined by gel electrophoresis in the presence of sodium dodecyl sulfate on $10 \%$ gels according to Laemmli (26). The specific activities of the protein preparation as determined with a clotting assay were 193,211, 74 and 100 units/mg for human 
factors IX, XI, and XII and bovine factor $\mathrm{X}$ respectively, assuming 1 unit of human factor IX, XI and XII to be present per per milliliter of human normal plasma and 1 unit of bovine factor $X$ in one milliliter of bovine normal plasma.

All proteins were stored at $-70^{\circ} \mathrm{C}$ after dialyzing against the following buffers: $50 \mathrm{mM}$ Tris-HCL, $175 \mathrm{mM} \mathrm{NaCl}$ at $\mathrm{pH} 7.9$ for human factor IX and bovine factor $\mathrm{X} ; 4 \mathrm{mM}$ sodium citrate, $2 \mathrm{mM}$ acetic acid, $0.15 \mathrm{M} \mathrm{NaCl}$, and 0.5 mM EDTA at pH 5.0 for human factor XI and XII; and $10 \mathrm{mM}$ morpholino ethane sulfonic acid, $175 \mathrm{mM} \mathrm{NaCl}, 10 \mathrm{mM} \mathrm{CaCl}_{2}$ and $10 \%$ glycerol at pH 6.5 for bovine factor VIIl. Trypsin was insolubilized by coupling trypsin (60 mg) in $0.1 \mathrm{M} \mathrm{NaHCO}_{3}$ to $\mathrm{CNBr}$ - activated Sepharose $4 \mathrm{~B}(3 \mathrm{~g})$ at $4{ }^{\circ} \mathrm{C}$ overnight according to the manufacturer's instructions.

Preparation of human factor XIa. Human factor XIa was prepared from human factor XI using human $\beta$-factor XIIa (27). To $10 \mathrm{~mL}$ of factor XI $(0.15$ $\mathrm{mg} / \mathrm{mL}$ ) in $4 \mathrm{mM}$ sodium acetate, $2 \mathrm{mM}$ acetic acid, $0.15 \mathrm{M} \mathrm{NaCl}, \mathrm{pH} 5.0$ was added $1.25 \mathrm{~mL} 0.5 \mathrm{M}$ Tris- $\mathrm{HCL}, 0.15 \mathrm{M} \mathrm{NaCl}, \mathrm{pH} 8.0$ at $37^{\circ} \mathrm{C}$. The reaction was started by addition of $1.27 \mathrm{~mL} \beta$-factor XIIa $(0.59 \mathrm{mg} / \mathrm{mL})$ in $4 \mathrm{mM}$ sodium acetate, $2 \mathrm{mM}$ acetic acid, $0.15 \mathrm{M} \mathrm{NaCl}$ at $\mathrm{pH} 5.0$. Factor XI activation was followed by measuring factor XIa amidolytic activity. Activation was completed within 90 minutes. Factor XIa was separated from $\beta$-factor XIIa on a DEAE-Sephadex column $(1.5 \times 11.5 \mathrm{~cm})$ at $4{ }^{\circ} \mathrm{C}$ in $50 \mathrm{mM}$ Tris-HCL and $150 \mathrm{mM} \mathrm{NaCl}$ at $\mathrm{pH} 8.0$. Factor XIa did not adhere to the resin, whereas $\beta$-factor XIIa was eluted by a linear salt gradient $(0.1-0.5 \mathrm{M}) \mathrm{NaCl}$.

Amidolytic activity of human factor XIa was measured using the chromogenic substrate $\mathrm{S} 2366$ in a buffer containing $50 \mathrm{mM}$ Tris-HCL, $150 \mathrm{mM}$ $\mathrm{NaCl}, 20 \mathrm{mM}$ EDTA, and $0.5 \mathrm{mg} / \mathrm{mL}$ human serum albumin $\mathrm{pH}$ 7.9. The kinetic parameters of the hydrolysis of the chromogenic substrate $\$ 2366$ by human factor XIa were $K_{\mathrm{m}}=0.42 \mathrm{mM}$ and $\mathrm{k}_{\text {cat }}=758 \mathrm{sec}^{-1} \cdot \mathrm{k}_{\text {cat }}$ was calculated using a concentration of factor XIa based on a molecular weight of 160,000 .

Prorein concentrations. Protein concentrations were routinely determined according to Bradford (28). Factors IXa, Xa and thrombin were determined by active-site titration with $p-N P G B$ as described earlier $(14,25)$. Concentrations of factor $\mathrm{IX}$ and factor $\mathrm{X}$ were determined by complete activation and subsequent determination of the active enzyme. Factor VIIlla concentrations were determined according the method of van Dieijen et al (24). Factor XIa concentrations were determined from the amount of protein present assuming a molecular weight of 160,000 . 
Phospholipid vesicles. Phospholipid vesicles were made from a mixture of $40 \mathrm{~mol} / 100 \mathrm{~mL}$ 1.2-dioleoyl-sn-glycero-3-phosphoserine (PS) and $60 \mathrm{~mol} /$ $100 \mathrm{~mL}$ 1.2-dioleolyl-sn-glycero-3-phosphocholine (PC) in a buffer containing $50 \mathrm{mM}$ Tris-HCL and $175 \mathrm{mM} \mathrm{NaCl}$ at $\mathrm{pH} 7.9$ as described by Rosing et al. (25).

Collagen. Collagen was added in the nonfibrillar form, dissolved in acidic dilution buffer obtained from Hormon Chemie as described by Rosing et al. (6). The minimal amount of collagen inducing aggregation and secretion was $1-2 \mu \mathrm{g} / \mathrm{mL}$.

Factor $\mathrm{IX}$ a determinations. To follow the activation of factor IX by factor $\mathrm{XIa}$ an assay system was developed in which factor IXa was determined via its ability to activate bovine factor $\mathrm{X}$ in the presence of $\mathrm{CaCl}_{2}$, phospholipid, and factor VIIIa. Factor IXa-containing samples were diluted in ice-cold buffer containing $50 \mathrm{mM}$ Tris ( $\mathrm{pH} 7.9), 175 \mathrm{mM} \mathrm{NaCl}, 0.5 \mathrm{mg} / \mathrm{mL}$ human serum albumin, and $20 \mathrm{mM}$ EDTA to block further activation of factor IX. The amounts of factor IXa present in the samples were then determined as follows. Three hundred five microliters buffer containing $50 \mathrm{mM}$ Tris ( $\mathrm{pH} 7.9$ ), $175 \mathrm{mM} \mathrm{NaCl}, 9.8 \mathrm{mM} \mathrm{CaCl}_{2}, 0.5 \mathrm{mg} / \mathrm{mL}$ human serum albumin and 16.4 $\mu \mathrm{M}$ phospholipid vesicles was prewarmed at $37^{\circ} \mathrm{C}$ for four and a half minutes after which forty-five $\mu \mathrm{L}$ bovine factor $\mathrm{X}(16,67 \mu \mathrm{M})$ and fifty $\mu \mathrm{L}$ sample were added. Factor $\mathrm{X}$ activation was started with the addition of $100 \mu \mathrm{L}$ factor VIIla $(1.75 \mathrm{nM})$.

The final reaction mixture $(500 \mu \mathrm{L})$ contained $50 \mathrm{mM}$ Tris $(\mathrm{pH} 7.9), 175$ $\mathrm{mM} \mathrm{NaCl}, 6 \mathrm{mM} \mathrm{CaCl}, 2 \mathrm{mM}$ EDTA, $10 \mu \mathrm{M}$ phospholipid, $1.5 \mu \mathrm{M}$ factor $\mathrm{X}, 0.35 \mathrm{nM}$ factor VIIIa, $0.5 \mathrm{mg} / \mathrm{mL}$ human serum albumin, and the factor IXa present in the sample. The rate of factor $\mathrm{X}$ activation was determined by measurement of the amounts of factor Xa formed after one and two minutes in these reaction mixtures using the factor Xa-specific chromogenic substrate $\mathrm{S} 2337$ as described earlier $(14,19)$. From the observed rate of factor $X$ activation, the amount of factor IXa present in the sample was calculated using a calibration curve made with known amounts of active-site titrated factor IXa (see also Figure 1).

Kinetic Parameters. $\mathrm{K}_{\mathrm{m}}$ for factor $\mathrm{IX}$ and $\mathrm{k}_{\mathrm{cat}}$ of factor $\mathrm{IX}$ activation were determined by measurement of the rate of factor IXa formation in a reaction mixture containing $10 \mathrm{mM} \mathrm{CaCl}, 0.5 \mathrm{mg} / \mathrm{mL}$ human serum albumin, 0.1 $\mathrm{nM}$ factor XIa, and varying amounts of factor IX in HEPES buffer, $\mathrm{pH} 7.5$, using the assay previously described. $K_{m}$ and $V_{\text {maxx }}$ (expressed as factor IXa formed per second) were then determined by statistical analysis of the data as described by Eisenthal and Cornish-Bowden (29). $k_{\text {cail }}$ was calculated by 
dividing $V_{\max }$ with the enzyme concentration assuming a $M_{r}$ of 160,000 for factor XIa.

Isolation of human platelets. Blood was drawn by venipuncture from healthy male volunteers who had not taken any medication for at least ten days. As anticoagulants, one volume of acid citrate dextrose $(0.18 \mathrm{M}$ glucose, $0.08 \mathrm{M}$ trisodium citrate and $0.052 \mathrm{M}$ citric acid) was added to five volumes of whole blood. Platelet rich plasma was obtained after centrifugation at $220 \mathrm{~g}$ for $25 \mathrm{~min}$. Platelets were isolated by centrifugation $1000 \mathrm{~g}$ for $20 \mathrm{~min}$ and the pellet was gently resuspended in calcium-free HEPES buffer $(10 \mathrm{mM}$ HEPES, $136 \mathrm{mM} \mathrm{NaCl}, 2.68 \mathrm{mM} \mathrm{KCl}, 2 \mathrm{mM} \mathrm{MgCl}$, and $5 \mathrm{mM}$ glucose), at pH 6.7, containing $0.4 \%$ human serum albumin. The platelets were washed twice in this buffer by centrifugation $600 \mathrm{~g}$ for $15 \mathrm{~min}$. During the whole procedure except the last wash, acid/citrate/dextrose was present in the buffer ( 1 vol. to 14 vol. buffer) (30). Finally, the platelets were resuspended in HEPES buffer, pH 7.5, containing $0.1 \%$ human serum albumin. Platelet concentrations were determined with a Coulter counter (Coulter Electronic, Luton, England) and were kept at room temperature.

\section{Results}

Validation of the Assay for Factor IXa. In this study an assay for the activation of factor IX was used in which functionally factor IXa activity was determined via the activation of bovine factor $X$ as described earlier (14). To increase its sensitivity, the activation of bovine factor $\mathrm{X}$ by human factor IXa was performed in the presence of $\mathrm{CaCl}_{2}$, phospholipids, and bovine factor VIIIa. The amount of factor Xa formed was linear with time for at least two minutes (data not shown), and the rates of factor Xa formation were determined from the amounts of factor Xa formed during these two minutes. Figure 1 shows that the rate of factor $\mathrm{Xa}$ formation was proportional to the amount of factor IXa added (closed circles). The slope of this plot reflects the rate of factor Xa formation per factor IXa present $(59.5 \mathrm{nmol} \mathrm{Xa} / \mathrm{min} . / \mathrm{nmol}$ IXa). An excellent day to day reproducibility of the calibration curve could be achieved, since four separate experiments carried out at different days showed a standard deviation of $1.7 \%$ in the slope of this plot.

This calibration curve was used in the experiments in which the activation of factor IX by factor Xla was determined. Since the experiments presented here concern the effect of platelets on the activation of factor IX by factor $\mathrm{Xla}$, the calibration curve was repeated in the presence of $3.2 .10^{7} / \mathrm{ml}$ thrombin/collagen-stimulated platelets (Figure 1, open triangels) or the supernatant thereof (Figure 1, open circles). As can be seen, the presence of the 


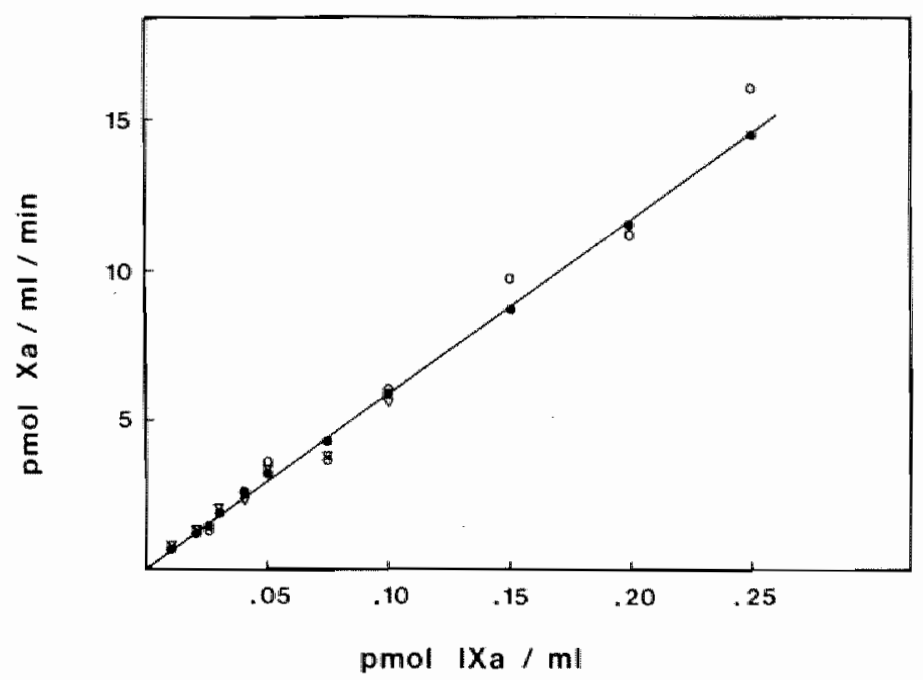

FIGURE I. Factor IXa calibration curve.

The rate of activation of bovine factor $X(1.5 \mu M)$ by warying amoumis of factor $1 X a$ was determined in the absence ( $\bullet$ ) or in the presence of $3.2 \times 10^{7} / \mathrm{m} /$ stimulated platelets $(\triangle)$ or their supernatants $(O)$ ar $37{ }^{\circ} \mathrm{C}$ in a reaction volume of $500 \mu /$ containing $50 \mathrm{mM}$ Tris (pH 7.9), $175 \mathrm{mM} \mathrm{NaCl}, 6 \mathrm{mM} \mathrm{CaCl}, 2 \mathrm{mM} E D T A, 10 \mu M$ phospholipid vesicles (40\% PS.60\% PC; mole/mole), $1.5 \mu$ M factor $X, 0.35$ nM factor VIIT, $0.5 \mathrm{mg} / \mathrm{mL}$ human serum albumin and amounts of factor IXa as indicated in the figure. When stimulated platelets or their supernatants were present, factor IXa was preincubated with the platelets or their supernatant for $4 \mathrm{~min}$ at $37{ }^{\circ} \mathrm{C}$ prior to addition to the assay. Stimulated platelets were prepared by incubation at $37{ }^{\circ} \mathrm{C}$ for 12 minutes with $1.2 \mathrm{nM}$ thrombin, $10 \mu \mathrm{g} / \mathrm{mL}$ collagen and $3 \mathrm{mM} \mathrm{CaCl}$ under con tinuous stiring. The supernatants were prepared by centrifuging the stimulated platelet for five mimutes in an Eppendorf microfuge. For experimental detalls, see Materials and Methods.

triggered platelets or their supernatants had no effect on the assay for factor IXa.

Factor IX Activation by Factor XIa. The assay just described was used to assess the kinetic parameters of factor IX activation by factor XIa in the presence of $10 \mathrm{mM} \mathrm{CaCl}_{2}$. It was verified that factor $\mathbb{X}$ activation was linear with time and proportional to the amount of factor Xla used (data not shown). Varying concentrations of factor $\mathrm{IX}$ were incubated with factor XIa and the rate of factor IXa formation was determined in the assay just described. Michaelis-Menten kinetics were observed throughout. The kinetic parameters were: $\mathrm{K}_{\mathrm{m}}=301 \mathrm{nM}$, and $\mathrm{k}_{\mathrm{cat}}=2.4 \mathrm{sec}^{-1}$ assuming a molecular weight of 160,000 for factor XIa.

The effect of platelets in the activation of factor IX by factor Xla was studied. Non-stimulated platelets up to concentrations as high as $5.10^{8} / \mathrm{mL}$ 


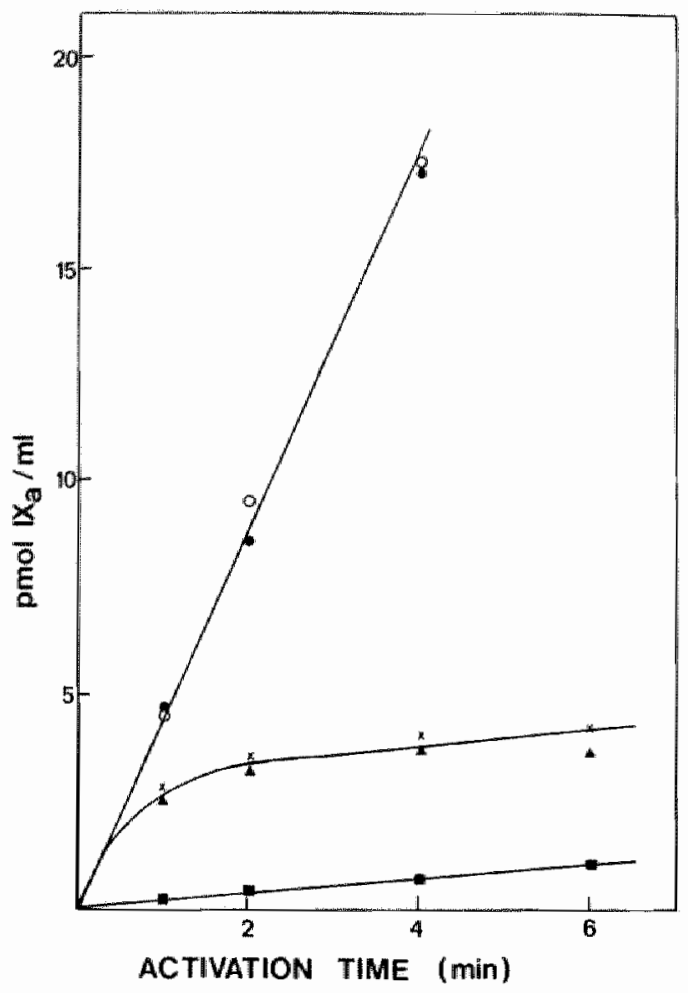

FIGURE 2. The effect of platelets in the activation of factor $I X$ by factor XIa. The activation of factor $I X(100 \mathrm{nM})$ by factor XIa (0.1 nM) was determined at $37{ }^{\circ} \mathrm{C}$ in the absence of platelets (O), in the presence of $5 \times 10^{8} / \mathrm{mL}$ unstimulated platelets $(\bullet)$, and in the presence of platelets $\left(5 \times 10^{8} / \mathrm{mL}\right)$ that had been stimulated for 12 minutes at $37{ }^{\circ} \mathrm{C}$ under continuous stirring by thrombin $(1.2 \mathrm{nM})$, collagen $(10 \mu \mathrm{g} / \mathrm{mL})$, and $3 \mathrm{mM} \mathrm{CaCl}_{2}(X)$. The final reaction mixture contained $10 \mathrm{mM} \mathrm{CaCl}, 0.5 \mathrm{mg} / \mathrm{mL}$ human serum albumin, $100 \mathrm{nM}$ factor $I X$, $0.1 \mathrm{nM}$ factor $X I \mathrm{la}$, and $5 \times 10^{\circ} / \mathrm{mL}$ platelets in HEPES buffer at $p H$ 7.5. At the time intervals indicated, samples were withdrawn and assayed for factor IXa as described in Materials and Methods. The points denoted (4) were obtained after factor $I X$ was incubated 4 mimutes with the stimulated platelets prior to the addition of factor XIa. The points denoted by (a) were obtained after a 4 minute incubation of factor XI a with the stimulated platelets prior to the addition of factor $I X$.

had no effect on factor IX activation. However, in the presence of platelets stimulated by the combined action of thrombin and collagen, the rates of factor IXa formation decreased with time until after two minutes a low rate of factor IXa formation remained (Figure 2). Preincubation of factor IX with the activated platelets for four minutes did not change the time course of factor IX activation. However, when factor XIa was preincubated with the triggered platelets, only the low rate of factor IXa formation remained. This 
Table 1. The Effect of Different Platelet Stmularors in Factor IX Activation by Factor XIa.

Trigger Substance

Rate of Factor IX Activation

No trigger

ADP

ADP/fibrinogen

Adrenalin

Collagen

Thrombin

A23187

Thrombin/collagen

Thrombin/collagen *

$100 \%$
$95 \%$
$92 \%$
$84 \%$
$84 \%$
$62 \%$
$58 \%$
$59 \%$
$58 \%$

* The platelets were actiwated by thrombin $(1.2 \mathrm{nM})$ and collagen $(10 \mu \mathrm{g} / \mathrm{mL})$ without stirring.

Platelets $\left(4.10^{7} / \mathrm{mL}\right)$ were incubated in HEPES buffer $(\mathrm{pH} 7.5)$ at $37^{\circ} \mathrm{C}$ for twelve min. in the presence of $\operatorname{ADP}(25 \mu \mathrm{M}), \operatorname{ADP}(25 \mu \mathrm{M})$ and human fibrinogen $(0.7$ $\mathrm{mg} / \mathrm{mL})$, adrenalin $(546 \mu \mathrm{M})$, collagen $(10 \mu \mathrm{g} / \mathrm{mL})$, ionophore $\mathrm{A} 23187(1 \mu \mathrm{M})$, thrombin $(1.2 \mathrm{nM})$ or thrombin $(1.2 \mathrm{nM})$ and collagen $(10 \mu \mathrm{g} / \mathrm{mL}$ ). During stimulation the platelets were stirred. After this incubation, factor Xla was added and incubated for ten minutes with the activated platelet suspension. The factor $\mathrm{IX}$ activation mixture contained $4.10^{7} / \mathrm{mL}$ platelets, $100 \mathrm{nM}$ factor IX, $0.1 \mathrm{nM}$ factor Xla and $10 \mathrm{mM}$ $\mathrm{CaCl}_{2}$ in HEPES buffer, $\mathrm{pH}$ 7.5. Factor IX activation rates were determined as described in Materials and Methods and expressed as a percentage of the activation rate measured in the presence of unstimulated platelets $(3.58 \mathrm{pmol} 1 \mathrm{Xa} / \mathrm{min} / \mathrm{mL})$.

strongly suggests that the inhibition was the result of a direct interaction with factor XIa that was completed within four minutes. Subsequent experiments showed that for platelet concentrations ranging from $10^{6}-10^{\%} / \mathrm{mL}$ a preincubation time with factor XIa of approximately ten minutes sufficed to result in linear rates of factor IXa formation. Therefore, in all subsequent experiments, factor XIa was preincubated for ten minutes with the platelets prior to addition of factor $1 X$.

The inhibitory effect of activated platelets at a suboptimal platelet concentration $(4.10 \% / \mathrm{mL})$ in the factor IX activation by factor XIa was studied using different platelet agonists (Table 1). The most potent were thrombin $(1.2$ $\mathrm{nM}$ ), calcium-ionophore $\mathrm{A23187}(1 \mu \mathrm{M})$, and the combined action of thrombin $(1.2 \mathrm{nM})$ and collagen $(10 \mu \mathrm{g} / \mathrm{mL})$, whereas platelets activated by collagen $(10 \mu \mathrm{g} / \mathrm{mL})$ or adrenalin ( $546 \mu \mathrm{M})$ caused a smaller inhibition. Platelets stimulated with $\mathrm{ADP}(25 \mu \mathrm{M})$ whether in the absence or presence of fibrinogen $(0.7$ $\mathrm{mg} / \mathrm{mL}$, showed no significant inhibition of the factor IX activation by factor XIa under these conditions. Stirring of the platelets was not necessary to achieve the inhibitory activity. 


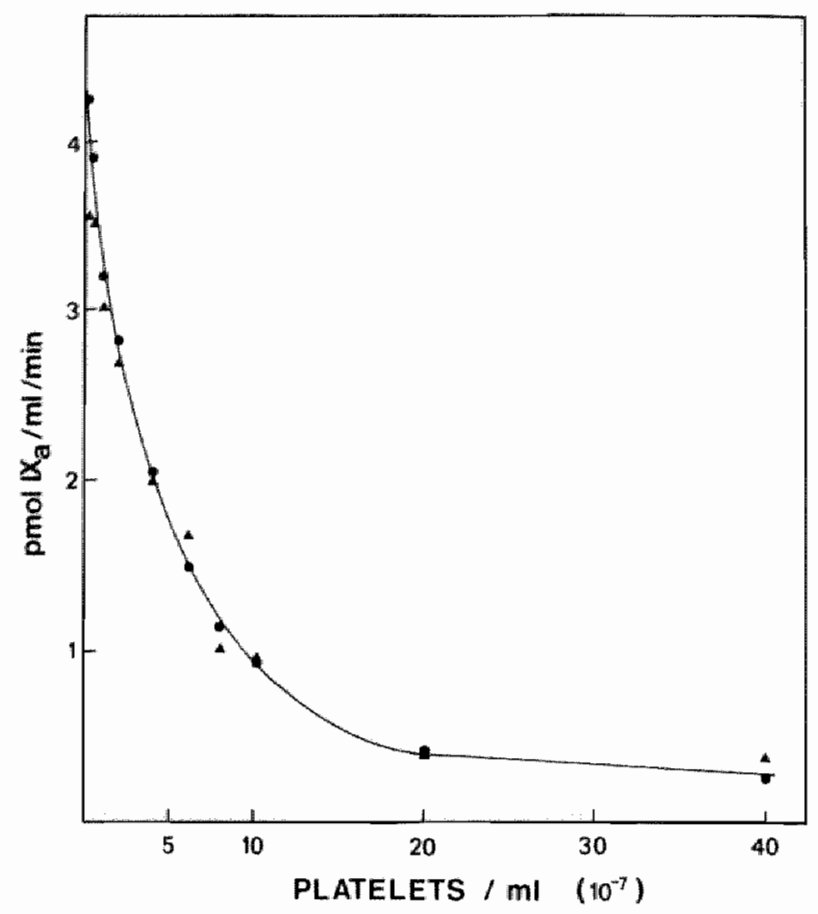

FIGURE 3 . Factor $I X$ activation in the presence of varying concentrations of activated platelets or their supernatants. Varying amounts of platelets were stimulated for 12 min at $37{ }^{\circ} \mathrm{C}$ under contimuous stirring with thrombin $(1.2 \mathrm{nM}$ ) and collagen (10 $\mu \mathrm{g} / \mathrm{mL})$ in the presence of $3 \mathrm{mM} \mathrm{CaCl}$. The platelets were then either incubated for an additional $5 \mathrm{~min}$ or centrifuged for $5 \mathrm{~min}$ in an Eppendorf Microfuge to obtain the supernatant. After this, the $\mathrm{CaCl}$ concentration was adjusted to $10 \mathrm{mM}$, and factor $X I a$ was added and incubated for an additional $10 \mathrm{~min}$ with the platelet suspensions. or the supernatants. Subsequently, factor $I X$ was added, and the rate af factor IXa formation was determined as described in Materials and Melhods. The final reaction mixtures contained $10 \mathrm{mM} \mathrm{CaCl}, 0.5 \mathrm{mg} / \mathrm{mL}$ human serum albumin, $100 \mathrm{mM}$ factor $I X$, and $0.1 \mathrm{wM}$ factor XIa in HEPES buffer (pH 7.5) and amounts of platelets ( or their supernatants ( $\mathbf{\Delta}$ ) as indicaled in the figure.

Figure 3 shows that factor IX activation was inhibited in a dose-dependent way. Factor IXa formation was not influenced at platelet concentrations less

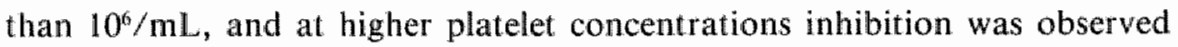
until at a concentration of $4.10^{8} / \mathrm{mL}$ factor IX activation was almost completely inhibited. During the platelet activation the lysis was allways smaller than $2 \%$. Lactic dehydrogenase ( $\mathrm{LDH}$ ) was taken as parameter for platelet lysis. Hundred percent lysis was the amount of LDH measured when the platelets were sonicated. When the triggered platelet suspension was centrifuged, all the inhibitory activity was recovered in the supernatant (Figure 3), indicating that the inhibition is the result of platelet secretion upon triggering. 

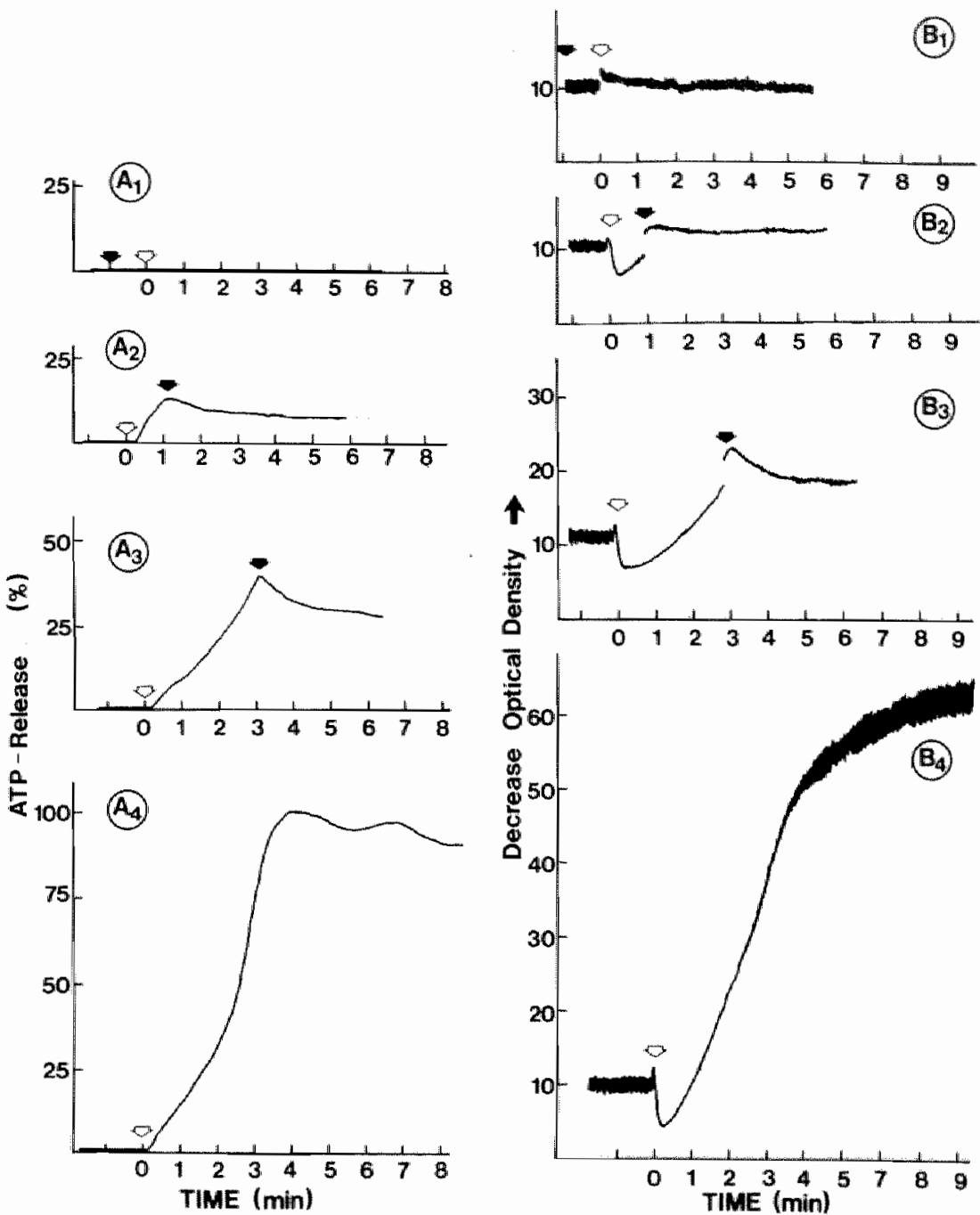

FIGURE 4. Influence of $Z K 36374$ on platelet aggregation and ATP-release. Platelet aggregation and ATP-release were measured in an aggregometer. Washed platelets 2.3 $x 10^{8} / \mathrm{mL}$ ) in HEPES buffer containing $2.6 \mathrm{mM} \mathrm{CaCl}_{2}$ and luciferin Inciferase reagents were placed in the aggregometer under stirring canditions. At time zero, platelet activation was started by adding $(0.7 \mathrm{nM}$, i.e. $0.06 \mathrm{U} / \mathrm{mL})$ thrombin (open arrow). At different rime points, ZK 36374 (90mM) was added to stop the platelet activation (closed arrow). A TP-release was monitored by the luciferin-luciferase reaction $(A)$, and platelet aggregation was measured at the same time (B). When ZK 36374 was added one minute before thrombin ${ }^{\prime}$ no $A T P$-release and platelet aggregation was measured $\left(A\right.$, and $\left.B_{1}\right)$. When $Z K$ 36374 was added one or three minutes after thrombin, ATP-release and aggregation sropped immediately $\left(A_{2}, B_{2}\right.$ and $\left.A_{3 *} B_{3}\right)$. A TP-release and platelet aggregation were also meastred in the absence of $Z K 36374\left(A_{4}\right.$ and $\left.B_{4}\right)$. ATP release is expressed as a percentage, with ATP-release in the absence of ZK 36374 taken as $100 \%$. 


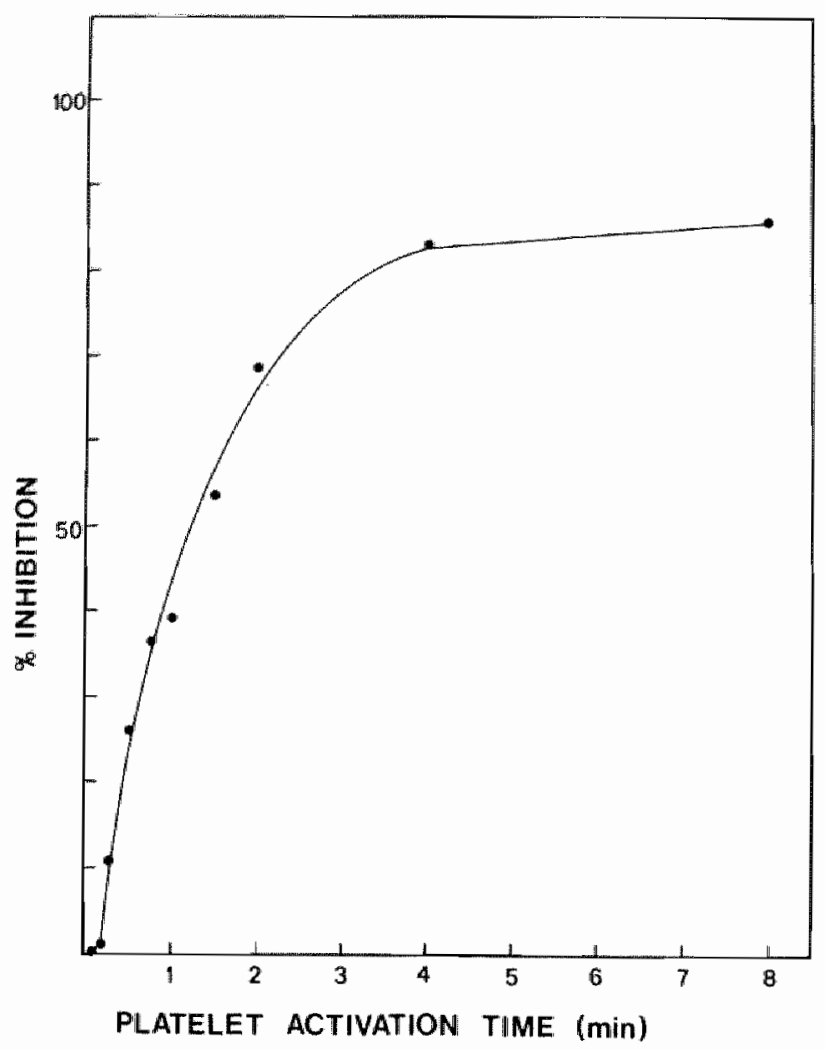

FIGURE 5. Time course of the appearance of inhibitory activity during platelet activaiion. Platelers $\left(2.6 \times 10^{\circ} / \mathrm{mL}\right)$ were stimulated at $37^{\circ} \mathrm{C}$ with thrombin $(0.2 \mathrm{nM})$ in the presence of $\mathrm{CaCl}_{2}(3 \mathrm{mM})$ under continuous stirring. At the vime points indicated, the release reaction was blocked by adding the prostacyclin analog ZK $36374(100 n M)$, and the plateler suspension. was centrifuged for 2 win in an Eppendor Microfuge to obtain the superwatant. After this, the $\mathrm{CaCl}_{2}$ concentration was adjusted to $10 \mathrm{mM}$, and facfor Xla was added and incubated with the supernatant for 20 min at $37{ }^{\circ} \mathrm{C}$, after which factor $I X$ arcivation was started with the addition of factor $I X$. The final activation mixthre contained $10 \mathrm{mM} \mathrm{CaCl}, 0.5 \mathrm{mg} / \mathrm{mL}$ human serum albumin. $100 \mathrm{nM}$ factor $1 X$, $0.1 \mathrm{nM}$ factor $X \mathrm{Ka}_{3}$ and supermatant of activated platelets $\left(2 \times 10^{8} / \mathrm{mL}\right)$ in $\mathrm{HEPES}$ buffer. The rate of factor $1 X$ activation in the reaction mixture was determined as described in Materials and Methods and was expressed as a percentage of the factor $I X$ activation rate measured in the presence of unstimulated platelets.

The release of inhibition was studied using the prostacyclin analog ZK 36374. This substance effectively blocks any further platelet aggregation (31) and platelet release reactions (32) when added to platelet suspensions (Figure 4). Addition of $100 \mathrm{nM}$ prostacyclin analogue prior to stimulation with 0.2 $\mathrm{nM}$ thrombin effectively blocked any release of inhibitory activity. The time course of release of inhibitor was determined by addition of $\mathrm{ZK} 36374$ at vari- 


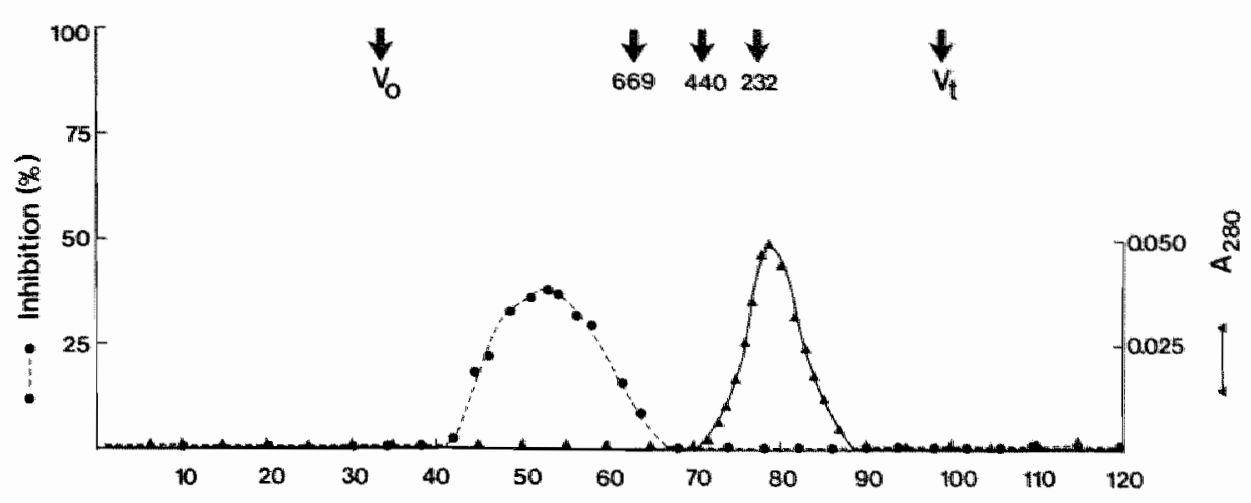

Fraction Number

FIGURE 6. ACA 22 gel filtration on the supermatant of stimulated platelets.

Platelets $\left(1.15 \times 10^{\circ} / \mathrm{mL}\right)$ were activated in the presence of $3 \mathrm{mMCaCl}$, whith $1.2 \mathrm{mM}$ thrombin and $10 \mu \mathrm{g} / \mathrm{mL}$ collagen at $37{ }^{\circ} \mathrm{C}$ for 15 minules in a total volume of 32.5 $m L$ HEPES buffer ( $p H 7.5$ ) containing $0.175 \mathrm{mg} / \mathrm{mL}$ human serum albumin. The stpernatant was obtained by centrifugation for 20 minutes at 15,000 rpm in a Beckman J2I B and subsequently concentrated eight-fold on an Amicon PM lo filler. Two milliliters were applied to an ACA 22 column $(2.5 \times 85 \mathrm{~cm})$ equilibrated in HEPES buffer (pH 7.5) at $4^{\circ} \mathrm{C}$. Elution was performed with the same buffer at a flow rate of 40 $m L / h$, and fractions of $4.5 \mathrm{~mL}$ were collected. Inhibitory activity was determined by incubating $450 \mu L$ of each fraction with $25 \mu L$ factor Xla ( $4 m M$ ) for 15 minutes at 37 ${ }^{\circ} \mathrm{C}$, after which $25 \mu \mathrm{L} S 2366(5.8 \mathrm{mM})$ was added and the rate of absorbance change at $405 \mathrm{~nm}$ recorded. The percentage of inhibitory activity was calculated from the amidolytic activity determined in the absence of inhibitor taken as 100\%. Calibration of the column was achieved in a separate run using dextran blue $2000\left(V_{0}\right)$, ihyroglobulin $(669,000)$, ferritin $(440,000)$, catalase $(232,000)$, and benzamidine $\left(V_{l}\right)$.

ous time intervals after the addition of thrombin to the platelets. The amounts of inhibitor activity released were then determined in the supernatant after centrifugation. Figure 5 shows that secretion of the inhibitor started after a small lag period of ten seconds and reached a plateau after a platelet activation time of approximately four minutes.

Preliminary Characterization of the Inhibitory Activity. To gain insight into the nature of the inbibitory activity secreted by platelets, the supernatant of a large amount of stimulated platelets $\left(1.8 .10^{10}\right)$ was collected, concentrated, and passed over a Sepharose ACA 22 column $(2.5 \times 85 \mathrm{~cm})$. Figure 6 shows that the inhibitory activity was included in the column volume but elured earlier than the largest molecular weight marker available $(669,000)$, thus precluding an accurate estimation of the apparent molecular weight. The fractions of the column containing inhibitor were pooled and concentrated after which a part was treated with trypsin-Sepharose. Table 2 shows that no inhibi- 
Table 2. The Effect of Trypsin on the Activity of the Imhibitor in the Factor $L X$ Activairon by Factor XIa

Activator

Rate of Factor IX

Activation

(pmol IXa/ $\mathrm{min} / \mathrm{mL})$

Factor XIa

3.97

Factor XIa, inhibitor

0.61

Factor Xla, inhibitor after incubation with Sepharose 4B $\quad 0.63$

Factor XIa, inhibitor after incubation with trypsin-Sepharose 4.06

Human factor IX was activated by human factor XIa at $37^{\circ} \mathrm{C}$ in HEPES buffer $(\mathrm{pH}$ 7.5) containing $100 \mathrm{nM}$ factor $1 X, 0.1 \mathrm{nM}$ factor $X I a, 0.5 \mathrm{mg} / \mathrm{mL}$ human serum albumin, and $10 \mathrm{mM} \mathrm{CaCl} \mathrm{L}_{2}$ in the absence or presence of the inhibitor. The rate of factor IXa formation was determined as described in Materials and Methods. Factor XIa has been preincubated with inhibitor for 15 min at $37^{\circ} \mathrm{C}$ before addition to the reaction mixture. The effect of trypsin on the inhibitor was determined by incubating $1.0 \mathrm{~mL}$ inhibitor with $0.25 \mathrm{~mL}$ trypsin-Sepharose slurry (or Sepharose $4 \mathrm{~B}$ as a control) at $4^{\circ} \mathrm{C}$. After $2 \mathrm{hr}$, the suspension was centrifuged and the supernatant added to factor XIa to determine the residual inhibitory activity. "The inhibitor preparation used was obtained from the ACA-22 column shown in figure 6. Fractions 48 to 58 of this column contained inhibitory activity and were poolled. Human serum albumin, $2.5 \mathrm{mg}$, was added to the pool $(44 \mathrm{~mL})$, which was subsequently concentrated terl-fold before use in the experiment described here.

Table 3. Effect of Dilution on the Activity of the Inhibitor in Factor IX Activation by Factor XIo

Activator

Rate of Factor IXa Formation

(pmole $\mathrm{IXa} / \mathrm{min} / \mathrm{mL}$ )

\begin{tabular}{|c|c|c|}
\hline & \\
\hline & Before Dilution & After Dilution \\
\hline Factor Xla $(0.1 \mathrm{nM})$ & 3.77 & 0.69 \\
\hline $\begin{array}{l}\text { Factor XIa }(0.1 \mathrm{nM}) \text {, supernatant } \\
\text { of } 2 \times 10^{8 / \mathrm{mL} \text { platelets }}\end{array}$ & 0.80 & 0.49 \\
\hline
\end{tabular}

Factor Xla (0.11 $\mathrm{nM}$ ) was incubated at $37^{\circ} \mathrm{C}$ in HEPES buffer ( $\mathrm{pH} 7.5$ ) containing $1 \mathrm{mg} / \mathrm{mL}$ human serum albumin and $10 \mathrm{mM} \mathrm{CaCl}$ in the presence or absence of supernatant from $2.2 \times 10^{8} / \mathrm{mL}$ stimulated platellets fobtained as described in the legend to Figure 6). After 15 minutes, part of this mixture was diluted five-fold in the same buffer and further incubated at $37^{\circ} \mathrm{C}$ for $30 \mathrm{~min}$ to allow reequilibration of factor XIa with inhibitor (see also legend to Figure 7). After this time interval, factor IX activation in each of these mixtures was determined by addition of factor IX so as to result in a final concentration of $100 \mathrm{nM}$. Final concentrations of factor Xla and platelet su pernatants reached are indicated in the table and were five-fold less in the diluted mixtures. The rate of factor IXa formation was then determined by withdrawing samples from these reaction mixtures at 2 and $4 \mathrm{~min}$ and assaying for factor $\mathrm{LX}$ as described in Materials and Methods. 


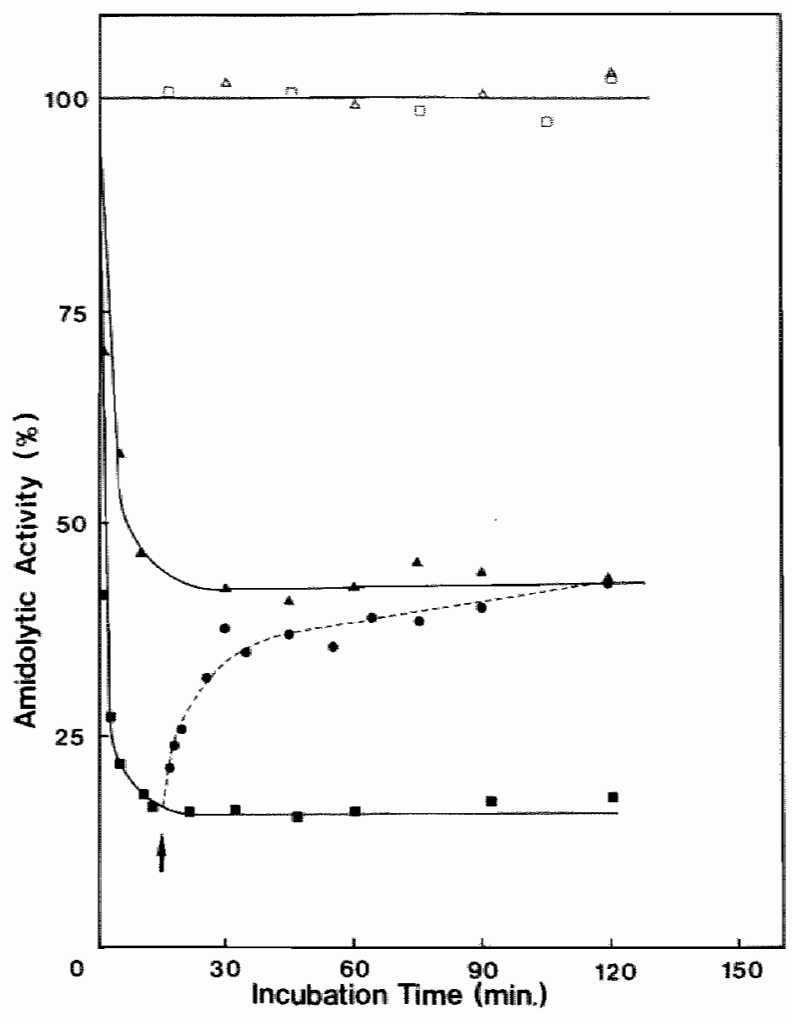

FIGURE 7. Reversibility of factor XIa inhibition.

The supernatant $(7.65 \mathrm{~mL})$ of $2.6 \times 10^{\circ} / \mathrm{mL}$ platelets (obtained as described in the legend to Figure 5) was incubated for five minutes at $37^{\circ} \mathrm{C}$, and $0.9 \mathrm{~mL}$ factor XIa (4 nM) was added. Immediately thereafter, $1.5 \mathrm{~mL}$ was subsampled and diluted fivefold in HEPES buffer containimg $0.5 \mathrm{mg} / \mathrm{mL}$ human serum albumin. The time course of inhibition in each reaction mixture was followed by subsampling $475 \mu L$ to a cuver at the time intervals indicated in the figure. Twenty-five $\mu L . \$ 2366(5.8 \mathrm{mM})$ werc ad. ded, and the rate of change of absorbance at $405-500 \mathrm{~mm}$ was determined at $37{ }^{\circ} \mathrm{C}$ on an Aminco DW2A Spectrophotometer. As a control, the amidolytic activity was followed over time in two reaction mixtures (prepared the same way) whout supernatant present. The final concentrations in each reaction mixure were $0.5 \mathrm{mg} / \mathrm{mL}$ human albumin in HEPES buffer ( $p H$ 7.5), factor XIa (0.4 nM), no platelet supernatant (D); factor XIa $(0.4 \mathrm{mM})$ and the supernatant of $2.2 \times 10^{8} / \mathrm{mL}$ platelets $(\mathbf{C})$; factor XIa $(0.08 \mathrm{mM})$ no platelet supernatant $\Delta ;$; and factor XIa $(0.08 \mathrm{nM})$ and the supernatant of $4.4 \times 10^{7} / \mathrm{mL}$ platelets $(\Delta)$. After equilibrium was reached, reversibility of the inhibition was verified by diluting part of the mixture containing the high concentrations of reactants five-fold and following the reappearance of anidolytic activity (*). The amidolytic activities determined for each reaction mixture in the presence of platelet supernatant were expressed as percentage of the activities determined in the reaction mixture containing corresponding amounts of factor XIa but without supernatant present ropen symbols). 


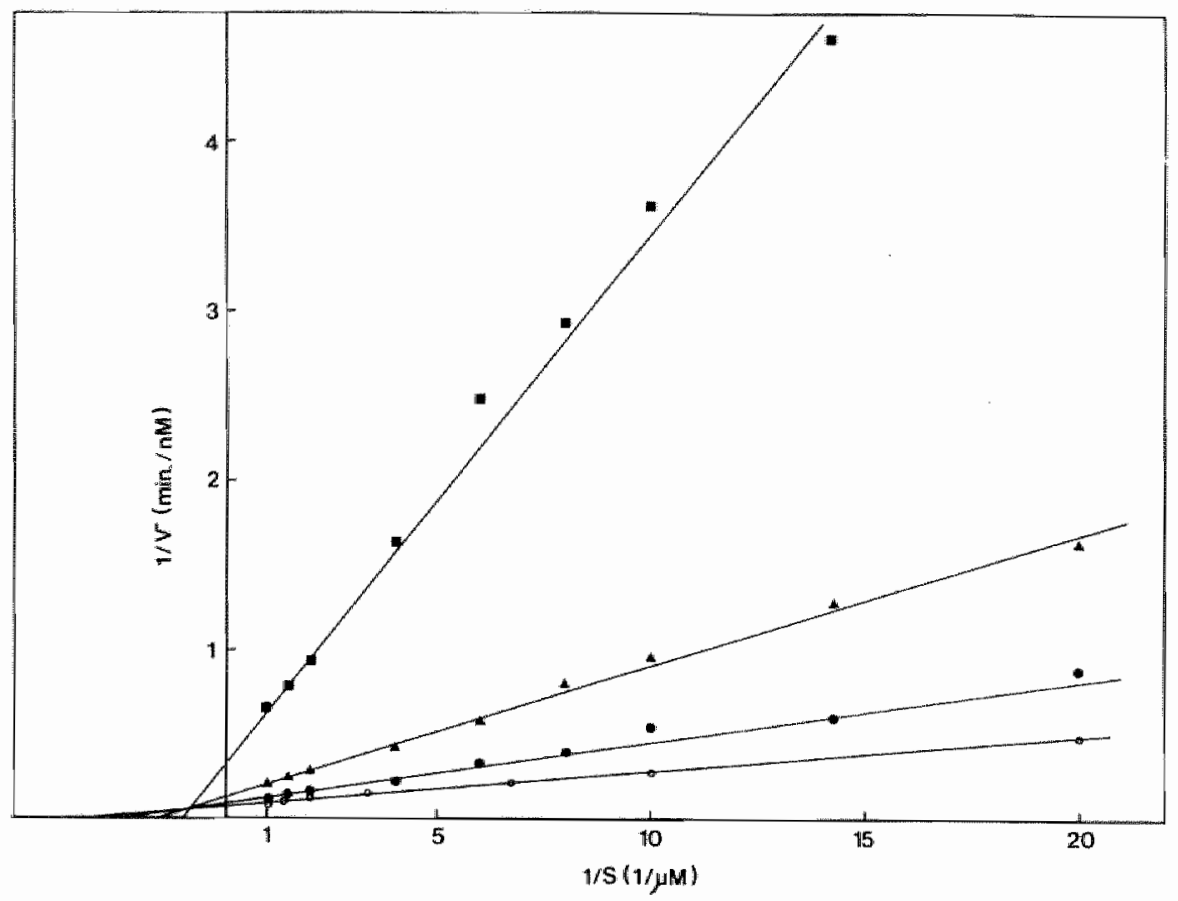

FIGURE 8. Limeweaver-Burk plots of factor $I X$ activation by factor XIa ar various inhibitor concentrations.

The kinetic parameters $\left(K_{m}\right.$ for factor $I X$ and $V_{\text {max }}$ ) were determined in the presence of varying amounts of inhibitor. Variation in the inhibitor concentrations was obtained by stimulating different platelet concentrations for twelve min at $37{ }^{\circ} \mathrm{C}$ in the presence of $3 \mathrm{mM} \mathrm{CaCl} 2$ with thrombin $(1.2 \mathrm{nM})$ and collagen $(10 \mu \mathrm{g} / \mathrm{mL})$ under contimwous stirring followed by centrifugation for two min in an Eppendorf Microfuge to obtain the supernatants. Subsequently, the $\mathrm{CaCl}_{2}$ concentration was adjusted to 10 $m M$, and factor XIa was added and incubaled for ten minutes at $37{ }^{\circ} \mathrm{C}$ before the addition of factor $I X$. The final reaction mixtures contained $10 \mathrm{mM} \mathrm{CaCl}, 0.5 \mathrm{mg} / \mathrm{mL}$ human serum albumin, varying amounts of factor $I X$, and 0.1 nM factor $X I$ a in HEPES buffer ( $p H$ 7.5) without inhibitor (O) and in the presence of supernatant obtained from $2 \times 10^{7} / \mathrm{mL}$ platelets $(\bullet), 6 \times 10^{7} / \mathrm{mL}$ platelets $(\Delta)$, and $2 \times 10^{8} / \mathrm{mL}$ platelets (四). Rates of factor IX activation were determined as described in Materials and Methods, and from these, the Lineweaver-Burk plots were constructed. The kineric parameters obtained were $14.4 \mathrm{nM}$ factor $1 X \mathrm{Xa} / \mathrm{min}$ and $0.3 \mu \mathrm{M}(\mathrm{O}) ; 10.0 \mathrm{mM}$ factor $I X a / m i n$ and $0.37 \mu M(\bullet) ; 7.9 \mathrm{mM}$ factor $L X a / m i n$ and $0.6 \mu M(\Delta)$ and $3.0 \mathrm{mM}$ factor IXa/min and $0.99 \mu M(\mathbb{M})$.

tory activity remained after this treatment, whereas a control experiment with only Sepharose showed no loss of inhibitory activity. When the experiment with the trypsin-treated inhibitor was repeated in the absence of factor XIa, no activation of factor IX was observed, indicating that no significant 
amounts of trypsin were coming off the beads (data not shown). The inhibitor was also destroyed when placed in boiling waterbath for one hour. From these data we conclude that the inhibitor is a protein or contains a protein part essential for its activity which is susceptible to trypsin and is heat labile.

The data in Table 3 show that the inhibitor did not destroy or irreversibly inhibit factor XIa. When factor XIa was incubated with a high amount of inhibitor, only $21 \%$ of the rate of factor IX activation remained. However, when this incubation mixture was diluted five-fold, the rate of factor IX activation was only 1.6 -fold less. Since rates of factor IX activation were linear with the amount of factor XIa present (see also the aforementioned), this indicated that some $50 \%$ of the factor XIa had become availabale again to participate in factor IX activation. The experiment in Figure 7 also illustrates this point. Here the time course of disappearance of factor XIa amidolytic activity towards the chromogenic substrate S 2366 was followed in an incubation mixture containing $0.4 \mathrm{nM}$ factor XIa and the supernatant of $2.2 .10^{8} / \mathrm{mL}$ activated platelets (closed squares). After equilibrium was reached, part of this mixture was diluted five-fold, and the remaining activity (expressed as percentage of the amount of factor XIa present) was followed with time (closed circles). As can be seen, the amidolytic activity increased in the difuted mixture until the same final level was found as in a mixture which had been diluted five-fold at time zero (closed triangles). Factor Xla activity was stable throughout the time course of the experiment in both diluted and undiluted mixtures in the absence of platelet supernatant (open symbols). These data indicate that the inhibition of factor XIa was completely reversible.

Figure 8 shows Lineweaver-Burk plots of factor IX activation by factor XIa in the presence of varying amounts of platelet supernatant. These data show that both $\mathrm{V}_{\max }$ and $\mathrm{K}_{\mathrm{m}}$ were affected, indicating that the inhibitor is of the mixed type.

\section{Discussion}

In this paper we report the effects of stimulated human platelets on the activation of human factor $\mathrm{IX}$ by factor XIa. We developed an assay that measures functional factor IXa via its ability to activate bovine factor $\mathrm{X}$ as described earlier (14) except that apart from phospholipids and $\mathrm{CaCl}_{2}$ also bovine factor VIIla was present in the assay. The presence of factor VIIIa increases the sensitivity some 3,000-fold but has the disadvantage that for each new batch of factor VIII a new standard curve must be made. When this is done, a good day-to-day reproducibulity can be achieved, and the assay allows accurate determination of factor IXa down to levels of $2.5 \mathrm{pmol} / \mathrm{mL}$ (Figure 1). Different batches of factor IXa, factor $X$, and phospholipid can be used 
interchangeably to produce the same standard curve provided equal amounts of these reagents are used. Using this assay, we determined the kinetic parameters of factor IX activation by factor XIa, and we found a $K_{m}$ for factor IX of $0.3 \mu \mathrm{M}$ and a $\mathrm{k}_{\text {cat }}$ of $2.4 \mathrm{~s}^{-1}$ per factor XIa molecule of $\mathrm{M}_{\mathrm{r}}$ 160 000 . Some disagreement exists in literature concerning these kinetic parameters. Walsh et al. (10) using factor Xla activated with bovine factor XIIa found a $\mathrm{K}_{\mathrm{m}}$ of $0.49 \mu \mathrm{M}$ and a $\mathrm{k}_{\mathrm{cal}}$ of $7.7 \mathrm{~s}^{-1}$, whereas Bajaj (13) using trypsin-activated factor XIa found a $K_{\mathrm{m}}$ of $2.0 \mu \mathrm{M}$ and a $\mathrm{k}_{\mathrm{cat}}$ of $0.34 \mathrm{~s}^{-1}$ (per $M_{1} \| 60,000$ factor XIa). Both these studies made use of the tritiated activation peptide release assay. The kinetic parameters determined by us are rather close to the data reported by Walsh et al. (10).

Using this assay, we determined the effect of platelets on the rate of factor IXa formation by factor Xla. The data reported here clearly demonstrate that stimulated platelets cause a dramatic decrease in the rate of factor IX activation by factor XIa, whereas unstimulated platelets have no effect. This inhibition is caused by a direct interaction with factor XIa, since steady-state rates of factor IXa formation can only be achieved by incubation of factor XIa with the stimulated platelets, whereas preincubation of factor IX has no effect (Figure 2). Moreover, factor XIa amidolytic activity towards the chromogenic substrate S2366 is also inhibited (cf. Figures. 6 and 7). Various platelet agonists can bring about this effect, the most potent being thrombin or the ionophore A 23187. The set of agonists that can induce this effect (Table I) as well as the rapid time course of appearance of inhibitory activity after stimulation of the platelets (Figure 5) suggests the involvement of a release reaction. This is in accordance with the finding that the inhibitory activity is quantitatively recovered in the supernatant after centrifugation in a microfuge for five minutes (Figure 3). The amount of inhibitory activity is dependent on the amounts of stimulated platelets present. Thus, under the conditions used in our experiments, factor IX activation is not affected by the presence of $10^{6} / \mathrm{mL}$ platelets. At the physiological platelet concentration $\left(2 \times 10^{8} / \mathrm{mL}\right)$, about $10 \%$ of the factor $\mathrm{IX}$ activition rate is left. Thus, the inhibitory activity reported here may play a role under physiological circumstances. However, more experiments will be needed to gain insight into this.

The high apparent molecular weight with which the inhibitor elutes from an ACA 22 column as well as the rather broad elution profile (cf. Figure 6) suggests that the inhibitor consists or is part of high molecular weight complexes. This may indicate that the inhibitor is associated with the so-called platelet dust (33). However, an essential part of the large inhibitor molecules eluting from the ACA 22 column must be proteinlike in nature, since the inhibitory activity was completeley destroyed after tryptic digestion. Moreover, 
the activity is also destroyed upon boiling. Therefore, at this moment we work under the hypothesis that the inhibitory activity is due to a protein that is released. This is most likely an antiprotease which reversibly blocks the factor XIa active sites both for factor IX activat on and for $\mathrm{S} 2366$ conversion, since the inhibition seems reversible (cf. Table 3 and Figure 6). This inhibition is of the mixed type as determined by Lineweaver-Burk analysis of factor IX activation by factor XIa in the presence of varying amounts of inhibitor (Figure 8).

The main plasma inhibitors of factor XIa are $\alpha_{1}$-antitrypsin and antithrombin III (34). $\alpha_{1}$-Antitrypsin is also present in platelets and can be secreted upon stimulation (35). However, these inhibitors have a much lower molecular weight and irreversibly block factor XIa. Therefore, our data do not suggest any involvement of these proteins in the inhibition that we observe in our experiments. At this moment we do not know whether under different experimental conditions the $\alpha_{1}$-antitrypsin present in platelets may become involved in the inhibition of factor IX activation by factor XIa.

It has been suggested that HMWK protects factor XIa against inactivation by plasma inhibitors (34), and a recent report of Schmaier et al. shows that HMWK can be secreted from human platelets upon stimulation (36). The results presented here show that despite these amounts of HMWK present in the platelets the rate of factor IX activation by factor XIa decreases in the presence of stimulated platelets. Sinha et al. have recently presented evidence that factor XIa needs HMWK to bind to stimulated platelets and that the amount of HMWK secreted by platelets is not sufficient to cause measurable factor XIa binding to triggered platelets (37). Therefore, it will be important to investigate whether factor XIa binding via HMWK to stimulated platelets can prevent the inhibition of factor IXa formation caused by stimulated platelets in the absence of external HMWK.

\section{Acknowledgement}

We thank dr. Gerbrand van Dieijen for inititating this investigation. Dr. J. Rosing and Dr. J. van Wersch are acknowledged for valuable discussions. We would also like to thank T. Camphuisen for typing this manuseript.

This paper has been published in Blood.

Soons, H., Janssen-Claessen, T., Hemker, H. C., and Tans, G.

The Effect of Platelets in the Activation of Human Blood Coagulation Factor IX by Factor XIa.

Blood 1986, 68: pp 140-148. 


\section{REFERENCES}

1. Davie EW, Füjkawa K: Basic mechanisms in blood coagulation. Annu Rev Biochern 44: 799,1975

2. Di Scipio $R G$, Kurachi $K$, Davie EW.: Activation of human factor IX (Chrisimas factor). J Clin Invest 61: 1528, 1978

3. Osterud $\mathrm{B}_{*}$ Bouma BN, Griffin, JH: Human blood coagulation factor IX: Purification, properties and mechanism of activation by activated factor $X I$. I Biol Chem 253: 5946, 1978

4. Osterud B, Rapaport SI: Activation of factor IX by the reaction product of tissue factor and factor VII: Additional pathway for initiating blood coagulation. Proc Natl Acad Sci USA 74: 5260,1977

5. Zur M, Nemerson Y: Kinetics of Factor IX activation wia the extrinsic pathway: Dependence of K.m on tissue factor. J Biol Chem 255: 5703,1980

6. Rosing $J_{\text {v }}$ van Rijn JLML $L_{\text {, }}$ Bevers EM, van Dieijen $G$, Comfurius $P$, Zwaal RFA: The role of activated human platelets in prothrombin and factor $X$ activation. Blood $65: 319,1985$

7. Watsh PN: The effects of collagen and kaolin on the intrinsic coagulant activities of platelets. Evidence for an alternative pathway in intrinsic coagulation not requiring factor XIL. Br I Heamatol 22: 393, 1972

8. Walsh PN, Griffin JH: Contributions of human platelets to the proteolytic activation of blood coagulation factors XII and XI. Blood 57: 106, 1981

9. Osterud B, Harper E, Rapaport $S$, Lavine $K$.: Evidence against collagen activation of platelet-associated factot $\mathrm{XI}$ as a mechanism for initiating intrinsic clotting. Scand $J \mathrm{Hae}-$ matol 22: 205, 1979

10. Walsh PN, Bradfrod H, Sinha D, Piperno JR, Tuszynski GP: Kinetics of the factor XIa catalyzed activation of human blood coagulation factor IX. J Clin Invest 73: 1392, 1984

11. Enfield DI, Thompson AR.: Cleavage and activation of human factor IX by serine prom teases. Blood 64: 821,1984

12. Griffith MJ, Breitkreuz L. Trapp $\mathbb{H}$, Briet E, Noyes CM, Lundblad RL, Roberts HR: Characterization of the clotting activities of structurally different forms of activated factor IX: Enzymatic properties of normal human factor IXac, factor IXa $\beta$ and activated factor IX Chapel Hill. J Clin Invest $75: 4,1985$

13. Bajaj $\mathrm{SP}$ : Cooperative $\mathrm{Ca}^{2}+$ binding to human factor $\mathrm{IX}$ : Effects of $\mathrm{Ca}^{2}$ * on the kinetic parameters of the activation of factor IX by factor XIa.J Biol Chem 257: 4127, 1982

14. Tans $\mathrm{G}$, Janssen-Claessen $\mathrm{T}$, wan Dieijen $\mathrm{G}$, Hemker HC, Rosing J: Activation of factor IX by factor XIa: A spectrophotometric assay for factor IXa in human plasma. Thromb Haemostas $48: 127,1982$

15. Silverberg SA, Nemerson $Y, Z$ Zur M.: Kinetics of the activation of bovine coagulation factor $X$ by components of the intrinsic pathway: Kinetic behaviour of two chain factor VII in the presence and absence of tissue factor. $\$ Biol Chem 252: 8481, 1979

16. Takati A, Enlield DL. Thompson AR: Cleavage and inactiwation of factor IX by granulocyte elastase. I Clin Invest 72: 1706, 1983

17. Di Scipio RG, Hermodson MA, Yates SG, Davie EW: A comparison of human prothrombin, factor IX (Christmas factor), factor X, (Stuart factor), protein S. Biochemistry 16:698, 1977

18. Miletich JP, Brose GJ, Majerus PW: The synthesis of sulfated dextran beads for isolation of human piasma coagulation factor II, IX and X. Anal Biochem 105: 304, 1980

19. wan Dieijen $\mathrm{G}$, Tans $\mathrm{G}$, Rosing $\mathrm{J}$, Hemker $\mathrm{HC}$ : The role of phospholipid and factor VIIIa in the activation of bovine factor $X$. J Biol Chem 256, 3453, 1981

20. Bouma BN, Vlooswijk RAA, Griffin JH: Immunologic studies of human coagulation factor XI and its complex with high molecular weight kininogen. Blood 62: 1123, 1983

21. Griffin JH, Cochrane CG: Human factor XII (Hageman factor). Meth Enzymol 45: 56, 1976

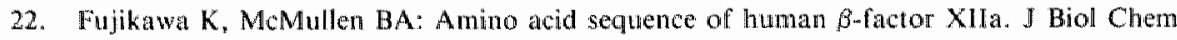
$258: 10924,1983$ 
23. Fujikawa $K_{n}$ Legaz ME, Davie EW: Bowine factor $X_{1}$ and $X_{2}$ (Stuart factor): Isolation and characterization. Biochemistry 11:4882, 1972

24. van Dieijen G, wan Rijn JLML, Govers-Riemslag JWP, Hemker HC, Rosing J: Assembly of the intrinisic factor $\mathrm{X}$ activating complex: Interactions between factor IXa, factor VIlla and phospholipid. Thromb Haemostas 53: 376, 1985

25. Rosing $J$, Tans $\mathrm{G}$, Govers-Riemslag JWP, Zwaal RFA, Henker HC: The role of phospholipid and factor $\mathrm{Va}$ in the prothrombinase complex. B Biol Chem 255: 274, 1980

26. Laemmli UK: Cleavage of structural proteins during the assembly of the head of bacteriophage T4. Nature 227: 680 , 1970

27. van der Graaf $F_{n}$ Greengard IS, Bouma BN, Kerbiriou DM, Griffin JH: Isolation and functional characterization of the active light chain of activated human blood coagulation factor XI. I Biol Chem 258: 9669,1983

28. Bradford MM: A rapid and sensitive method for the quantitation of microgram quantities of protein utilizing the principle of protein-dye binding. Anal Biochem 72: 248, 1976

29. Eisenthal $\mathrm{R}$, Cornish-Bowden A: The direct linear plot: A new graphical procedure for estimating enzyme kinetic parameter. Biochern. J. 139: 175, 1974

30. van Rijn JLML, Rosing J, wan Dieijen G: Activity of human blood platelets in prothrombin and factor $X$ activation induced by ionophore A23187. Eur J Biochem 133: 1, $\| 983$

31. Schrör K, Darius $H$, Matzky $R$, Ohlendorf $R$ : The antiplatelet and cardiovascular actions of a new carbacyclin derivate (ZK 36374): Equipotent to $\mathrm{PGI}_{2}$ in vitro. Arch Pharmacol 316: 252,1981

32. Baruch D, Hemker HC, Lindhout T: Kinetics of thrombin induced platelet factor $V$ rellease and activation. Eur J Biochem 154: 213, 1986

33. Bode AP, Sandberg H, Dombrose FA, Lentz BR: Association of factor V activity with membranous vesicles released from human platellets: Requirement for platelet stimulation. Thromb. Res. 39: 49, 1985

34. Scott CF, Schapira M, James HL, Cohen AB, Colman RW: Inactivation of factor XIa by plasma protease inhibitors: Predominant role of $\alpha_{1}$-protease inhibitor and protective effect of high molecular weight kininogen. $\mathrm{J}$ Clin Invest 69: 844, 1982

35. Bagdasarian A, Colman RW: Subcellular localization and purification of platelet $\alpha_{1}$-antitrypsin. Blood 51: 139, 1978

36. Schmaier AH, Zuckerberg A, Silverman C, Kuchibhotla J, Tuszynski GP, Colman RW: High molecular weight kininogen, a secreted platelet protein. J Clin Invest 71: 1477, 1983

37. Sinha D, Seaman FS, Koshy A, Knight LC, Walsh PN.: Blood coagulation factor Xla binds specifically to a site on activated human platelets distinct from that for factor XI. J Clin Invest $73: 1550,1984$ 



\section{CHAPTER VI}

\section{General discussion}

Intrinsic coagulation is initiated when normal plasma comes in contact with negatively charged surfaces, such as glass, kaolin or sulfatides. This so-called contact activation results in the formation of factor XIa. This is the enzyme that links the contact activation system to intrinsic factor IX activation. The data presented in this thesis concern the regulation of the factor Xla dependent activation of factor IX by naturally occuring inhibitors and by platelets.

It is already known from the literature that plasma contains four protease inhibitors of factor XIa (1). Table 1 shows the rate constants of inhibition of factor XIa by these inhibitors. These rate constants are relatively low and using the concentration of each inhibitor present in plasma it has been suggested that $\alpha_{1}$-antitrypsin is the main plasma inhibitor of factor XIa. However, inhibition of factor XIa by antithrombin III can be accelerated in the presence of heparin (2) and consequently antithrombin III may under certain conditions become the main inhibitor of factor XIa circulating in plasma. In the first part of this general discussion we will go into more detail concerning our studies on the mechanism of inhibition of factor XIa by antithrombin III and the effect of heparin in this inhibition. The data in Table I also illustrate that the four plasma inhibitors are relatively poor inhibitors of factor XIa and it will take minutes rather than seconds to inhibit half of the factor XIa present at a certain time in plasma. Therefore, other regulatory systems of factor XIa may have to be involved in order to inhibit factor XIa if needed. As shown in this thesis blood platelets might provide such an extra regulator. Blood platelets are generally thought of as strong stimulators of the blood coagulation reactions. They contain cofactors of several of the blood coagulation reactions and can serve as a surface on which these reactions take place. However, platelets also contain inhibitors such as $\alpha_{1}$-antitrypsin, $C_{1}$-inhibitor 
Table 1. Relative contributions of plasma protease inhibitors of factor XIa.

\begin{tabular}{|c|c|c|c|c|}
\hline inhibitor & $\left.\mathrm{k}^{\prime-1} \cdot \mathrm{min}^{-1}\right)$ & $\stackrel{[1]}{(\mu \mathrm{M})}$ & $\begin{array}{l}\mathrm{k}^{\prime} \\
\left(\min ^{-1}\right)\end{array}$ & $\begin{array}{l}t / 2 \\
(\min )\end{array}$ \\
\hline$a_{0}$-antitrypsin & $1.3 \quad 10^{4}$ & 45.4 & 0.59 & 1.17 \\
\hline antithrombin $\mathrm{Ill}$ & $3.0 \quad 10^{4}$ & 4.7 & 0.14 & 4.95 \\
\hline$C_{\text {-inhibitor }}$ & $4.0 \quad 10^{4}$ & 1.7 & 0.069 & 10.05 \\
\hline$a_{2}$-antiplasmin & $6.0 \quad 10^{4}$ & 1.1 & 0.066 & 10.50 \\
\hline
\end{tabular}

This table summarizes some characteristics of the four main plasma inhibitors of factor XIa. $k$ "ss the second order rate constant, [1] is the plasma inhibitor concentration, $\mathrm{k}^{\prime}$ is the pseudo first order rate constant derived by multiplying $\mathrm{k}^{\prime \prime}$ by [1], and $t / 2$ is the time necessary to inhibit half of factor Xla activity at the plasma inhibitor concentration. Taken from ref. (1).

and antithrombin III, that are released upon stimulation and that could be involved in keeping some of these reactions under control. The involvement of platelets on the activation of factor IX by factor XIa will be discussed in the second part of this general discussion.

\section{Plasma inhibitors of factor XIa.}

Factor XIa is the enzyme that links the contact activation system to the intrinsic activation of factor $\mathbb{I X}$. It is a dimeric enzyme and it is composed of two heavy chains and two light chains. Each light chain contains an active site. It is the only known enzyme participating in blood coagulation that contains two active sites $(3,4)$. Antithrombin III can inactivate factor XIa and the stoichiometry of the formed complex has been shown to be 1 mol of factor Xla and 2 mol of inhibitor, indicating that both active sites interact with antithrombin III (4). In the presence of excessive inhibitor concentrations, the inactivation of factor Xla follows pseudo first order reaction rate kinetics and the final reaction product, factor XIa complexed with two antithrombin III"s, has no amidolytic activity $(1,4)$. This indicates that either both active sites of factor Xla are inhibited simultaneously or both active sites are inhibited independent of each other with the same rate constant. The experiments presented in Chapter II clearly demonstrate the occurrence of an intermediate, consisting of one factor Xla with one antithrombin III molecule as a transient product during the time course of the reaction. This is the first time that this intermediate has been unequivocally demonstrated. The presence of this intermediate and the fact that pseudo first order reaction rate kinetics are observed during the whole time course of inactivation can best be explained by a mechanism in which both active sites of factor XIa interact with antithrombin 
III independent of each other with the same rate constant. The intermediate is seen during the inactivation of factor XIa by antithrombin III in the absence and presence of heparin. The inactivation of factor XIa by antithrombin III in the presence of heparin also follows pseudo first order reaction rate kinet ics. This suggests that also in the presence of heparin both active sites are inactivated independent of each other with the same rate constant.

The inhibition of factor XIa by antithrombin III in the presence of heparin is a three component reaction and the measured first order rate constant appears saturable with respect to antithrombin III and heparin. This suggests that the rate of inactivation of factor XIa by antithrombin III in the presence of heparin is a direct measure for the binding of antithrombin III to heparin. Analysis of the kinetic data according to this assumption give a $K_{d}$ of 142 $\mathrm{nM}$ for antithrombin III binding to heparin, which is in good agreement with that reported in literature (5). The obtained stoichiometry of the interaction of antithrombin III with heparin ( $0.42 \mathrm{~mol}$ antithrombin $\mathrm{IIL} / \mathrm{mol}$ heparin) was confirmed for the used reactants by independent measurement using the fluorescence technique described by Nesheim et al. (6). Therefore, it seems justified to conclude that the stimulation of the reaction by heparin is due to the binding of antithrombin III to heparin (Chapter II).

With regard to the kinetics of heparin catalyzed enzyme inhibition by antithrombin III, the coagulation enzymes may be divided into two groups. In one group (factors Xa and XIIa) it is thought that the stimulation is solely due to binding of antithrombin III to heparin and that binding of the enzyme to heparin is not required. The reaction rate is proportional to the amount of heparin-antithrombin III complexes and increases with increasing heparin concentrations untill finally a plateau is reached. In the second group (thrombin and factor IXa) binding of the enzyme is also required to obtain optimal reaction rates. In this group the reaction rate increases with increasing heparin concentration $\left(10^{-9}\right.$ to $\left.10^{-5} \mathrm{M}\right)$, reaches a pseudo plateau and subsequently decreases at high heparin concentrations (7). The data, presented in Chapter II, show that the inactivation rate of factor XIa is a direct measure for binding of antithrombin III to heparin. This suggests that factor XIa is a member of the first group. In Chapter III data are presented, concerning the inhibition of factor Xla by antithrombin III in the presence of different well characterized heparin preparations. In the presence of these preparations the inactivation of factor XIa by antithrombin III can also be satisfactorily explained in terms of binding of antithrombin III to heparin. However, the final magnitude of the rate constant obtained at saturating heparin concentrations is dependent upon the type of heparin used. The most likely explanation for this is that factor XIa-heparin interactions influence the rate of inactivation of 
Table 2. Second order rate constants of inactivation of factor Xla by antithrombin III in the presence and absence of saturating heparin.

\begin{tabular}{lllll} 
& - heparin & theparin \\
\hline Scott et al. (ref. J0) & 3.1 & $10^{4}$ & 1.51 & $10^{5}$ \\
Beeler et al. (ref. 11) & 0.47 & $10^{4}$ & 1.59 & $10^{5}$ \\
present study & 6.0 & $10^{4}$ & 16.0 & $10^{5}$ \\
\hline
\end{tabular}

factor XIa by antithrombin III bound to heparin. This is supported by the observation that factor XIa has affinity for heparin-Sepharose (8). Firm conclusions considering an interaction between factor XIa and heparin can however not be drawn untill direct binding experiments are performed. Nonetheless, the data of chapters II and III show that the stimulation of factor XIa inactivation by antithrombin III in the presence of heparin can be quantitatively correlated to the binding of antithrombin III to heparin and that this heparin catalyzed inhibition of factor Xla is not only dependent upon the degree of binding of antithrombin III to heparin, but also upon the type of heparin to which antithrombin III is bound.

The data reported in this thesis also give some additional insight in the importance of antithrombin III as an inhibitor of factor XIa in plasma. As already mentioned in the beginning of this discussion four plasma protease inhibitors have been reported to inactivate factor XIa. From the second order rate constants for the inactivation of factor XIa which are available in literature it can be predicted that $\alpha_{1}$-antitrypsin accounts for $68 \%$, antithrombin III for $16 \%$ and that $C_{1}$-inhibitor and $\alpha_{2}$-antiplasmin each account for $8 \%$ of the total inhibitory activity of plasma against factor XIa (1). However, the inactivation of factor XIa by antithrombin III is accelerated in the presence of heparin. In the literature there is no agreement on the rate enhancement of the inactivation of factor XIa caused by heparin (9). For comparison, the second order rate constants of the inactivation in the absence and in the presence of saturating heparin concentrations reported in the literature and obtained in the present study are shown in table 2 . The rate enhancement induced by heparin, reported in the present study, is in good agreement with the value reported by Beeler et al. (11). However, the actual values of the rate constant reported here are 10-fold higher than reported by Beeler et al. The rate constant obtained in the absence of heparin agrees with the value reported by Scott et al. (10). Beeler et al. have argued that under certain conditions antithrombin III may become a physiologically significant inhibitor of factor XIa (11). The data presented in this study can be regarded to support this concept. However, as will be discussed later, the conditions in whole plasma are 
much more complicated than those in purified systems. Therefore, much more will need to be done to gain insight in the biological importance of the regulation of factor Xla inactivation by antithrombin III.

The effect of platelets in the activation of factor IX by factor XIa.

Factor XIa can efficiently activate factor IX in the presence of calcium ions. The kinetic parameters reported in the literature are summarized in table 3. The first two reports showed a considerable difference in the kinetic parameters $(12,13)$. Reinvestigation of the kinetic parameters by both groups have resulted in a consensus concerning the actual values of these parameters $(14,15)$. In all four investigations the tritiated activation peptide release assay was used to measure the rate of factor IX activation. In the present study an assay was used that measures functional factor IXa activity via its ability to activate bovine factor $X$ in the presence of phospholipids and calcium ions. To increase sensitivity bovine factor Vllla was also present in the assay. The kinetic parameters for the activation of factor IX by factor XIa in the presence of calcium obtained with this assay are in good agreement with the data reported in the literature (Table 3). The catalytic efficiency $\left(\mathrm{k}_{\mathrm{cat}} / \mathrm{K}_{\mathrm{m}}\right)$ of factor IX activation in the absence of a cofactor and a surface is relatively high as compared to the other reactions of the cascade. For example, the activation of prothrombin by factor Xa in the presence of calcium $\left(k_{c a r} / K_{m}=\right.$ $\left.0.008 \mathrm{~min}^{-1} \mu \mathrm{M}^{-1}\right)$ is four orders of magnitude slower than the activation of factor IX by factor XIa. This can be regarded as an indication that actually no surface or cofactor are required since the activation of factor IX by factor XIa is already an efficient reaction.

Table 3. Kinetic parameters of the activation of factor $I X$ by factor XIa.

\begin{tabular}{|c|c|c|c|c|c|}
\hline & & & $K_{m}(\mu \mathrm{M})$ & $\mathrm{k}_{\mathrm{atat}}\left(\operatorname{minin}^{-1}\right)^{*}$ & $\mathrm{k}_{\mathrm{cat}} / \mathrm{K}_{\mathrm{si}}\left(\mu \mathrm{M}^{-1} \min ^{-1}\right)$ \\
\hline Bajaj & 82 & (12) & 2.0 & 10.4 & 5.5 \\
\hline Walsh al. & 84 & (13) & 0.49 & 231.0 & 471.4 \\
\hline $\begin{array}{l}\text { Warn-Cramer } \\
\text { and Bajaj }\end{array}$ & " 86 & (14) & 0.31 & 25,0 & 80.6 \\
\hline Sinha et al. & 87 & (15) & 0.37 & 39.6 & 107.0 \\
\hline present study & & & 0.37 & 84.0 & 227.0 \\
\hline
\end{tabular}

${ }^{*} \mathrm{~K}_{\text {cat }}$ is expressed per active site of factor XIa. 
As mentioned in Chapter 1 , the role of platelets in the activation of factor IX by factor XIa has not yet been established. In Chapter $V$ experiments are described, that were performed to gain more insight in the effect of platelets on the rate of factor IXa formation by factor XIa. The data clearly demonstrate that stimulated platelets cause a dramatic decrease in the rate of activation of factor IX by factor XIa, whereas unstimulated platelets have no effect. This inhibition is caused by a direct interaction with factor XIa and not by binding of factor $\mathbb{X}$ to the activated platelets. This conclusion is based on several abservations. Steady-state rates of factor IXa formation can only be achieved by preincubation of factor Xla with the stimulated platelets, whereas preincubation with factor IX has no effect. The amidolytic activity of factor Xla towards the chromogenic substrate S2366 is also inhibited. Further, after centrifugation the inhibitory activity is quantitatively recovered in the supernatant.

Further, the data of Chapter $V$ suggest that the inhibitor consists or is part of high molecular weight complexes and is a protein that is released by the platelets. The inhibitor is an antiprotease that reversibly blocks the factor XIa active sites both for factor $\mathbb{I X}$ activation and for $\mathrm{S} 2366$ conversion. This indicates that the inhibitor is not one of the main plasma inhibitors, $\alpha_{1}$-antitrypsin, antithrombin III or $\mathrm{C}_{1}$-inhibitor, of factor XIa. These inhibitors have been shown to be present in platelets but they irreversibly inhibit factor XIa. From this it can be inferred that the initial inhibition of factor XIa by stimulated platelets is not caused by the release of $\alpha_{1}$-antitrypsin, antithrombin III or $\mathrm{C}_{1}$-inhibitor but by the release of another inhibitor. Recently, similar findings were reported by Walsh et al. (16).

The question however, remains as to what role this inhibitor may have in the hemostatic process. Walsh et al. introduced a hypothesis that phatelets can actually regulate the activation of factor $\mathbb{I X}$ by factor XIa in two ways. One way is by secreting this inhibitor of factor XIa, which acts primarily outside the platelet microenvironment. The second way is by protecting factor XIa against this inhibitor by binding via specific receptors to platelets, thereby localizing factor $\mathrm{IX}$ activation to the platelet plug. This second way originates from the fact that platelets have been reported to contain specific receptor sites of factor XIa $(17,18)$ and factor IX $(19)$ which are exposed upon stimulation. Moreover, Walsh et al. have shown that factor XIa bound to platelets is still capable of efficiently activating factor $\mathrm{IX}$ which is added to an isolate platelet preparation containing bound factor XIa (20). It is however not known whether under these conditions factor XIa activates factor IX which is bound to the platelets or whether factor IX out of the fluid phase is activated. To gain more insight in whether factor XIa is actually capable of activat- 
ing bound factor IX the experiments presented in Chapter IV were performed. As a model-surface negatively charged phospholipid vesicles were used.

It is generally thought that upon stimulation the platelets expose negatively charged phospholipids at the outer layer of the membrane bilayer and that this negatively charged bilayer serves as a surface on which vitamin K-dependent protein activations take place (21). Factor $\mathrm{X}$ and prothrombin activation are accelerated by the presence of calcium and phospholipids. In literature some reports are available concerning a possible effect of negatively charged phospholipids on the activation of factor IX by factor XIa $(14,22,23)$. It has been reported that phospholipids enhance (22), have no influence (23) or even inhibit (14) the activation of factor IX by factor XIa. The data presented in this study clearly demonstrate that negatively charged phospholipids inhibit the activation of factor IX by factor XIa in the presence of calcium, whereas neutral phospholipid vesicles have no influence on the reaction rate. A possible explanation for the inhibition of factor IX activation caused by negatively charged phospholipids can be obtained by assuming that phospholipid-bound factor IX cannot or can only be activated at a much lower rate by factor Xla. This assumption is derived from several reports recently published in the literature. First, the binding data of human factor IX binding to negatively charged phospholipid vesicles have been reported (24). Second, it has been shown that the presence of the heavy chain of factor Xla accelerates the activation of factor IX in the presence of calcium ions at least a hundred fold $(15,23)$. Finally, it has been reported that the domain of factor IX required for calcium-dependent binding to phospholipids is also essential in the calcium-dependent activation of factor IX by factor XIa (25). From this last mentioned report it may be inferred that phospholipid vesicles can compete with the heavy chain of factor XIa for the same domain of calcium stabilized factor IX. As a result factor IX bound to phospholipids lacks the interaction with the heavy chain of factor XIa and will be activated at least a hundred fold slower than free factor IX. Under the just derived assumption analysis of the experimental data yield a $\mathrm{K}_{\mathrm{d}}$ of $0.26 \mu \mathrm{M}$ and 0.022 moles binding sites per mole phospholipids for the binding of factor $\| X$ to the negatively charged phospholipid vesicles used in the present study (Chapter IV). These data are in good agreement with the values reported in the literature (24). Using light scattering a $\mathrm{K}_{\mathrm{s}}$ of $1.0 \mu \mathrm{M}$ and 0.023 factor IX binding sites per phospholipid were reported for the binding of factor IX to negatively charged phospholipid vesicles $(\mathrm{PS} / \mathrm{PC}=25 / 75)$. This good agreement, concerning the binding parameters, strongly supports the assumption that phospholipid bound factor IX is not or much less activated by factor Xla. It also suggests that negatively charged phospholipids will probably not be the surface on which factor IX activation by factor Xla will take place if indeed a surface is at all required. 
In summary, the work presented in this thesis has given some new insights in a possible regulatory function of platelets in the activation of factor IX by factor Xla. The data suggest that platelets localize the factor IX activation to the platelet plug by secreting an inhibitor that inactivates free factor XIa and by protecting bound factor Xla against inhibition. The position of factor IX in this platelet mediated factor IX activation by factor XIa is not yet known. Negatively charged phospholipids are probably not the binding site at which factor IX is activated. Maybe the recently reported specific receptor of factor IX at stimulated platelets can serve as the binding site at which factor IX is activated. With respect to this it should not be forgotten that the activation of factor IX by factor XIa in the fluid phase needs no surface or cofactor to be efficient. From this a possible alternative mechanism can be inferred in which factor IX is activated in the fluid phase and the activation rate is solely regulated by platelet-factor XIa interactions.

\section{References}

1. Scott, C. F., Schapira, M., James, H. L., Cohen, A. B. and Colman, R. W. (1982) J. Clin. Invest. $69,844-852$

2. Damus, P. S., Hicks, M. and Rosenberg, R. D. (1973) Naure (London) 246, 355-357

3. Bouma, B. N. and Griffin, J. H. (1977) J. Biol. Chem. 252, 6432-6437

4. Kurachi, K. and Davie, E. W. (1977) Biochemistry 16, $5831-5839$

5. Griffith, M. J. (1982) J. Biol. Chem. 257, 13899-13902

6. Nesheim, M., Blackburn, M. K. llawler, C. M. and Mann, K. G. (1986) N. Biol. Chen. $261,3214-3221$

7. Jordan, R. E., Oosta, G. M. , Gardner, W. T, and Rosenberg, R. D. (1980) J. Biol. Chem. $255,10081-10090$

8. Qsterud, B. and Rapaport, S. I. (1977) Proc. Natl. Acad. Sci. USA 74, 5260-5264

9. a. Colman, R. W. and Scott, C. F. (1987) Blood 69, 703 (letter)

b. Beeler, D. L., Marcum, J. A., Schiffman, S. and Rosenberg, R. D. (1987) Blood 69, 704 (letter)

10. Scoti, C. F., Schapira, M. and Colman, R. W. (1982) Blood 60, 940-947

11. Beeler, D. L., Marcum, J.A., Schiffman, S. and Rosenberg, R. D. (1986) Blood 67 , $1488-1492$

12. Bajaj, S. P. (1982) J. Biol. Chent. 257, 4127-4132

13. Walsh, P.N., Bradford, H., Sinha, D., Piperno, J. R. and Tuszynski, G. P. (1984) J. Clin. Invest. 73, 1392-1399

14. Warn-Cramer, B. J. and Bajaj, 5. P. (1986) Biochem. J. 239, $757-762$

15. Sinha, D., Seaman, F. S. and Walsh, P. N. (1987) Biochemistry 26, 3768-3775

16. Winlsh, P. N., Sinha, D., Kueppers, F., Seaman, F. S. and Blankstein, K. B. (1987) Thromb. Haemostas. 58, 2 (abstract)

17. Sinha, D., Seaman, F. S., Koshy, A., Knight, L. C. and Walsh, P. N. (1984) J. Clira. Invest. $73,1550-1556$

18. Greengard, J. S., Heeb, M. J., Eesdal, E., Walsh, P. N, and Grifin, J. H. (1986) Biochemistry $25,3884-3890$

19. Ahmad, S. S., Rawala, R. and Walsh, P. N. (1987) Thromb. Haemostas. 58, 351 (abstrac)

20. Walsh, P. N., Sinha, D., Koshy, A., Seaman, F. S. and Bradford, H. (1986) Blood 68, 225-230 
21. Zwaal, R. F. A., Bevers, E. M. and Comfurius, P. (1986) In Blood Coagulation (2wal, R. F. A and Hemker, H. C. , editors), 141-169, Elsevier, Amsterdam.

22. Mannhalter, C., Schiffman, S. and Deutsch, E. (1984) Br. J. Haenatol. 56, 261-271

23. Van der Graaf, F., Greengard, J. S., Bouma, B. N., Kerbiriou, D. M. and Griffin, J. H. (1983) J. Biol. Chem. 258, $9669-9675$

24. Jones, M. E., Griffith, M. J., Monroe, D. M., Roberts, H. R. and Lentz, B. R. (1985) Biochemistry 24, 8064-8069

25. Liebman, H. A., Furie, B. C. and Furie, B. (1987) J. Biol. Chem. 262, 7605-7612 



\section{SUMMARY}

In this thesis work is presented which gives insight in the various mechanisms via which blood coagulation factor XIa can be regulated. Factor XIa is the enzyme that links intrinsic coagulation to the contact activation system. It is the only known enzyme, participating in blood coagulation, that contains two active sites. Inhibition of these active sites can be accomplished by the plasma inhibitor, antithrombin III, in a reaction in which each active site of factor XIa irreversibly binds an antithrombin III molecule. The data presented in Chapter II show that this inhibition occurs via a mechanism in which both sites are inhibited independent of each other with the same rate constant. The rate of inhibition of factor XIa by antithrombin III can be stimulated by heparin. In Chapter II and III is shown that this stimulation can be used to determine the binding of antithrombin III to heparin. In addition, the data of Chapter III suggest that the rate of inhibition of factor XIa in the presence of heparin is not only determined by the degree of binding of antithrombin III to heparin, but that it is also dependent upon the type of heparin to which antithrombin III is bound.

Factor XIa is capable of efficiently activating intrinsic blood coagulation factor IX in a reaction that is stimulated by calcium ions. It is the only reaction of blood coagulation for which no surface requirement has been described. In order to be able to investigate the effects of negativeiy charged phospholipid vesicles or platelet membranes on the initial rate of activation of factor IX by factor XIa a sensitive assay system was developed that quantitatively measures functional factor IXa. The clata presented in Chapter IV show that negatively charged phospholipids inhibit the activation of factor IX by factor XIa, whereas neutral phospholipids have no effect. This inhibition is most likely due to binding of factor IX to the negatively charged phospholipid vesicles. In Chapter $V$ it is shown that activated human platelets will also inhibit factor XIa, whereas non-stimulated platelets have no effect. This inhibition is due to the fact that platelets, upon stimulation, secrete an inhibitor that interferes witl the activation of factor IX by factor XIa. Finally, in Chapter VI the findings presented in this thesis are discussed. 
In dit proefschrift worden resultaten beschreven, die inzicht geven in de verschillende mechanismen via welke bloedstollingsfaktor Xla kan worden gereguleerd. Faktor XIa is het enzym dat de intrinsieke stolling verbindt met het contact-activeringssysteem. Het is het enige bekende enzym van het bloedstollingsproces dat twee actieve centra bezit. Inactivatie van deze centra kan worden volbracht door de plasma remmer antitrombine III, in een reactie waarin beide actieve centra onafhankelijk van elkaar worden geremd met dezelfde reactie konstante. De snelheid waarmee faktor XIa wordt geremd door antitrombine III kan worden gestimuleerd door heparine. De hoofdstukken II en III tonen dat deze stimulatie gebruikt kan worden om de binding van antitrombine III aan heparine te bepalen. Tevens suggereren de gegevens van hoofdstuk III dat de inactivatie snelheid van faktor XIa in aanwezigheid van heparine niet alleen bepaald wordt door de mate van antitrombine III binding aan heparine, maar ook afhankelijk is van het type heparine waaraan antitrombine III gebonden is.

Faktor XIa is in staat de intrinsieke bloedstollingsfaktor IX op een efficiente wijze te activeren in een reactie die gestimuleerd wordt door calcium ionen. Het is de enige reactie van het bloedstollingssysteem waarvoor de noodzakelijkheid van een oppervlak niet is aangetoond. Om in staat te zijn de effecten van negatief geladen phospholipiden of plaatjes membranen op de initiële snelheid van de activering van faktor IX door faktor XIa te onderzoeken, werd een gevoelige bepalingsmethode ontwikkeld, die kwantitatief functioneel factor IXa bepaalt. De data weergegeven in hoofdstuk IV tonen dat negatief geladen phospholipiden de activatie van factor IX door faktor XIa remmen, terwijl neutrale phospholipiden geen effect hebben. Het is zeer waarschijnlijk dat deze remming wordt veroorzaakt door de binding van faktor IX aan negatief geladen phospholipiden. Hoofdstuk $V$ laat zien dat geaktiveerde humane bloedplaatjes ook faktor XIa remmen, terwijl niet gestimuleerde plaatjes geen effect hebben. Deze remming wordt veroorzaakt doordat plaatjes na stimulatie een remmer secreteren, die interfereert met de activatie van faktor IX door faktor Xla. Tenslotte wordt in hoofstuk VI een algemene beschouwing gegeven van de resultaten die in dit proefschrift worden beschreven. 
Een proefschrift kan niet zonder samenwerking van de promovendus met anderen tot standkomen. Daarom wil ik een ieder die hieraan heeft bijgedragen, bedanken.

Mijn promotor Coen Hemker, bedank ik voor de geboden gelegenheid om onder zijn leiding op het biochemisch laboratorium van de Rijksuniversiteit Limburg het promotie-onderzoek te verrichten. Zijn sturende adviezen waren daarbij van grote waarde.

Guido, bedankt voor de tijd en energie die jij eraan spendeerde. Onze discussies waren vaak heftig en luidruchtig, maar desalniettemin onmisbaar.

Gerbrand van Dieijen, jij gaf de aanzet tot het onderzoek en hebt mij de beginselen van de kinetiek en het zuiveren van eiwitten bijgebracht. Onze samenwerking blijft voor mij een dierbare herinnering.

Truus, voor mij waren jouw vakkundige kennis en jouw warme persoonlijkheid altijd zeer aangenaam. Op momenten waarop het onderzoek minder voortgang kende, was jouw niet aflatende steun erg belangrijk.

Theo Lindhout en Jan Rosing bedank ik voor al hun adviezen op het enzymkinetische vlak.

Jean, Pieter, Jo, Ron, Dominique en Piet, jullie stonden altijd garant voor een goede werksfeer op het lab.

Trees Camphuisen-Engel en Mariet Molenaar "vertaalden" vier jaar lang mijn handschrift in een meer werkbare vorm.

Buiten de vakgroep Biochemie, wil ik George Willems (vakgroep Biofysica) en Jan van Wersch (de Wever-ziekenhuis, Heerlen) bedanken voor hun geboden hulp. Guus van Rooy verzorgde de lay-out van de omslag.

Dr. Bertina (Rijksuniversiteit Leiden) en Prof. Blijham (Rijksuniversiteit Limburg) hebben op zorgvuldige wijze het manuscript van het proefschrift van commentaar voorzien. Ook hen bedank ik voor de gespendeerde tijd en energie.

Lieve Jellie, bedankt voor al jouw liefde, begrip en steun in de afgelopen tijd (is dit kort genoeg?). 
De schrijver van dit proefschrift werd geboren te Valkenburg op 5 november 1955. Hij behaalde het diploma Atheneum-B in 1974, aan het Bernardinus College te Heerlen. Vanaf 1974 studeerde hij scheikunde aan de Rijksuniversiteit van Utrecht. In juni 1978 werd het kandidaatsexamen afgelegd, en het doktoraalexamen volgde in juni 1981. Zijn keuzevak en bijvakken waren respectievelijk biochemie, klinische chemie en hematologie.Tot september 1982 was hij werkzaam als vrijwilliger bij het huisartsenlaboratorium te Utrecht. Daarna werkte hij een jaar als toegevoegd onderzoeker bij de afdeling immunologie van het Acadernisch Ziekenhuis te Utrecht. Vanaf augustus 1983 is hij werkzaam als wetenschappelijk assistent bij de vakgroep biochemie van de Rijksuniwersiteit Limburg, alwaar hij onder leiding van Prof. Dr. H. C. Hemker en Dr. G. Tans het onderzoek verrichtte dat heeft geleid tot dit proefschrift. Per 1 januari 1988 begint hij aan zijn opleiding tot klinisch chemicus in het ziekenhuis 'de Stadsmaten' te Enschede. 